University of Louisville

ThinkIR: The University of Louisville's Institutional Repository

Electronic Theses and Dissertations

$5-2020$

\title{
Selective laser melting 17-4 PH stainless steel and the effect of varied thermal treatments on fatigue behavior.
}

\author{
Sean Daniel Dobson \\ University of Louisville
}

Follow this and additional works at: https://ir.library.louisville.edu/etd

Part of the Manufacturing Commons, and the Metallurgy Commons

\section{Recommended Citation}

Dobson, Sean Daniel, "Selective laser melting 17-4 PH stainless steel and the effect of varied thermal treatments on fatigue behavior." (2020). Electronic Theses and Dissertations. Paper 3431.

https://doi.org/10.18297/etd/3431

This Master's Thesis is brought to you for free and open access by ThinkIR: The University of Louisville's Institutional Repository. It has been accepted for inclusion in Electronic Theses and Dissertations by an authorized administrator of ThinkIR: The University of Louisville's Institutional Repository. This title appears here courtesy of the author, who has retained all other copyrights. For more information, please contact thinkir@louisville.edu. 
SELECTIVE LASER MELTING 17-4 PH STAINLESS STEEL AND THE EFFECT OF VARIED THERMAL TREATMENTS ON FATIGUE BEHAVIOR

By

Sean Daniel Dobson

\begin{abstract}
A Thesis
Submitted to the Faculty of the in Partial Fulfillment of the Requirements

for the Degree of

Master of Science

in Mechanical Engineering

J.B. Speed School of Engineering

University of Louisville,

Louisville, Kentucky
\end{abstract}

J.B. Speed School of Engineering of the University of Louisville

May 2020 
Copyright 2020 Sean Daniel Dobson

All Rights Reserved 

SELECTIVE LASER MELTING 17-4 PH STAINLESS STEEL AND THE EFFECT OF VARIED THERMAL TREATMENTS ON FATIGUE BEHAVIOR

\author{
By \\ Sean Daniel Dobson \\ A Thesis Approved on \\ April 3, 2020 \\ by the following Thesis Committee: \\ Thesis Director \\ Dr. Thomas A. Berfield \\ Thesis Co-Director \\ Dr. Thomas L. Starr \\ Dr. Sundar Atre
}




\section{ACKNOWLEDGEMENTS}

I would like to first and foremost acknowledge my family and friends for their encouragement and support. Thank you for your understanding despite long nights in the lab. Thank you to my parents, for both being an inspiration and demonstrating the meaning of hard work and perseverance.

Thank you to Dr. Thomas L. Starr for being a mentor not only through this process, but for the last two and a half years. I have learned more than I thought possible and thank you for allowing me to explore my passion and believing in me. I could not have come this far and grown this much these past years without the opportunities you have given me.

Thank you to Dr. Thomas A. Berfield for providing me the guidance and support on a project and subject that I had limited knowledge of going into. I appreciate your willingness to always help and offering me the resources you had at your disposal. I thank you for your advice not only on this project, but towards my future as well.

Thank you Dr. Sundar V. Atre for is assistance and guidance both as my independent study advisor as well as being a member of my thesis committee.

Thank you to the other professors who have assisted and provided guidance, for this project or otherwise, namely Dr. Li Yang, Dr. Jonathan Kopechek, and Dr. Stuart Williams.

Thank you to all the staff working in the Rapid Prototyping center for their support provided on this project. Namely Joe Vickers, Gary Graf, Kate Schneidau, Teresa Rohr, and Brittany Beaufait.

Thank you to the team at Questek Innovations LLC. and the Naval Air Systems Command for their financial support through this endeavor. 


\section{ABSTRACT \\ SELECTIVE LASER MELTING 17-4 PH STAINLESS STEEL AND THE EFFECT OF VARIED THERMAL TREATMENTS ON FATIGUE BEHAVIOR \\ Sean Dobson}

April $3^{\text {rd }}, 2020$

Fatigue failure is the leading source of loss in industry. In order for new means of manufacturing to move towards mainstream use a complete understanding of material and mechanical behavior must be gained. This endeavor seeks to aide in that task by observing the fatigue behavior of selective laser melting (SLM) additive manufacturing (AM) specimens and the effect of differing thermal treatment conditions for an optimized AM process.

Stainless steel 17-4 PH specimens were fabricated using SLM AM and thermally treated to three conditions: as-built, solutionized and hardened, and direct hardened. These specimens were characterized for material (powder quality, density, and microstructure) and mechanical properties (tensile, hardness, and fatigue). The fatigue specimens were tested in a tensiontension $(\mathrm{R}=0.1)$ to observe the effect of the variable thermal treatments on that behavior.

The internal and surface defects present within the AM specimens were found to be the first order limiting factor in the fatigue life for a given stress. Ultimately this resulted in scatter and a conclusion that intrinsic limitations of additive manufacturing contributed more to the fatigue performance than other typically used measurements and predictors of mechanical 
performance such as yield stress. Following this the thermal treatment performed on the specimens compared to as-built material led to a slight increase in fatigue life for a given stress.

Currently there is no available literature discussing the effects of variable thermal treatments on fatigue behavior of SLM 17-4 PH stainless steel. There are also limited sources discussing the fatigue behavior of other AM materials and manufacturing methods. This will provide an understanding of the fatigue behavior of 17-4 PH and the intrinsic fatigue behavior of AM. 


\section{TABLE OF CONTENTS}

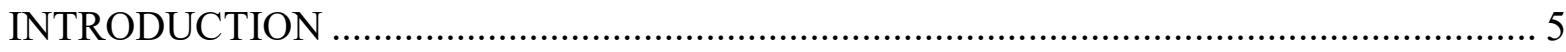

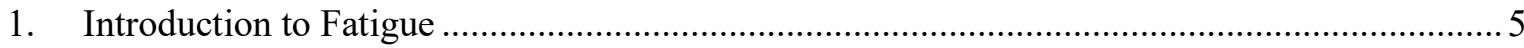

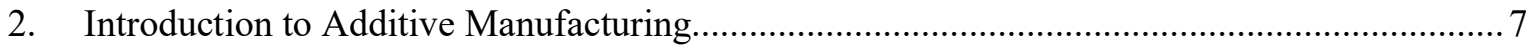

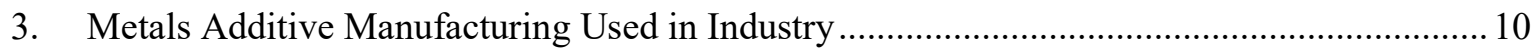

4. Metallic Material Feedstock and the Effects on Part Quality ................................................. 13

5. Properties of 17-4 PH Additive Manufacturing Material and a Comparison to Wrought........ 14

6. The Fatigue Process and Fatigue Properties of 17-4 PH Wrought Stainless Steel.................. 17

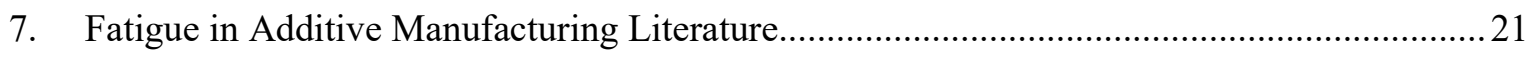

8. Justification for Further Examination of Metals Additive Manufacturing Parts .....................26

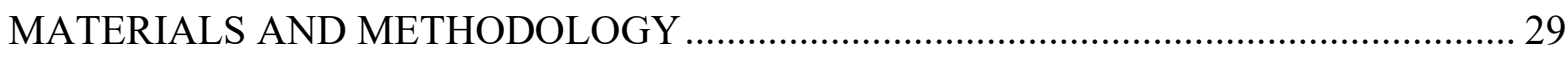

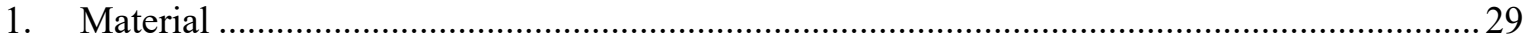

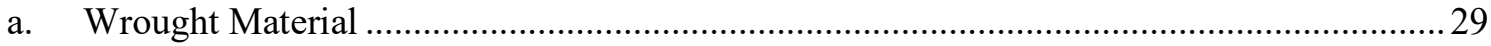

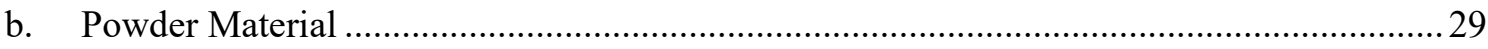

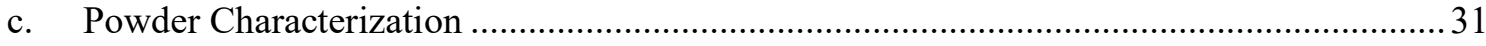

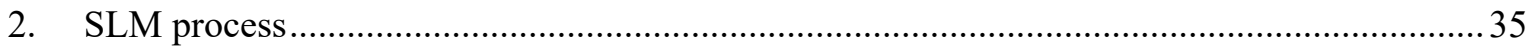

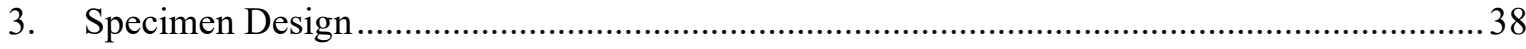

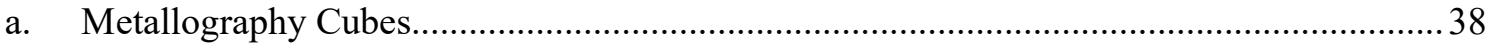

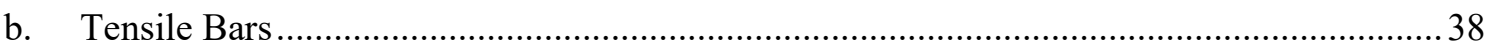

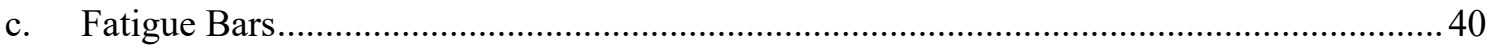

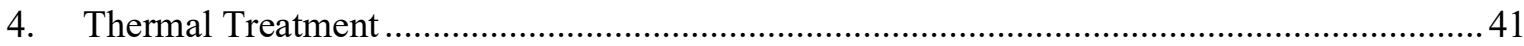

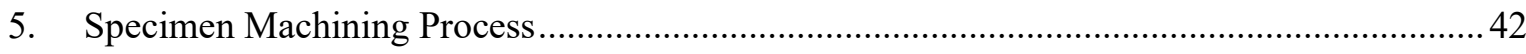

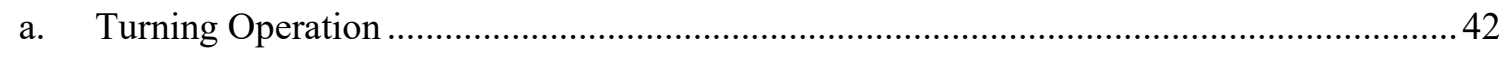

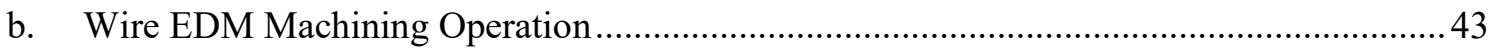

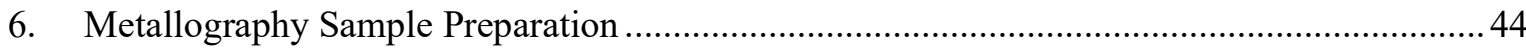

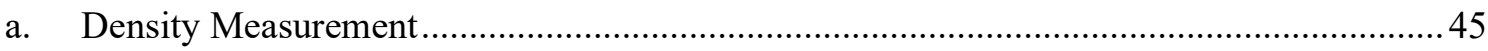

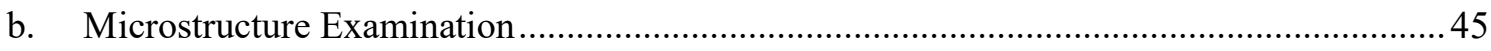

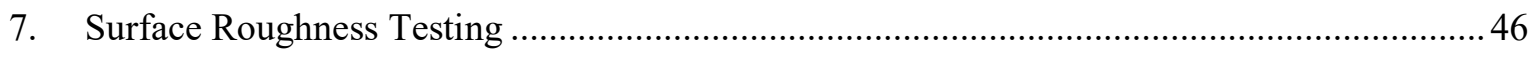

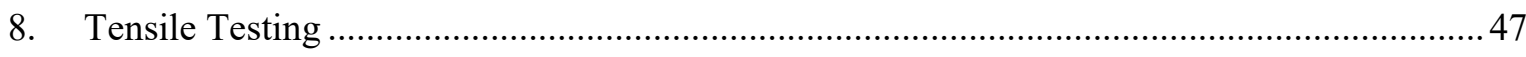

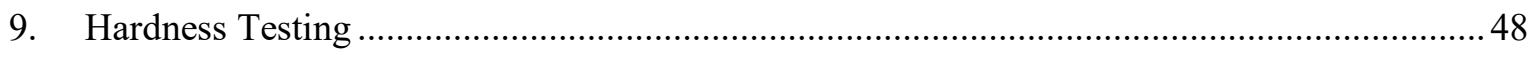

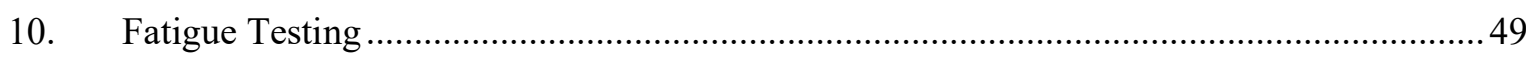

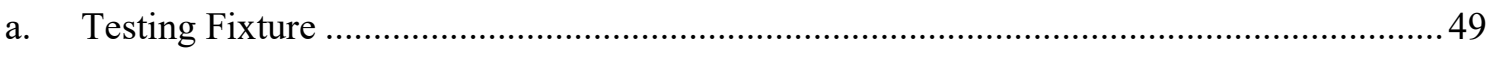




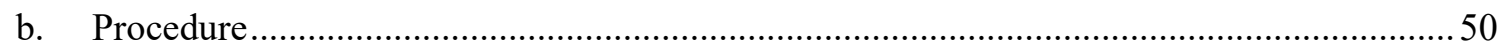

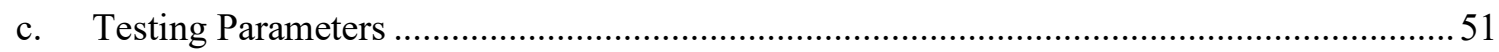

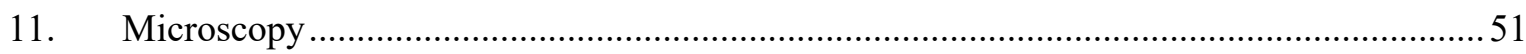

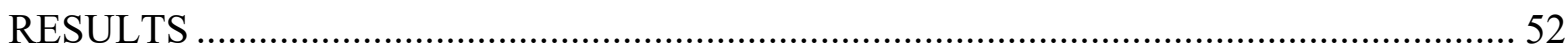

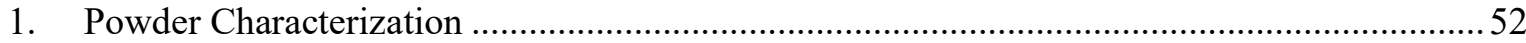

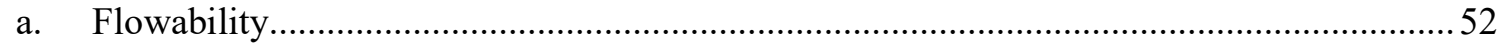

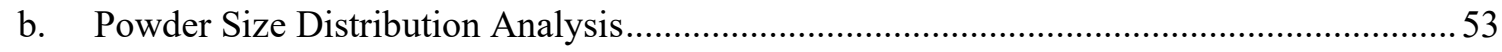

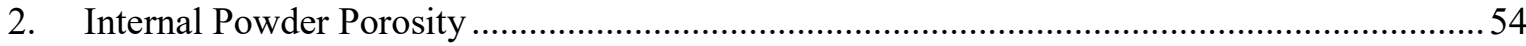

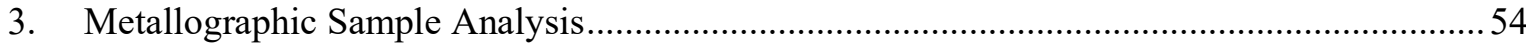

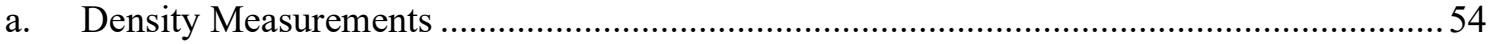

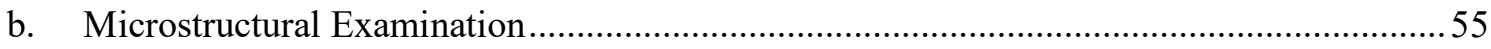

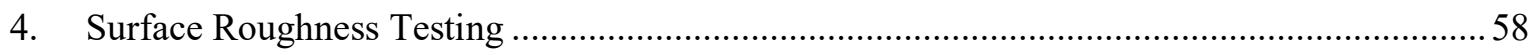

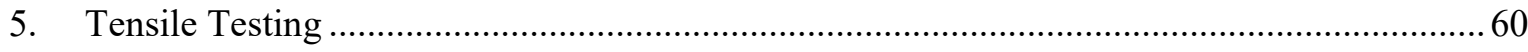

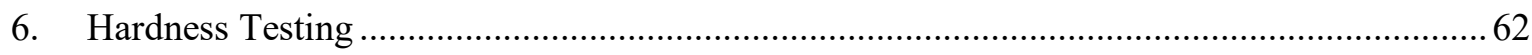

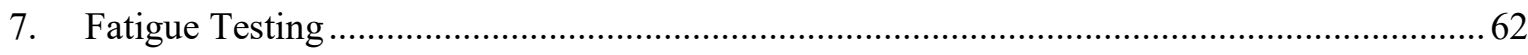

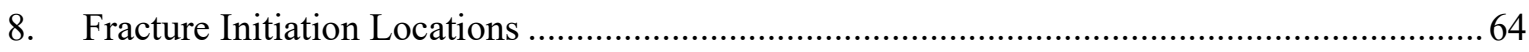

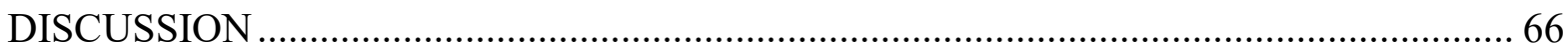

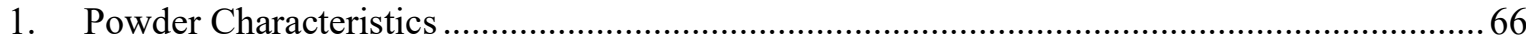

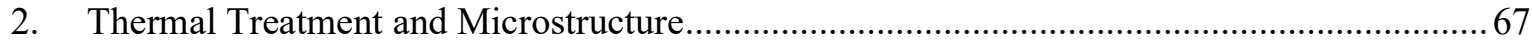

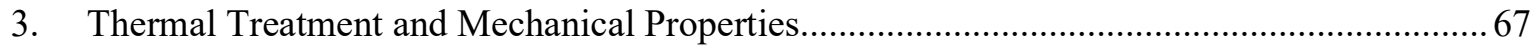

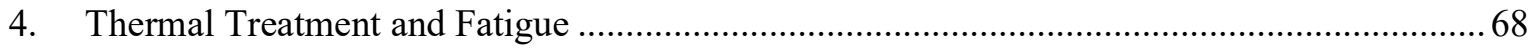

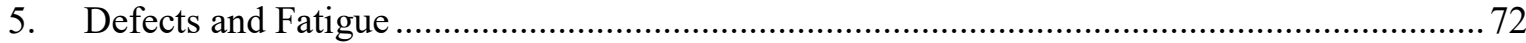

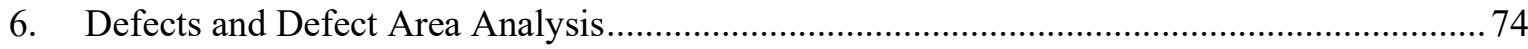

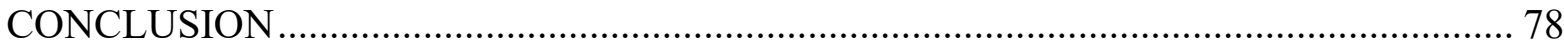

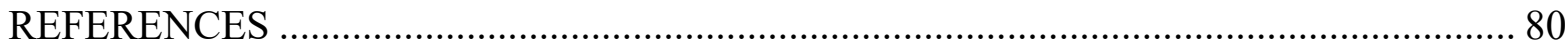

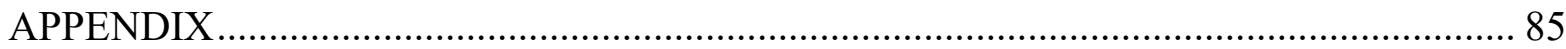

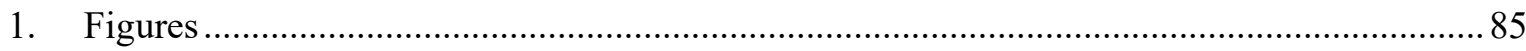

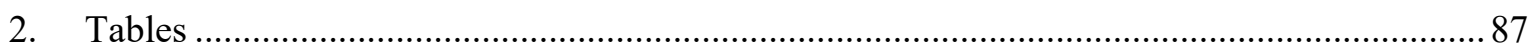

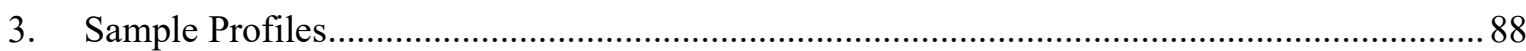

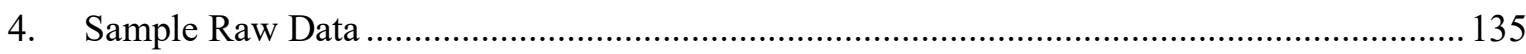

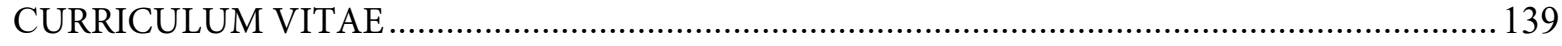




\section{INTRODUCTION}

\section{Introduction to Fatigue}

Mechanical failure has been the source of financial loss, injury, and unfortunately loss of life. As a manufacturer, designer, or engineer it is important to understand the modes of failure and how those are reached in order to work towards prevention. Typically, failure due to yielding is most often examined and tested for as it is easy to determine the point of failure through visible detection. However, as it is easy to detect and the yield point of a material is fairly consistent, failure due to yielding if one of the least common modes of recorded mechanical failure. There are several modes of failure, but one in particular stands out among the rest as it is often credited with 50 to 90 percent of mechanical failures. This mode is failure due to fatigue [1].

Fatigue is the process of repeated loading of a material or component, where the load applied may be well below the yield point, and over time damage accumulates. Often fatigue failure begins with a surface or internal defect where stress is concentrated. At this point and after a certain number of cycles, or number of times the load has been applied, micro-cracks appear near this concentration. Soon, a crack begins to propagate from these micro-cracks and once the stress intensity criteria is satisfied a fast fracture occurs resulting in complete failure due to fatigue [2]. This brief summary does not encompass the full scope of what is or can occur during this mode of failure, but it does demonstrate why 50 to 90 percent of mechanical failures are the result of 
fatigue. As the load applied is often under the yielding point it can be near impossible to detect and failure is unpredictable as well as sudden.

Our understanding of fatigue began initially in the 19th century when large industrial machinery began to fail due to repetitive loading. In 1837 William Albert published the first paper concerning the correlation of metal durability to cyclic loading. Later in the mid 1860's August Wöhler introduced the concept of the stress-life or S-N curves, which are still used today. An S-N curve provides an estimate of material life or endurance limit of a material relative to the number of cycles a certain stress can be applied. It was in the end of the 19th century when Gerber and Goodman posed a simplified version of the fatigue life estimation and based on this theory engineers and designers began to implement fatigue analysis into product development [3].

Although advancement and understanding continued throughout the 20th century, fatigue failure plagued many industries. One of the most notable occurrences was the Comet, the first jet propelled passenger aircraft. After flying 300 hours and four days after an inspection it crashed into the Mediterranean Sea in January 1954. After recovering the wreckage, it was determined that it failed due to fatigue. Initial micro-fatigue cracks began in the corner of an opening in the fuselage. Through many cycles of pressurizing and depressurizing the cabin, it catastrophically failed at an altitude of 10,000 meters from crack propagation along the fuselage [4]. 


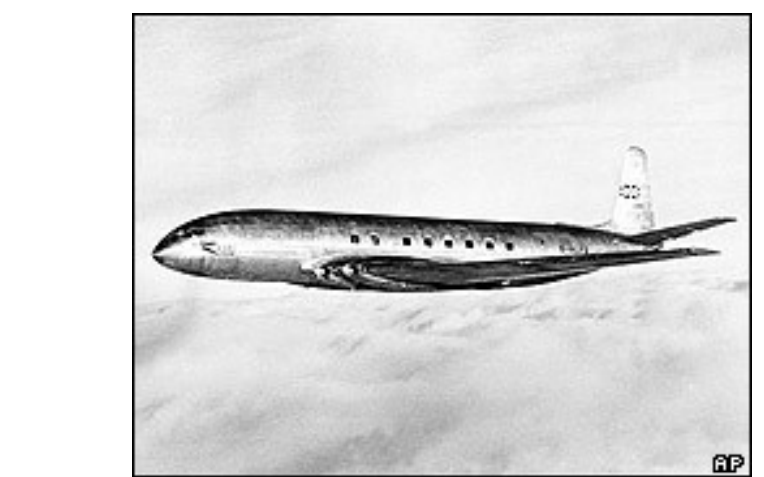

Figure 1. Image of the Comet, taken before failure [4].

Today innovation has not ceased nor has the push towards safer and more reliable parts through improved computer synthesis for part performance. However, fatigue continues be a major topic of analysis for engineers and it is vital, more than ever, to have a complete understanding of how a part will perform under cyclic loading conditions. This is especially true for new materials and methods of manufacturing.

\section{Introduction to Additive Manufacturing}

Additive manufacturing (AM), or occasionally referred to as 3D printing, has experienced significant growth in the past decades and currently has a plethora of parts in industry use today. A primary attraction of AM by manufacturers and engineers is its ability to create complex geometry parts that may not even be possible to fabricate using traditional means of manufacturing. AM is defined by the standard ASTM F2792 as "a process of joining materials to make objects from 3D model data, usually layer upon layer, as opposed to subtractive manufacturing methodologies" [5]. This definition covers a wide range of AM methods and materials. Perhaps the most well-known method today is extrusion-based printing where material, often thermoplastic, is extruded through a nozzle to construct geometry. It is popular due to the cost-effective nature of the machines and materials. But these inexpensive machines are far from the only method or material available. Modern AM found its beginning in a system proposed by Munz in 1951. The technology proposed resembled stereolithography (SLA), 
using a transparent photopolymer that is selectively exposed by light curing the material and causing it to harden. This process would continue layer by layer. The first use of powder was introduced in 1971 by Ciraud, in a plasma or electron beam based system typical of selective laser sintering (SLS). Soon the first commercial SLA and SLS machines would be available in the 1980's [6]. In the past few decades metals AM has taken off for its ability to make near net shape, ready to use, fully dense metal parts. Powder bed systems became the leader in metal AM utilizing methods such as selective laser melting (SLM) and electron beam melting (EBM). Powder bed fusion (PBF) uses a blade-type mechanism to spread powder over a build volume and a laser or beam melts the metallic powder in the desired geometry and the process continues until the part is complete [7].
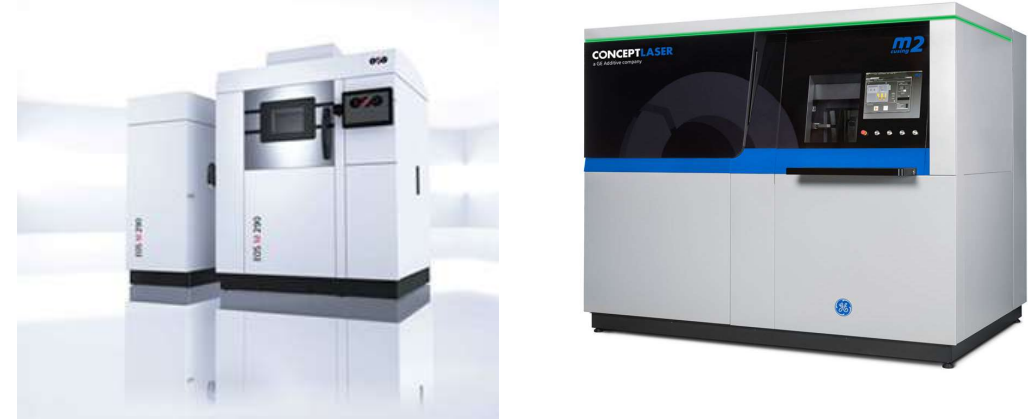

Figure 2. PBF machines widely used today. EOS M290 (L) \& Concept Laser M2 (R) [8].

A particular advantage of metals AM is the ability to use a multitude of materials in the same machine with only a simple alteration of processing parameters. Commonly used production metals such as titanium, aluminum, and super alloys along with steels are common materials used in AM. However, due to the nature of the process each layer may experience a repeated solid-liquid transformation. This results in a time dependent and complex internal microstructure that can be dissimilar from traditional wrought or even different AM methods of the same material [7]. This dissimilarity can lead to a diverse and unpredictable range of 
mechanical properties, even across the same grade material. Thermal history is not the only difference that AM metals experience compared to that of wrought materials. Again, due to the nature of the process contrasts in surface finish of AM parts is noticeable with a far rougher exterior post-fabrication. However, perhaps the most significant difference are the internal defects that arise from the process such as keyholing or lack of fusion porosity [7]. Defects like these are the typical causation of poor mechanical performance in metal AM parts.

There is a certain area where AM is fiscally advantageous and areas where it would be costly to integrate into production. A simple copying of existing parts from traditional production methods to AM will typically not yield significant cost reduction. AM requires redesign for optimization for the process and can be extremely cost effective if used properly. AM has a significant amount of reduced waste during the production process. Where most traditional methods of manufacturing have a waste material to part material weight ratio of 10:1, AM commonly experiences ratios of 1:1 [9]. Complex assemblies can also be fabricated in a single part, reducing labor of assembly and time to manufacture. Figure 3 offers insight into where AM can be leveraged for maximum cost effectiveness relative to part complexity, essentially the more complex the geometry the more cost effective. Furthermore, with its ability to fabricate complex geometry weight reduction is a key factor that can be advantageous economically through material savings. Typically, low volume, high complexity is where AM is the most economically effective. This is why it is seen used most often in aerospace or specialized fields where light weight, complex assemblies are needed in low volume [10]. 


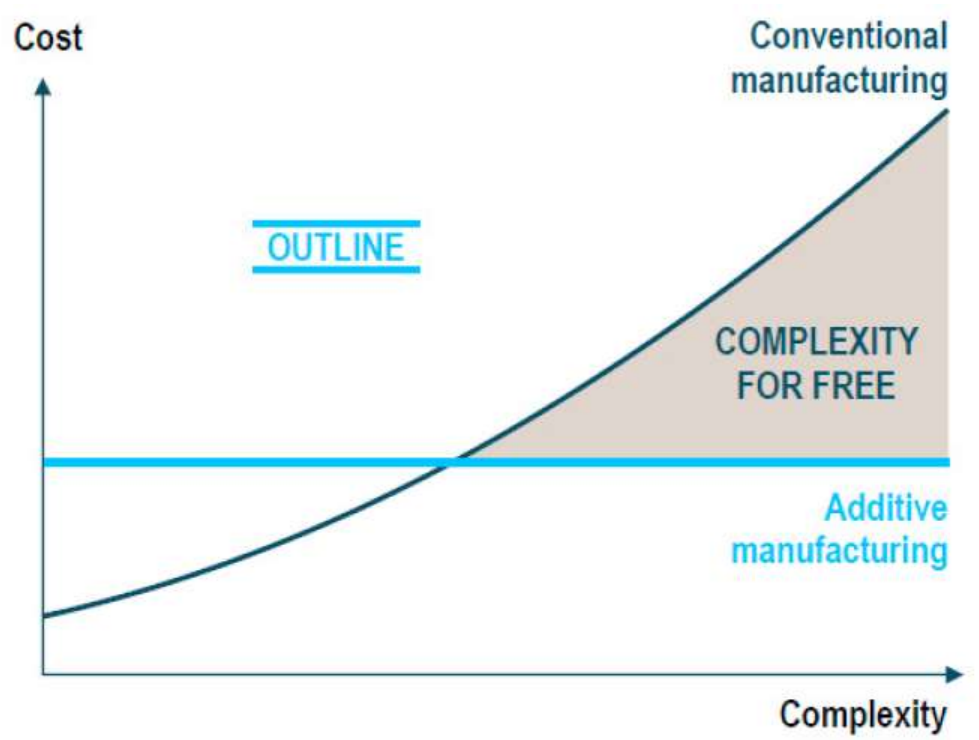

Figure 3. Cost vs. complexity between AM and Conventional fabrication methods [9].

3. Metals Additive Manufacturing Used in Industry

Today AM is used around the world and in various product realization steps, from concept to production. It can be found utilized in many industries such as healthcare and as mentioned previously, aerospace. Healthcare in particular has worked its way into the scope of AM with personalized care. In the field of dentistry, patient tailored denture molds and crown fillings are being created and used today. Specialized prosthetics designed around the individual wearing the piece are being utilized, allowing it to conform perfectly to the user's appendage [11]. Titanium is often used in the human body as a it is biocompatible. Currently titanium PBF implants are being created using a porous computer aided design, CAD, to promote cellular growth, allowing for seamless integration. This type of designed surface porosity is incredibly difficult to achieve using traditional manufacturing. In addition to the leveraged use of designing with complexity the human body was not designed for "one size fits all" manufacturing and AM ensures that personalized healthcare is available for all.

The aerospace industry, as mentioned, is currently on trajectory to implement AM in a major way. From full engines to internal components AM seems to be an extremely viable resource 
for this sector of industry. The number of complex parts in an aircraft coupled with the low volume output per year means that AM has a considerable advantage. A fairly well-known instance of AM being used in aerospace today comes from the Airbus A350 XWB cabin bracket.

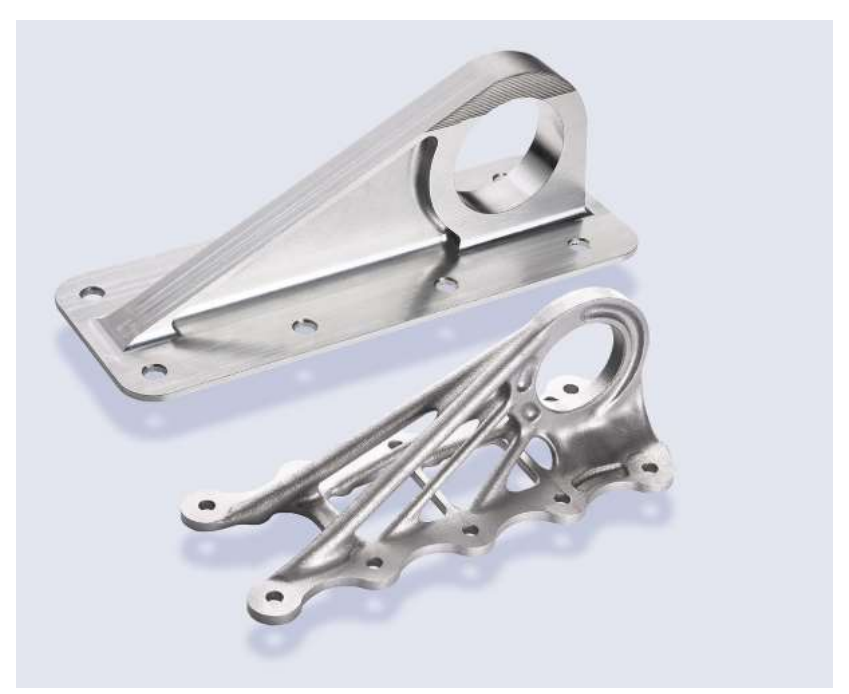

Figure 4. (Top) traditional and (bottom) additively manufactured Airbus A350 XWB bracket [12].

Figure 4 demonstrates just how effective AM can be when integrated to the development process properly. Utilizing PBF AM in titanium material the component has a reduced weight of $30 \%$ while still retaining its mechanical properties and functionality [12]. Airbus is not the only aerospace manufacturer who has benefited from the advantages of AM.

Boeing has also recognized the technology's benefit and is currently leveraging AM integration. There are select components for Boeing products across various platforms deemed 'satellite' parts. The company uses this term to identify products that are of an extremely mass critical, low production, speed to market nature. These 'satellite' category components are the exact part type where AM is most advantageous and is why Boeing sought to implement the technology. As the Boeing development and additive teams learned how best to implement AM, they began to identify other areas throughout the company the technology could be used. 
Now, they have moved past using AM solely for 'satellite' components and leveraging the technology wherever possible. The space systems development team alone is currently outputting over one-thousand AM components [13].

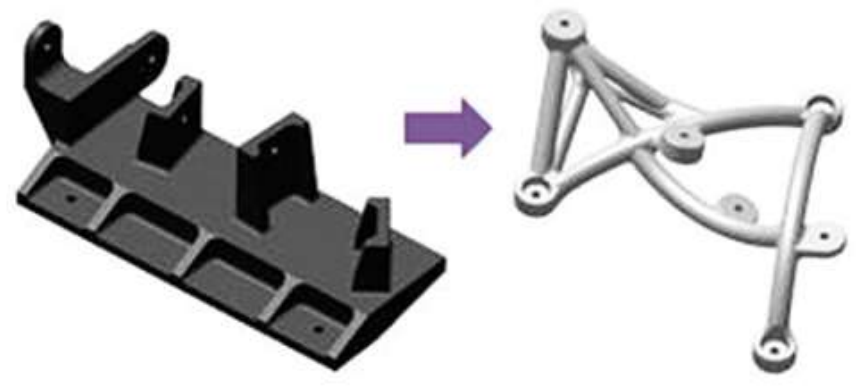

Figure 5. (Left) traditional and (right) additively manufactured Boeing bracket.

The company is not only implementing parts on their aircraft, but have also assisted in progressing the AM industry along by investing in the technology [14]. There is also a large potential for AM beyond our world as companies discuss the possibility of reaching the moon, mars, and planets far away. The immediate application would be to fabricate a broken part to a critical mission on another planet in a matter of hours. This could not only save a multibillion dollar mission but the lives of those astronauts. However, the possible reach of AM extends far beyond this. From AM habitats to bio-printing all options are being explored as we venture out to become a race of interplanetary travelers [15]. While there are some machine constraints and push back from some certification and standardization firms, AM continues to push into the aerospace industry. While this development and integration of AM needs to continue to ensure innovation, there needs to be a complete understanding of all materials and process therein. 


\section{Metallic Material Feedstock and the Effects on Part Quality}

Much of part manufacturing depends on material quality for resulting part quality. AM and more specifically metals AM is not an exception to this rule. The quality of the powder is considered vital for successful PBF AM of metals [7, 16-22]. There are several key factors that determine the powder quality. One major factor is flowability [21, 23-28]. For the common blade-type spreading method, good powder flowability is needed to create smooth, uniform layers. This characterization approach focuses on bulk physical behavior of the powder using methods originally developed for other processes that involve powder flow. Such methods can be implemented in a production environment and may be useful for quality control, ensuring that a powder from a new vendor or a powder that has been used many times is suitable for continued use.

Another key factor in determining powder quality is the physical structure, shape and, size of powder particles. It known that particle size has an effect on a powder's flowability [24, 26, 28, 29]. In a study from Baitimerov, Lykov et al. 2018 [24] it was found that powders with a lower particle size distribution, $\mathrm{d}_{10}<20$ and $\mathrm{d}_{50}<45$, had worse measured flowability. It is also found that powder morphology has a direct effect on flowability as well $[26,29,30]$. When metallic powder is produced it is typically desierable for the powder to be sphereical, the more sphereical a powder is the better the powders flowability. The more irregularly shaped a batch of metallic particulate is, the worse the flowability, resulting in potential adverse effect to the final part. This is due to inability rounder particulate being stacked as steeply as irregular particulate, from the interlocking type interaction between particles of irregular powder morphology. 
Part density measurements and porosity elimation have been the focus of many AM research topics [31]. A plausible explanation for porosity found in as-built structures could be the presence of internal powder porosity, or entrapped gas inside of the powder particle from the atomization process. Powder porosity has been recorded in the past [32] and can be found in gas-atomized powders [33].

5. Properties of 17-4 PH Additive Manufacturing Material and a Comparison to Wrought

Stainless steels are used in all facets of manufacturing from the tools used to make products to the products themselves. It is a versatile material. Particularly, grade 17-4 PH stainless steel as it is the most widely used of the precipitation hardening, $\mathrm{PH}$, steels. 17-4 PH stainless steel is a martensitic steel in the wrought solutionized state. PH steels are able to be directly hardened to improve mechanical properties and, in this case, introduce copper precipitates into the martensitic grain structure, strengthening the material. 17-4 $\mathrm{PH}$ is widely used for this reason, but also due to its good corrosion resistance and is comparable to that of 304 steels. This unusual combination of high strength and good corrosion resistance up to temperatures of $315^{\circ} \mathrm{C}$ is attractive to many designers and manufacturers [34]. By industry standard the chemical composition of the steel must be of the following to be consider 17-4 PH grade.

Table 1. Chemical composition by weight\%.

\begin{tabular}{|c|c|c|c|}
\hline Chromium & $15.0-17.5$ & Phosphorus & 0.04 \\
\hline Nickel & $3.0-5.0$ & Sulfur & 0.03 \\
\hline Copper & $3.0-5.0$ & Silicon & 1.0 \\
\hline Carbon & 0.07 & Niobium plus Tantalum & $0.15-0.45$ \\
\hline Manganese & 1.0 & Iron & Balance \\
\hline
\end{tabular}


Industries like aerospace use this property combination to their advantages in large assembled parts such as turbines. However, with the complexity of components in turbines AM is an incredibly attractive manufacturing method. For this reason, many studies have been conducted to determine the mechanical and material properties of additively manufactured parts from 174 PH grade stainless steel. Murr, Martinez et al. 2012 [35] found the differences in using Ar and $\mathrm{N}_{2}$ atomized powders in $\mathrm{Ar}$ and $\mathrm{N}_{2}$ SLM fabrication environments. Ar atomized powder phase was bcc $(\alpha-\mathrm{Fe})$ dominant while $\mathrm{N}_{2}$ atomized was fcc $(\gamma-\mathrm{Fe})$. Furthermore, it was found that building in an Ar environment with both powders produced a martensitic grain structure and in a $\mathrm{N}_{2}$ environment the Ar and $\mathrm{N}_{2}$ powders produced martensitic and austenitic grain structures, respectively. The martensitic structures were successfully able to be directly hardened. Mahmoudi, Elwany et al. 2017 [36] also demonstrated a highly martensitic grain structure when building with Ar atomized powder in an Ar fabrication environment. These martensitic specimens once successfully direct hardened experienced improved mechanical properties. This type of microstructure is not uncommon for the as-built condition using this material, it was also seen in a study from Cheruvathur, Lass et al. 2016 [37].

In the previous three studies heavily, martensitic grain structures are found in the as-built condition and can be direct hardened. However, in the study conducted by Sun, Hebert et al. 2018 [38] the specimens in the as-built condition were predominately ferritic with small martensite grains at the ferrite boundary. The reason for dissimilar microstructure between same grade stainless steel is attributed to cooling rate post-melt of each layer. These samples are still able to gain the benefits of a hardening process but must first be solutionized for a homogenous martensitic grain structure. It is evident that the microstructure of AM materials 
can reach the same standard as wrought 17-4 PH stainless steel, despite any difference in the as-built microstructure through thermal treatment.

Mechanical properties of a materials are also a subject of much interest. Typically, metals asreceived are not put directly into use. A material that has been only solutionized is brittle and does not perform well under loading. The material as received will be directly hardened. This is the case for many metals including 17-4 PH stainless steel. The following table is a complete set of tensile mechanical properties for wrought 17-4 $\mathrm{PH}$ stainless steel at minimum specification for as-received and several treatment conditions [39].

Table 2. Properties Acceptable for Material Specification.

\begin{tabular}{|l|c|c|c|c|c|c|}
\hline \multirow{2}{*}{ Property } & \multicolumn{6}{|c|}{ Condition } \\
\cline { 2 - 7 } & As-Received & H900 & H925 & H1025 & H1075 & H1150 \\
\hline $\begin{array}{l}\text { Ultimate Strength } \\
(\mathrm{MPa})\end{array}$ & 1276 & 1310 & 1172 & 1069 & 1000 & 931 \\
\hline $\begin{array}{l}\text { 0.2\% Yield Strength } \\
(\mathrm{MPa})\end{array}$ & 1103 & 1172 & 1069 & 1000 & 862 & 724 \\
\hline Elongation \% in 2" & 3 & 5 & 5 & 5 & 5 & 8 \\
\hline Rockwell Hardness C & $38(\max )$ & $40-48$ & $38-46$ & $35-43$ & $31-40$ & $28-38$ \\
\hline
\end{tabular}

In a study conducted by Yadollahi, Shamsaei et al. 2015 [40] found that there AM specimens were under the minimum acceptable properties for material specification, even after performing an H900 treatment. It was also determined that build orientation has an effect on mechanical properties. The horizontally fabricated samples had a higher ultimate and yield strength than the vertical specimens. But this seems to be attributed to a poor parameter set because in a recent study by Vunnam, Dobson et al. 2019 [41] and Dobson, Vunnam et al. 2019 [42] a optimized parameter set was used and acceptable material specification were met. 
The three argon atomized powders used produced differing microstructures two were highly ferritic and another martensitic. The two ferritic specimens were solutionized for a homogenous microstructure then H900 hardened in [42] and the martensitic specimen was directly hardened using an H900 treatment in . The result were tensile specimens that exceed minimum specifications. This is not uncommon, even with other AM materials as seen in this study by Shunmugavel, Polishetty et al. 2015 [43] using Ti6A14V material and exceeding wrought specification.

6. The Fatigue Process and Fatigue Properties of 17-4 PH Wrought Stainless Steel While the simple mechanical characterization such as tensile or hardness testing is important. A far more vital and complicated mode of failure still requires to be thoroughly addressed in the AM field. As mentioned previously, fatigue failure makes up 50-90\% of all mechanical failures because of the unexpected nature of the failure. The slightest surface or internal defect can cause fracture to propagate and with AM and its unique disadvantages in this particular area it is crucial to gain a full understanding of fatigue behavior. This mechanical characterization should not only focus on AM but should proceed first with a clear understanding of the behavior of wrought materials as well.

Compared with solutionized 17-4 PH stainless steel, the direct hardening step H900 outperformed it by a considerable margin in the study $\mathrm{Wu}$ and Lin 2002 [44]. The H900 hardened steel had a fatigue life of approximately $10^{6}$ when tested at $500 \mathrm{MPa}$, compare this to $400 \mathrm{MPa}$ for the solutionized steel. This further justifies the use of further heat treatment upon receiving the steel, especially the H900 thermal treatment in particular, the same result was found in [45]. The $\mathrm{Wu}$ and $\mathrm{Lin} 2002$ [44] test was performed with $\mathrm{R}$ ratio of $\mathrm{R}=0.1$, often referred to as the tension-tension method. An $\mathrm{R}$ ratio is the ratio of the minimum stress applied 
to the specimen during the cycle to the highest. This implies that if the sample were stress controlled, meaning a sample is tested at a constant maximum stress each cycle, that the minimum stress would be $10 \%$ of the maximum. There are other common $\mathrm{R}$ ratios used, for example $\mathrm{R}=-1.0$ or fully reversed (implying the max. and min. stress are proportional only in tension and compression) in this method the specimen is pulled in tension then compressed with the same stresses.

When conducting a fatigue test the sample will undergo what is known as mean stress. This mean stress is highly dependent upon the R ratio. Since the loading is cyclic there will be highs and lows to the applied stress, the mean stress is the average of the maximum and minimum stresses. The $\mathrm{R}$ ratio can quickly provide details of where the mean stress is located or even what the value is. For ratios of $\mathrm{R}=0.1$ or $\mathrm{R}=0$, it points towards a mean stress that is well into the range of tension on the order of perhaps hundreds of $\mathrm{MPa}$. For a ratio of $\mathrm{R}=-1$, it is known that the mean stress is 0 . In a study conducted by Kamaya and Kawakubo 2015 [46] as long as the strain range is maintained mean stress will not need to be included in fatigue prediction. In the textbook by Stephens et al. 2001 [1] mean stress for a positive $\mathrm{R}$ ratio $(\mathrm{R}=0.1)$ promotes fatigue crack growth. This means the mean applied tension or compression forces constantly applied to the specimen results in a significantly shorter lifetime of the specimen.

As mentioned previously, fatigue testing is cyclic testing. It loads the specimens and then unloads them at the same rate, forming a sinusoidal curve of stress application. The number of cycles tested for is often set before hand and can range anywhere from 10 to $10^{10}$. The applied stresses or strains can be determined by using the S-N curve or something equivalent like the Goodman diagram. This will provide an estimate of when failure should be expected based off of the applied load. Two denotations for testing specimens at a certain cycle count is either 
high or low cycle fatigue. High cycle fatigue implies testing at a higher count of cycles (typically $>10^{5}$ ) and uses low amplitude (low stress) high frequency testing parameters to operate within elastic strain. Low cycle fatigue implies testing at a low count of cycles (typically $<10^{5}$ ) and uses high amplitude (high stress) low frequency testing parameters to operate within plastic strain.

Stress controlled testing has been mentioned, where the sample is set to experience a predetermined load each cycle. There is also a strain controlled testing method where the strain percent is the predetermined factor and the sample is deflected that value each cycle. Strain controlled testing is more closely associated with low cycle fatigue testing as it relies upon plastic strain for failure. Stress controlled is used in either low or high, but most often in high as it is the repeated stresses that result in failure not so much the strain values as it operates in the elastic region. However, in a study conducted by Vincent, Le Roux et al. 2012 [47], stress and strain controlled testing provides similar fatigue lives so long as the mean stress is the same. There is no benefit to designing in a particular method or testing parameter set. It is wise to examine the environment the part will operate in and design the method around that.

Fracture propagation and examination is as important to the fatigue life measurement when attempting to grasp the full picture of fatigue. There are three primary modes of crack extension, these are given below. 


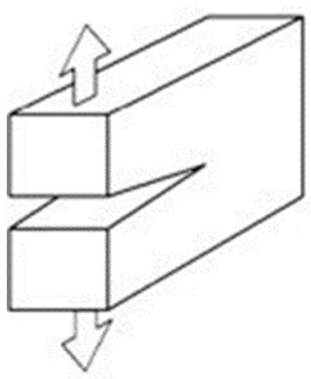

(a)

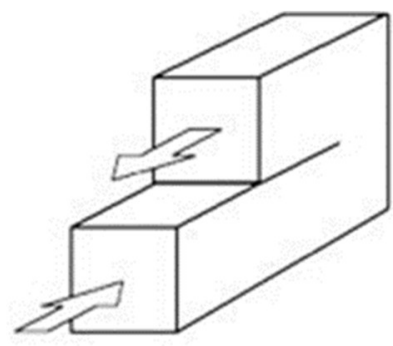

(b)

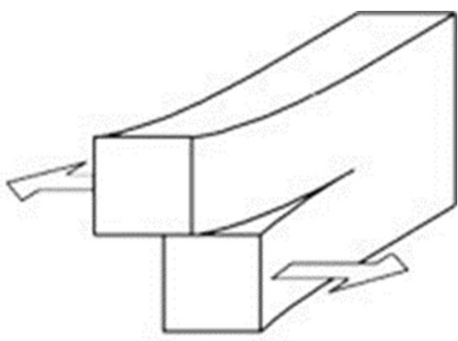

(c)

Figure 6. Modes of crack extension: Mode I (a), Mode II (b), and Mode III (c).

Mode I is the most common type of crack growth, especially in fatigue it is known as the opening method. Mode II is known as in-plane shearing and mode III as anti-plane shearing. Mode I is most common primarily because failure will occur where the maximum tensile stress is located. While mode I is often a common fracture mode, many times the specimen will experience something known as mixed-mode fracture, a combination of modes I and II. This will typically occur for the microscopic cracks that form during a fatigue test [1]. There is also a vital number used in fracture mechanics known as the stress intensity factor, often denoted ' $\mathrm{K}$ '. It is used to predict the stress intensity of a crack or notch caused by a given stress. While it is theoretical it can be used predict failure and provide insight into material behavior. $\mathrm{K}$ can be calculated using Equation 1 below,

$$
K=S \sqrt{\pi a}
$$

where $S$ is the applied stress in MPa and $a$ is the crack length in meters. It can be calculated in various ways, but this is the core concept of $\mathrm{K}$ calculation. It is known widely that fracture propagation begins at a stress concentration, typically an internal or surface defect. This is supported in Schönbauer, Yanase et al. 2017 [48] that created defects through drilling or corrosion pitting in 17-4 PH. It was found that the fatigue life was reduced with the presence of these artificial defects and that they were the epicenter of the failure. It was also determined 
that fatigue failure due to the defects was dependent upon the $\mathrm{R}$ ratio. The life of the specimen was reduced with a higher, more positive $\mathrm{R}$ ratio. This could be a combination of the defect and mean stress as it is known the effect it has on fatigue life. It will be interesting to see the comparison of fatigue life between wrought and AM specimens given that AM introduces considerable variability as well as internal and surface porosity.

\section{Fatigue in Additive Manufacturing Literature}

With so few studies conducted on the fatigue properties of 17-4 PH stainless steel, the literature review required extending to a plethora of AM materials used to study fatigue in AM. How the AM specimen fatigue performance compares to that of traditional manufacturing means is the subject of much interest to the industry and research community. In a literature review it was noted that SLM has evolved in recent years to having significantly improved material quality and fatigue resistance [49]. This was found to be the case in several studies. In an experiment using Ti6Al4V it was found that SLM specimens were governed by the same principles as wrought fatigue behavior, surface finish, residual stress, internal defects and microstructure. It was discovered that a post process surface and thermal treatment was required for superior fatigue performance to wrought material with the SLM specimens [50]. In another study using SLM specimens conducted by Rafi, Starr et al. 2013, the Ti6Al4V AM specimens outperformed wrought material. However, the steel specimens used displayed an endurance limit of less than that of standard steels due to surface finish [51]. In other studies, conducted using steel a higher ductility and yield strength were found in 316L stainless steel as-built state fabricated using SLM than in the wrought materials. In the same study using 17-4 PH material it was found that the steel had a lower ductility and yield strength than conventional materials [52]. In a study using 304L fatigue specimens fabricated using wire and arc AM in a high cycle 
fatigue loading regime the specimen fatigue life exceeded that of conventional wrought $304 \mathrm{~L}$ [53]. This was the case for another study using wire and arc AM for 304L [54]. The studies demonstrate variation in AM material performance ranging from superior to inferior compared to wrought.

Based upon the literature reviewed, metal fatigue for AM fabricated parts are limited by the same factors that govern fatigue behavior in traditionally manufactured specimens. The major factors being internal and surface defects. However, given the nature of AM it has also demonstrated limitations from the fabrication process. Namely anisotropic effects from build orientation limiting the fatigue life. Due to this fatigue and durability have become major challenges posed against widespread adoption of AM parts [55]. In a study using SLMprocessed 17-4 PH from Yadollahi, Simisiriwong et al. 2016 demonstrated that build orientation does have an effect on the materials fatigue life with vertical specimens underperforming compared to horizontal [56]. This was also discovered in numerable studies. Build orientation effects were experienced at high cycle fatigue due to greater effects of crack initiation, horizontally fabricated specimens outperformed vertical specimens [57]. The same result was found in a study using SLM maraging steel conducted by Meneghetti, Rigon et al. 2019, where anisotropy was discovered at higher cycles of fatigue while not present at low $(<30,000$ cycles) [58]. These failures were primarily attributed to inter-layer defects; there was detected anisotropy of stainless steel specimens with separation at the layer-layer interaction location [52]. It is also mentioned that the anisotropy may be the result of a microstructural issue. As-built homogenous microstructures are difficult to achieve in the current state of SLM for complex geometries [55]. The vertical specimens were reported having long columnar grains in the tension direction whilst the horizontal specimens have finer grains in the tension 
direction improving strength and hardness [59]. A similar result was found with SLM Ti6Al4V material study where anisotropy was detected in the low cycle fatigue region due to a favorable microstructure in the horizontal orientation [60]. This is notion is further reinforced from another experiment observing strain-hardening in 17-4 $\mathrm{PH}$ fatigue testing with elongation longer than $0.3 \%$ being attributed to unusual material microstructural behavior of austenitic transformation to martensite [61].

Residual stresses are near impossible to avoid in AM due to the short solidification times and are determinantal to fatigue life and mechanical behavior [62]. There are post-manufacturing steps for improved mechanical performance and were prevalent in literature from machining and shot-peening to heat treatments and hot isostatic pressing or HIP. While this is often used to reduce residual stresses in tensile behavior, these methods do not always lead to improved fatigue life [63]. It was observed in a literature review that thermal history of the component also is a large factor in part performance [62]. This was discovered not only in the as-built condition, but for specimens that had been thermally treated as well. In a study conducted using AlSi10Mg material fabricated using AM it was found the there was no anisotropic effects in the as-built condition, however in the heat treated conditions it was surprising to find anisotropic behavior, but in favor of the build direction [64]. In a study using SLM AM to fabricate maraging steel specimens the properties of the as-built and heat-treated conditions were both lower for wrought and hardened wrought materials. There was no detectable difference between heat treated and as-built condition fatigue life for vertical specimens, while the horizontal demonstrated that the as-built condition had a lower fatigue life than the thermally treated specimens [65]. In several studies utilizing 17-4 PH SLM the results of the fatigue testing demonstrate that post thermal treatment improves fatigue performance [56], 
however fatigue results also showed that thermal treatment is beneficial for low cycle and detrimental for high cycle fatigue testing [61]. For a strain controlled $R=-1$ employed test design it was found that high cycle fatigue life of heat treated (solution annealing and aging) SLM specimens was lower than as-built condition [66]. There is much evidence in the literature to suggest that limiting the thermal treatment does improve mechanical properties for fatigue alone. This is quite different than other examinations of heat treatments and their effects on the mechanical properties of AM specimens where noticeable improvement was measured.

It is observed in a study using Ti64 that a HIP process was used and successfully increased the fatigue life of the specimen [67]. The HIP process is often used as a tool to reduce voided volumes while at times also serving as a thermal treatment. It is known that defects such as voids and impurities are major limiting factor in fatigue life. The variability in size, location, and shape of voids are the main cause of scattered fatigue life in AM. This is what makes the HIP process so attractive to manufacturers. In a study using Ti64, the effects of HIP treatment were observed in low and high cycle fatigue testing. The HIP process reduced internal porosity and improved ductility by obtaining a different microstructure to the as-built condition which in turn improved fatigue life [60]. However, it does have its limitations as HIP does not have the capability to reduce voided volume of pressurized entrapped gas [55]. This type of porosity is unavoidable even for an optimized parameter set [42]. It seems that fatigue is highly dependent upon powder characteristics which is suggested by the literature [68].

Fatigue failure was primarily rooted in two factors, internal and surface defects. In an SLM study it was found that fatigue crack initiation was due to lack of fusion porosity, inclusions formed from partially melted powder, and un-melted powder clustered near the voids [57]. These were all internal defects, and this is not an uncommon conclusion for many studies. 
Fatigue failure was determined to be caused by voids from un-melted powder and irregular pores such as lack of fusion in the case of this SLM study using 17-4 PH [61] and the case for a similar study using the same material at high cycle conditions [66]. It was also found to be the major cause in the following studies [52], [58], [62], [64], and [69]. As mentioned surface defects are another large source of failure for as demonstrated in this study where the as-built surface, unmachined, was considered to be the crack initiator [67]. In another study using stainless steel processed through direct energy deposition AM, surface strain localization is what caused crack initiation and ultimate failure [53]. The surface roughness of the as-built state has been found to be the leading source of surface crack initiation, literature suggests [60].

In summary AM fatigue specimens still operate under the same limitations as typical fatigue testing specimens with life limitations centralized around defects. However, due to the fabrication method it also has the potential for other sources of limitations namely in the form of anisotropic effects and unique-to-process thermal history. It was suggested in the conclusion of a study that once the largest contributors to crack initiation are minimized (surface and internal defects such as porosity) that aspects such as microstructure and build direction become the limiting factor in many cases [70]. This suggests that once a part has been fabricated using an optimized parameter set for limiting porosity and the surface of the testing gauge length machined that the other intrinsic AM defects will take over. Meaning that thermal history such as in the as-built condition vs. thermally treated and the build direction could become first order limiting factors. Now, there was a prevalent high level of variability in the literature. This was also a comment in the literature and many hold firm that there needs to be 
a standardization of processing methods for AM materials in order to draw upon past data and build upon those studies.

\section{Justification for Further Examination of Metals Additive Manufacturing Parts}

The fatigue studies reviewed used combinations of high cycle or low cycle, stress or straincontrolled test setups. Many testing parameters were altered to understand how a certain material will behave under a particular condition. This is necessary to understand the full limitations of a material in a variety of environments. However, it would require extensive testing, labor, and machining to fully understand and characterize a material's fatigue properties. One of the current issue plaguing the AM research community is a lack of unification in how fatigue life is examined, tested, and presented. It is widely believed that despite the efforts of so many experimental studies to characterize AM fatigue behavior that far more investigation is required, but that the limiting factor is the lack of standardization in testing and measuring. There is currently a significant push back on the use of AM parts in major industries. This is partially because of the lack of complete understanding of AM material fatigue behavior. If the data presented in these studies was conducted and presented in a specified manner then it would be far more reliable to make a statement, with a relatively high level of confidence, that a material will operate at a certain specification.

Other than the call for generalized standardization through the AM research community, there needs to be further investigation into limiting the negative effects attributed to the AM process, such as internal and surface defects and unique thermal history. As for defects, a key factor is processing parameters. Once an optimized parameter set is established that eliminates lack of fusion porosity without introducing keyholing than internal defects will be minimized. The only pores detected would be the internal powder porosity present in the material pre- 
fabrication. Surface defects are another factor that can be difficult to prevent and are material dependent in some cases. These could also be limited through a particular contour setting in the PBF parameter set or a post treatment such as machining or electropolishing. Thermal history in particular is a subject of much interest to the research community and is often a source of error. The thermal history of a particular part has the potential to be different than another part even in the same build. The time between exposures does have an effect on residual stresses present in the part as well as the microstructural makeup. Often thermal treatments are used, to negate any error in thermal history by homogenizing the microstructure. However, as determined from the literature thermal treatments can have unpredictable and undesirable effects on a material's performance. There are several statements made in the literature warranting the investigation of AM specific thermal treatments. However, before testing new methods of thermal treatments a complete understanding of the mechanical profile of a material is needed.

While AM has the potential to leverage the manufacturing of complex, low volume parts for production, and in some cases already has, there are still some factors that call for examination. The mechanical behavior and, thus, reliability of AM metal part performance is still to be fully understood. Despite the use of some AM parts in prototype testing and non-critical part assembly integration, the industries of biomedicine, aerospace, and many others require the complete understanding of part and material performance. It is speculated currently that fatigue is one of two major factors of mechanical performance that is inhibiting the widespread adoption of this manufacturing method. Any obtained information through further examination may be used to adjust the process or post process to achieve the desired microstructure, limit internal and external defects, and, in turn, improve mechanical properties. That is why it is 
worthwhile to examine the effect of as-built, direct harden, and solutionizing and harden on fatigue life for additively manufactured 17-4 PH stainless steel. 


\section{MATERIALS AND METHODOLOGY}

\section{Material}

There were two types of material selected for this study. The first was wrought 17-4 PH stainless steel and the second was gas atomized 17-4 PH stainless steel powder to be used for SLM processes.

\section{a. Wrought Material}

The wrought 17-4 PH stainless steel material selected is within AMS specification, noted in Table 1. It was purchased from an outside vendor in a solutionized state, denoted as Condition A. The vendor fabricated the rods using a cold drawing method. The dimensions of the bar purchased were $1 / 2$ " diameter rods with a length of 2'. Upon receiving the material, the bars were sectioned into the desired length for sample preparation using a bandsaw. This operation was followed by a thermal treatment and machining operation, respectively. These operations are detailed further below.

\section{b. Powder Material}

The powder material selected for the AM process was typical for that of SLM processes. A powder size distribution of $15-45 \mu \mathrm{m}$ was selected. The powder fabrication method is argon gas atomization. This process involves the molten material being poured into an atomizing chamber, in which high speed gas, in this case argon, fragments the molten material into mostly spherical particles. See the Figure 7 below for a depiction on the process. 


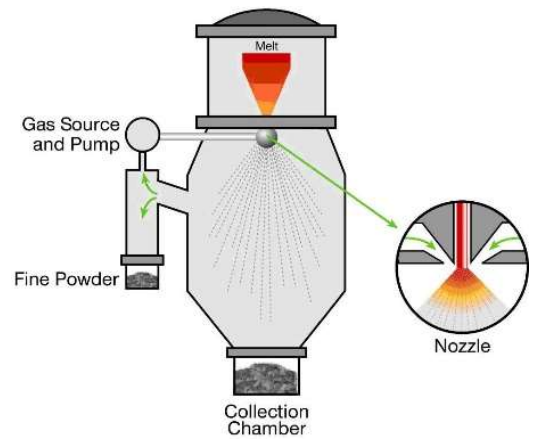

Figure 7. Gas atomization of metallic material into powder.

This powder was selected based upon results from a previous study [71], where powder characteristics for 17-4 PH stainless steel SLM powder were examined to understand their effect on mechanical and material properties. The powder from this vendor, when fabricated, produced parts with a heavily martensitic microstructure with some retained $\delta$-ferrite. This allows for the material to be directly hardened and provides the opportunity to exam the effects of various thermal treatments on the material. The chemical composition of the powder is provided below. This data was given by the powder vendor.

Table 3. Composition of powders in wt \%.

\begin{tabular}{cccccccc}
\hline \multirow{2}{*}{ AM Powder } & $\mathbf{C r}$ & $\mathbf{N i}$ & $\mathbf{C r} / \mathbf{N i}$ & $\mathbf{C u}$ & $\mathbf{N}$ & $\mathbf{M o}$ & $\mathbf{N b}$ \\
\cline { 2 - 8 } & 15.60 & 4.70 & 3.31 & 3.61 & 0.036 & - & 0.22 \\
\hline
\end{tabular}

This material is within the specification of 17-4 PH stainless steel, however, given the wide range of the specification the chromium - nickel ratio falls close to that of another type of stainless steel, 15-5. 


\section{c. Powder Characterization}

Powder characteristics have demonstrated to have a substantial effect on the quality of fabricated SLM parts. It is necessary to evaluate not only the chemical composition, but the physical aspects of the material $[16,17,20,28,30,33]$.

\section{a. Flowability}

Powder flowability was tested using the Hausner ratio. The Hausner ratio is the ratio of tap to apparent density. Tap density is measured according to ASTM B527-06, in which powder is loaded into a graduated cylinder and tapped repeatedly allowing the powder to compact, removing void volumes. The volume is measured, and density is calculated from the total weight of the powder. Apparent density is determined by measuring the volume prior to tapping then calculated using the total weight of the powder. A powder is considered to have poor flowability with a Hausner ratio greater than 1.25 [21, 72].

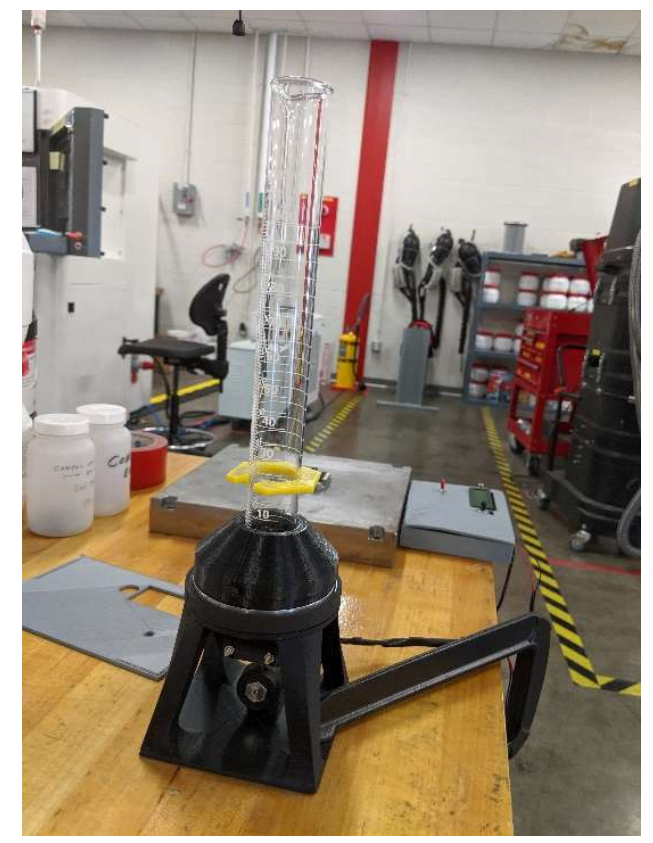

Figure 8. Tap density apparatus fabricated according to ASTM standard. 
The Hall flow measurement method which follows ASTM B213-11 was also measured. It is the time required for $50 \mathrm{~g}$ of powder to flow through a standard funnel. In conjunction with the Hall flowmeter test, the powder flowed onto a circular platform and accumulated in a conic shape. An image was taken from three separate points of view and uploaded to an image analysis software. Following this, two lines of best fit were imposed on the image. One for the base (horizontal) and another from the edge of the base to the point on the cone. An angle measurement is then taken between the two lines of best fit and averaged across the images taken. This measurement is known as the angle of repose.

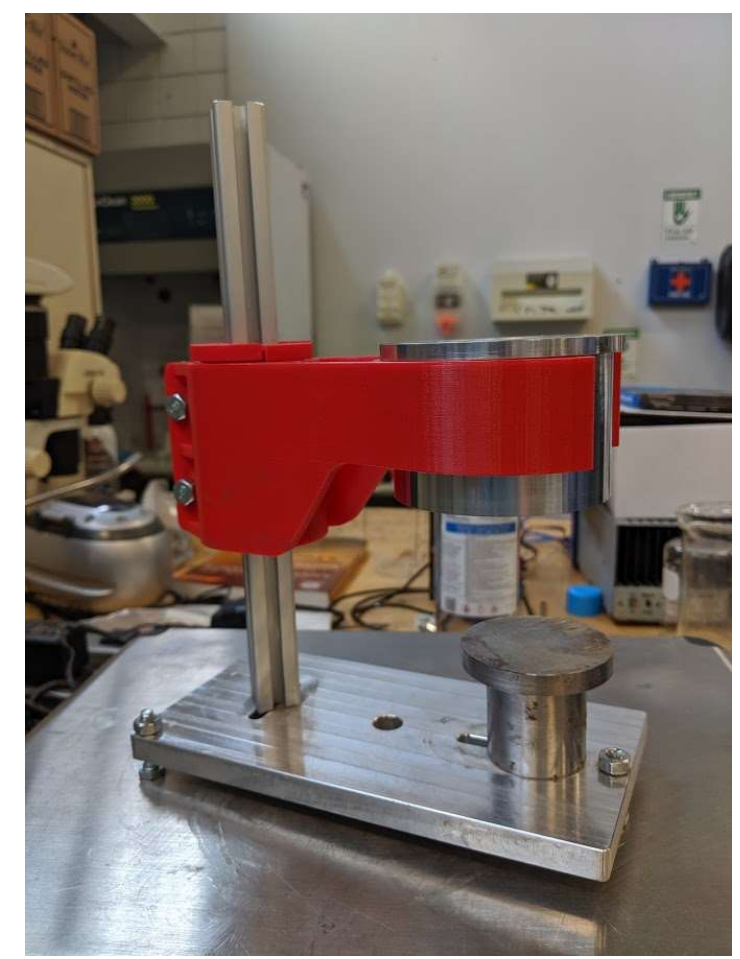

Figure 9. Hall flowmeter and angle of repose testing apparatus.

The rotational powder analyzer method was used for measuring avalanche angle. In this method a cylinder with diameter $120 \mathrm{~mm}$ and length of $55 \mathrm{~mm}$ was half filled with powder and at a constant speed of $6 \mathrm{rpm}$. A video camera captures the behavior of the powder, which avalanches when it reaches a critical angle. A MATLAB [73] code analyzes this video and detects these avalanches, recording the critical angle for each and reporting average and 
standard deviations for multiple events. Figure 10 shows an example of how the MATLAB [73] script analyzes the video of the powder rotation. By taking the individual frame of the powder and converting it a binary image, the script can trace the top surface of the powder (in red) and calculate a linear line of best-fit (in blue). The script can detect when the powder folds over on itself, or avalanches, and the angle of the line from the horizontal becomes the avalanche angle.

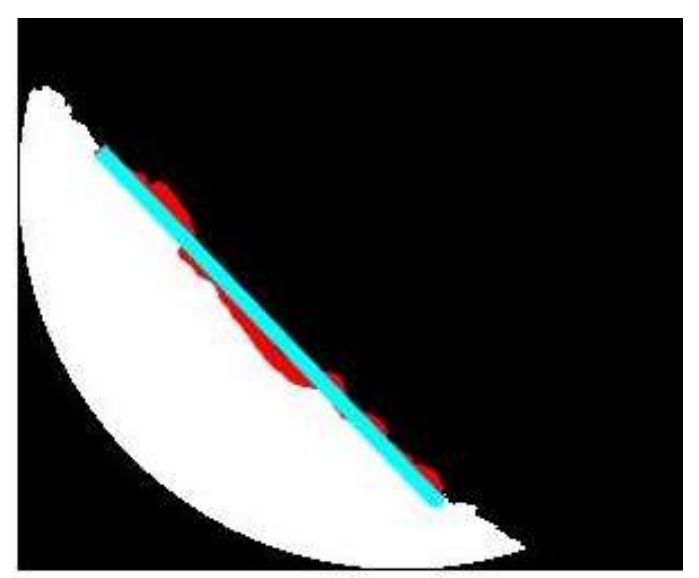

Figure 10. MATLAB [73] code analyzes each video frame and calculates angle of the surface and fraction area of the cylinder.

b. Particle Size Distribution

Particle size distribution was measured using light scattering method in accordance with ASTM B822-10. Utilizing the Microtrac S3500, 1010 particles were measured then sectioned into 20 bands by diameter size. The test provides a particle size distribution of the powder sample by volume of powder for the measured diameter of the powder. Figure 11 is the testing device used to complete the analysis. The test was performed by loading the material into the dispenser followed by a set-zero for the intake funnel to clear out any unwanted particles. Following this a flow analysis was conducted to determine if the current settings provided the right quantity of powder to conduct the test. The powder flows down a channel due to vibration where the frequency of said vibration can be altered to increase or decrease powder flow. Once 
the settings were approved the machine would take three 10 second runs with 20 second breaks in between the runs and average the distribution over all three runs. This would provide the particle size distribution of the powder.

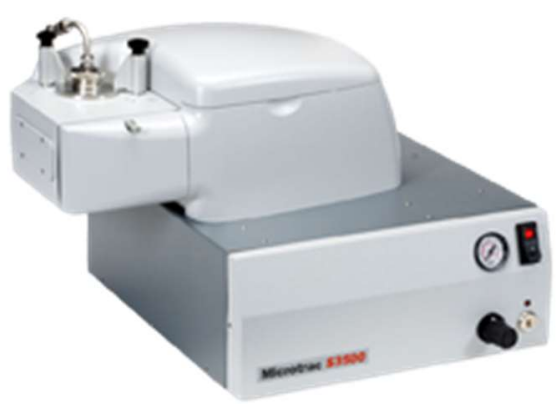

Figure 11. Microtrac S3500 particle size distribution testing device.

\section{c. Internal Powder Density}

Internal powder porosity was measured and is the presence of the atomizing gas becoming entrapped within the powder particle upon powder fabrication. A small sample powder was mounted in epoxy resin and polished using a standard metallography preparation method. Once polished, optical micrographs were taken of the powder in five separate fields. For each field an area fraction porosity was measured using an image analysis code written in MATLAB [73]. The script converts each image to binary and traces each particle individually. The script then examines inside of each outlined powder particle and outlines each pore. Following this a calculation is made of total pore area to total area outlined and a percent porosity is output. A standard deviation is calculated from all measurements made. 


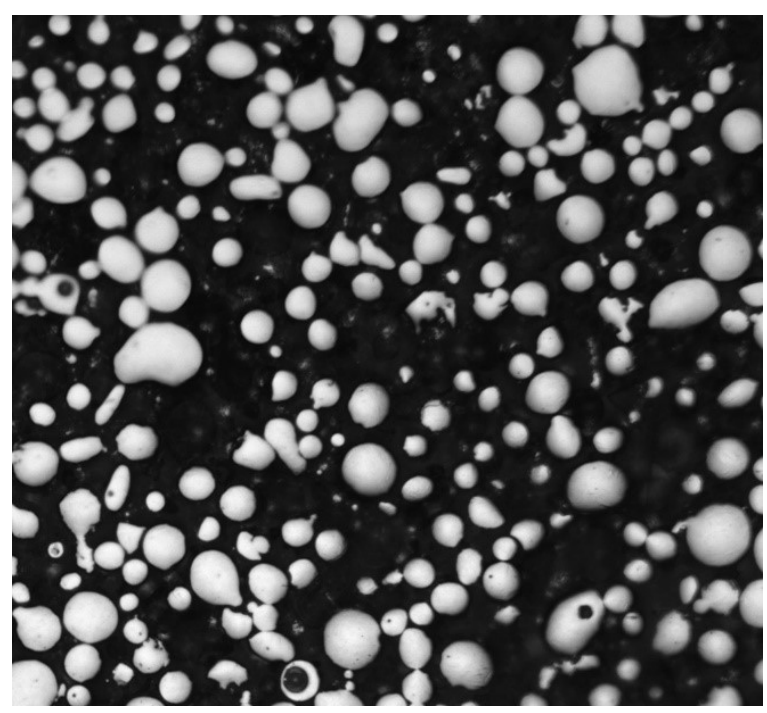

Figure 12. Polished sections of atomized powder show gas entrapped within some particles.

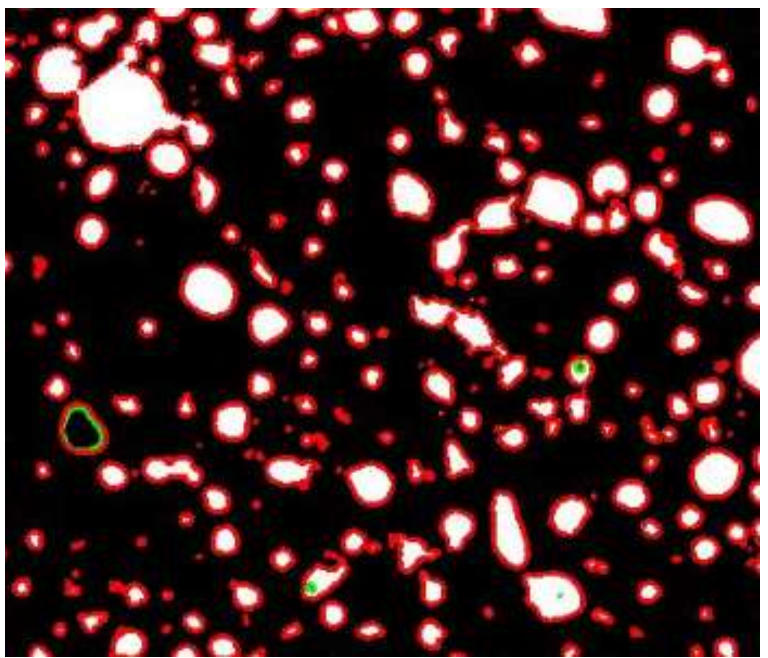

Figure 13. MATLAB[73] script measures internal porosity to receive density measurement.

2. SLM process

The SLM process starts by using CAD software to design parts for fabrication. The software used for this project was Solidworks. Once designed, the parts are saved to a .stl file and uploaded into a build design software. The build design software used for this project was Materialize Magics. This software allows the user to place the desired parts in the available build volume and design any support structures required for the parts. After the parts have been placed in the correct location within the build volume the parts are saved as .stl file once more however the retain there positioning within the build volume and the support structures are 
saved as .cli files. Following this, the .stl and .cli files are placed into the slicing software, in this study RIS slicing software was used. The slicing software takes the parts and supports and slices them into their individual layers and the parts are converted into .sli files or slice files. The sliced parts and supports are then uploaded into the software package for the particular machine being used. In this software the fabrication parameter sets are designed and applied to the specific parts and supports. The parameters for the supports were the support default, however the part parameters are available in Table 4 . The parts for this project were fabricated using an EOS M290, Figure 14, and the EOS software package was used.

Table 4. Exposure parameters and scanning strategy.

\begin{tabular}{cccccc}
\hline Power & Scan Speed & $\begin{array}{c}\text { Hatch } \\
\text { Spacing }\end{array}$ & $\begin{array}{c}\text { Layer } \\
\text { Thickness }\end{array}$ & $\begin{array}{c}\text { Scan } \\
\text { Strategy } \\
\text { Contour/ } \\
\text { Hatch }\end{array}$ & $\begin{array}{c}\text { Scan Rotation } \\
\text { Angle }\end{array}$ \\
\hline
\end{tabular}

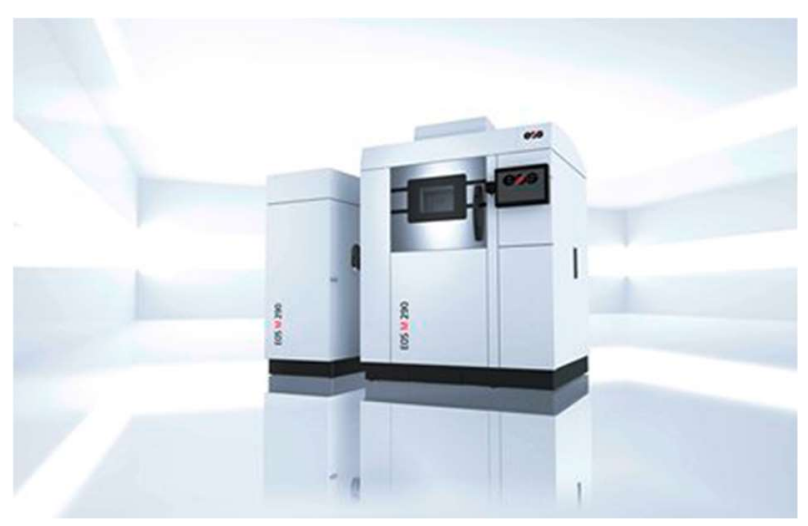

Figure 14. EOS M290 SLM Machine.

Following the build file setup process, part fabrication can commence. The process occurs by spreading thin layers of atomized metallic powder over a build volume using a roller or mechanical arm. Once the powder has spread a high power-density fiber laser fuses the metal particulate in the desired 2D geometry of that particular sliced layer. The fabrication process takes place in a safe inert gas environment, typically either $\mathrm{N}_{2}$ or Ar, this project fabricates in 
a $\mathrm{N}_{2}$ environment. Once the layer fabrication is complete the build volume will descend approximately one layer, the mechanism will again spread powder, the laser will rotate the preset angle, and the fabrication process will continue in this layer-by-layer fashion. Figure 15 is a depiction of the SLM process.
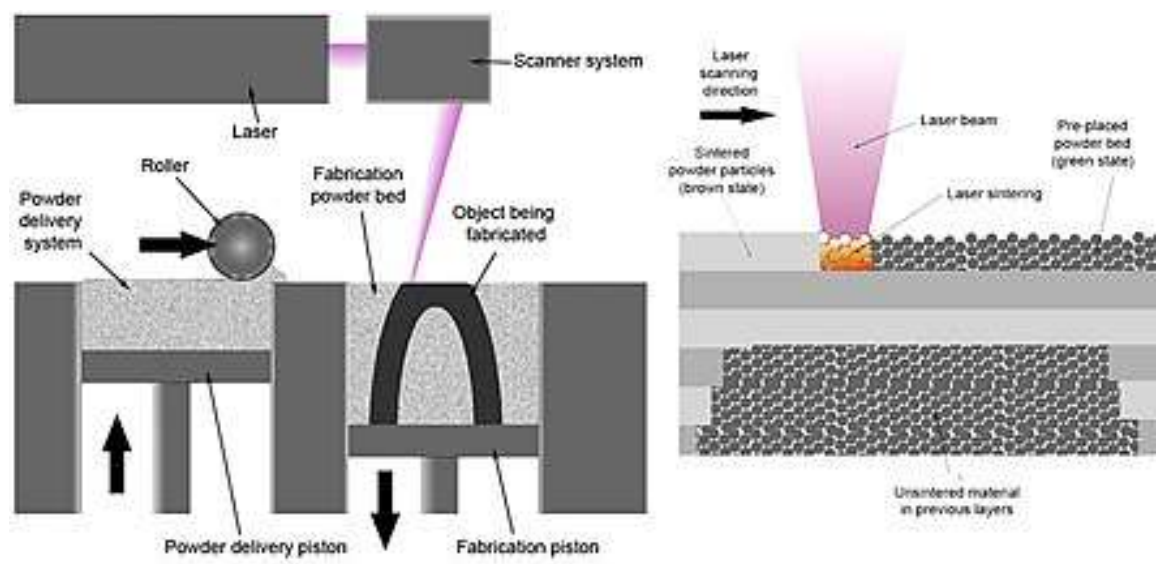

Figure 15. Schematic of the SLM process.

Concluding the fabrication process the parts are removed from the machine and the excess material is recycled and reused, and the machine cleaned properly. The parts are removed from the building substrate, typically, by using a band saw to remove the connection of the support material to the building substrate. Following this the support materials is carefully removed. This concludes the typical SLM fabrication process. Figure 16 is an image of the completed builds for the fatigue specimens.

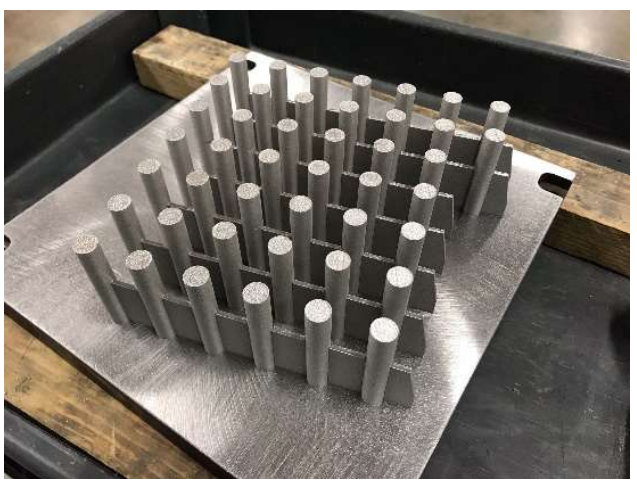

Figure 16. Completed build of fatigue bar samples on M290. 


\section{Specimen Design}

All samples were designed using Solidworks 2019a CAD modeling software.

\section{a. Metallography Cubes}

The metallography cubes were designed with dimension $9 \mathrm{~mm} \times 10 \mathrm{~mm} \times 11 \mathrm{~mm}$. This was done to be of sure which orientation the cube was in during the fabrication process once the part was removed from the build plate. The orientation is as follows $9 \mathrm{~mm}$ was parallel with the $\mathrm{X}$ axis, $10 \mathrm{~mm}$ parallel with the $\mathrm{Y}$ axis which was parallel to the recoating blade, and $11 \mathrm{~mm}$ is parallel to the $\mathrm{Z}$ axis which is parallel to the build direction.

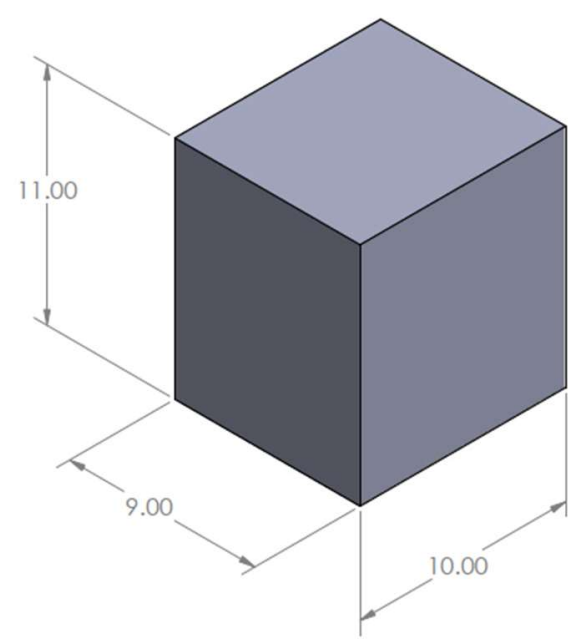

Figure 17. CAD design of metallography cubes.

b. Tensile Bars

The tensile bars were first fabricated in large blocks then afterwards taken through a wire EDM machining process to cut to the shape of the rectangular tensile bars. This was done characterize the bulk material property and not be affected by the poor-quality surface of the part post high temperature thermal treatment. Figure 18 below is the CAD drawing of the block 
and Figure 19 is the CAD drawing of the tensile bar that is cut from the block. Typically there were five tensile bars able to be machined from a single block.

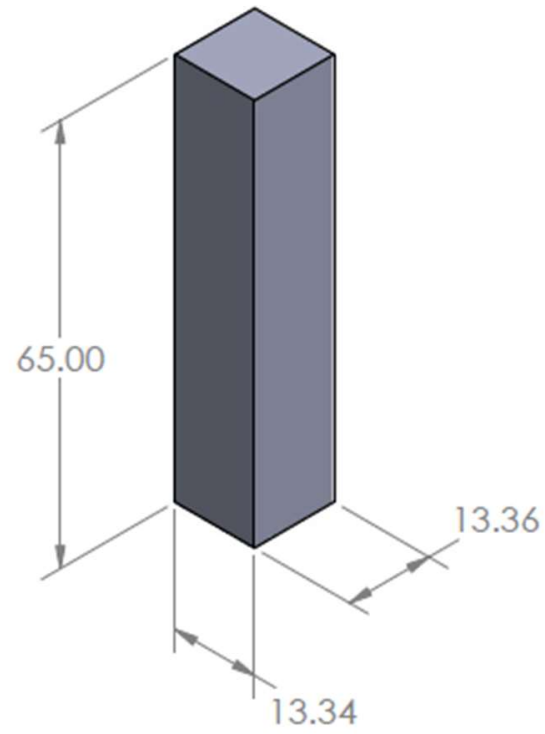

Figure 18. CAD of tensile block.
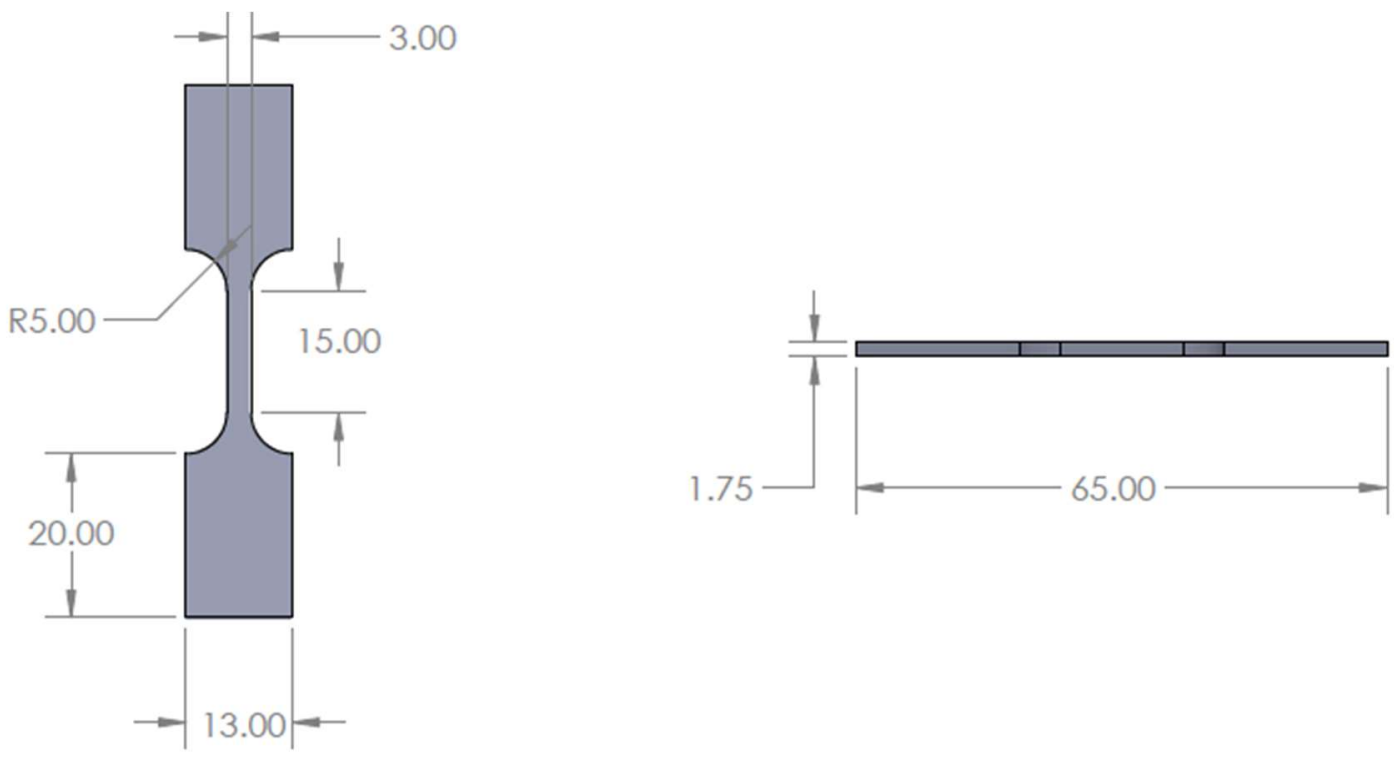

Figure 19. CAD of tensile bar. 


\section{c. Fatigue Bars}

The fatigue bars were first fabricated in cylinders then taken through a turning operation to the contour of the fatigue bar geometry. This was done in order to eliminate the rough surface quality of AM parts and characterize the bulk material properties and not the poor-quality surface of the parts post high temperature thermal treatment. Figure 20 below is the CAD drawing of the cylinders and Figure 21 is the CAD drawing of the fatigue bars post turning process. Typically there were five tensile bars able to be machined from a single block.

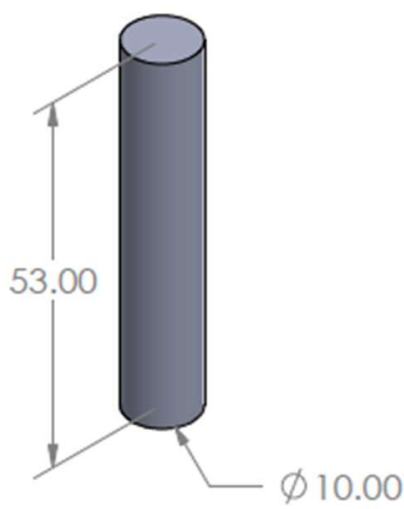

Figure 20. CAD of fatigue cylinder.
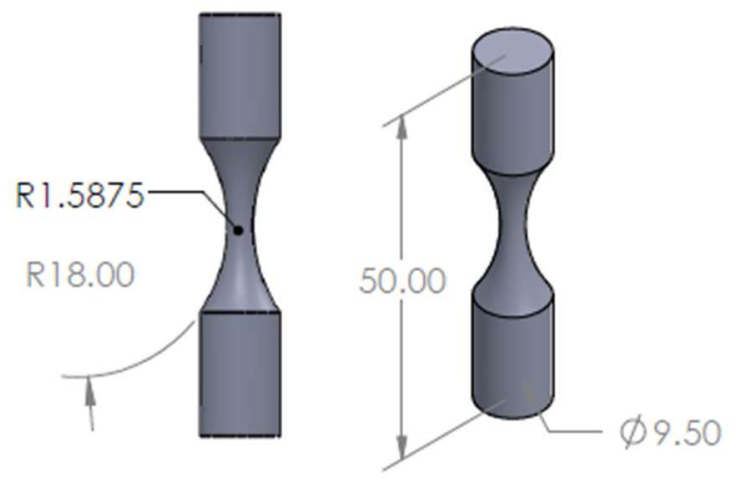

Figure 21. CAD of fatigue specimen. 


\section{Thermal Treatment}

One of the key factors of this study is the examination of varying thermal treatments on the fatigue behavior of the material. All specimens were in one of the three conditions: as-built, directly hardened or solutionized and hardened. The direct hardening was an industry standard H900 thermal treatment. The solutionizing and direct hardening thermal treatment was a twostep process with an elevated homogenizing temperature treatment followed by the industry standard H900 hardening step. The wrought material was solutionized as-received and therefore only went through a direct hardening process. The full thermal treatment step information is provided in Table 5 below. The oven used is pictured in Figure 22.

Table 5. Heat treatment procedure.

\begin{tabular}{|c|c|c|c|}
\hline $\begin{array}{ll}\text { Heat } & \text { Treatment } \\
\text { Step } & \end{array}$ & $\begin{array}{l}\text { Temperature } \\
\left({ }^{\circ} \mathrm{C}\right)\end{array}$ & $\begin{array}{l}\text { Treatment } \\
\text { Time (hr.) }\end{array}$ & $\begin{array}{l}\text { Cooling } \\
\text { Method }\end{array}$ \\
\hline Solutionizing & 1038 & 1 & Air Quench \\
\hline H900 Hardening & 482 & 1 & Air Quench \\
\hline
\end{tabular}

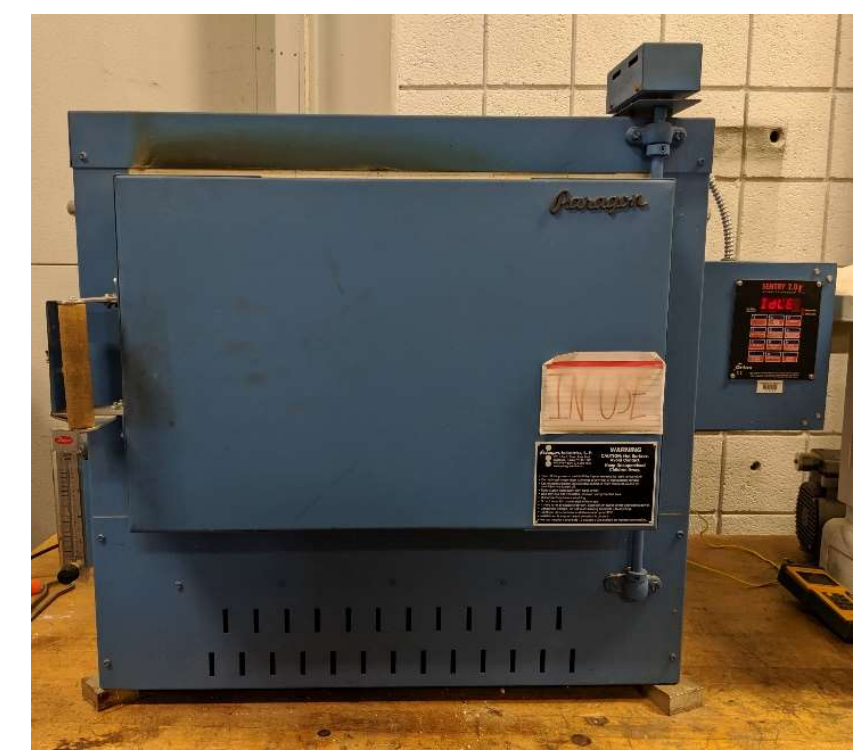

Figure 22. Paragon furnace used in study for thermal treatments. 


\section{Specimen Machining Process}

All mechanical testing specimens were taken through post-processing machining operations. The purpose was to remove the thermally effected surfaces of the thermally treated specimens as well as remove the rough surface attributed to AM. The two machine operations were turning and wire EDM for the fatigue and tensile specimens, respectively.

\section{a. Turning Operation}

The turning operation was completed in two steps. The first step was removing a thin layer of surface material. As the specimen was held in the clamps pictured in Figure 23 the process would machine one half of the specimen then the specimen would be removed and the unmachined surface exposed followed by the other half of the surface being machined. This would effectively remove any unwanted rough or thermally affected surface. The second step was a contour turning process and this step would form the continuous radius testing gauge length of the specimen. This process would begin with inputting the radius of the contour followed by the path of the turning operation using in-machine commands and g-code. Once the path was selected turning RPM and tool movement speed were selected. Figure 24 is the lathe used for the machining process.

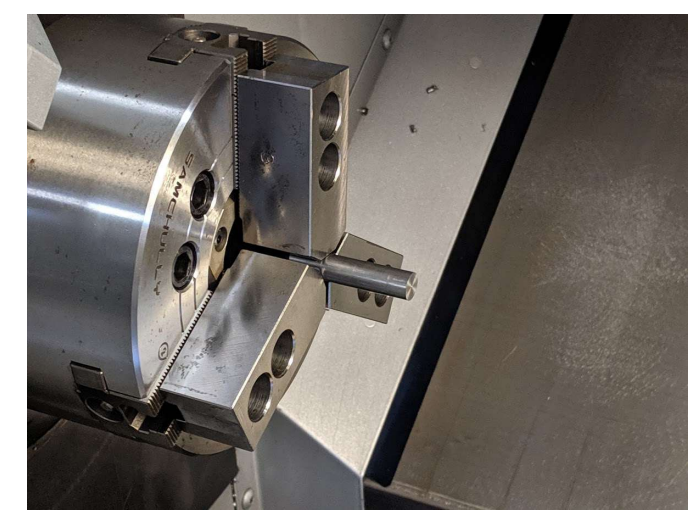

Figure 23. Specimen in lathe preparing for turning operation. 


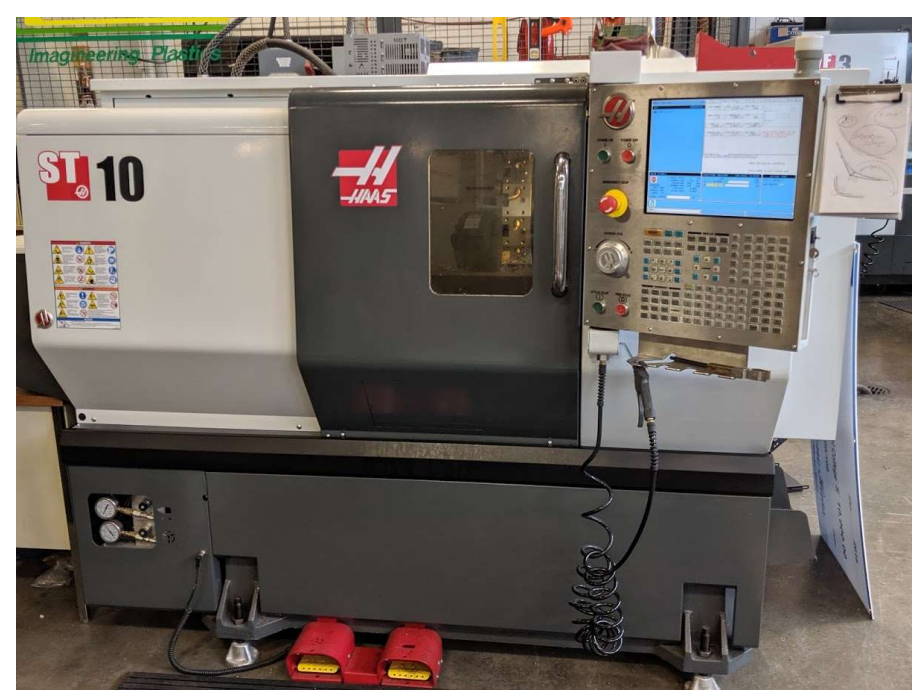

Figure 24. Lathe used for turning operation.

\section{b. Wire EDM Machining Operation}

The wire EDM process was used to form the tensile specimens from the tensile block. This process was completed in two steps. The first was to machine the contoured surface of the specimens using in-machine commands and g-code. The contour inputs were provided directly from the CAD of the specimen. Once the contour geometry of the specimen was machined. The samples were individually sliced from the larger block. The thickness of each specimen was provided in the CAD.

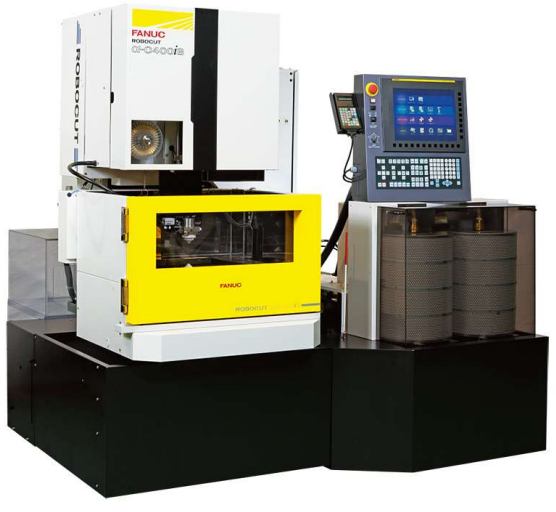

Figure 25. Wire EDM used to machine tensile blocks. 


\section{Metallography Sample Preparation}

Metallography sample preparation is used in order to examine the polished surface of a material particularly for imaging and etching to further characterize the material. The sample preparation process began concluding the fabrication process. The samples were cut in two directions, the first the XY section view which is the plane perpendicular to the build direction and the YZ section which is parallel to the build plane. Once cut, the specimens were placed inside a plastic rounded mold with diameter of 1". A 2:3 mixture of hardener and acrylic powder, respectively, are mixed together to form a resin to mount the specimens. The mixture is poured into the mold and encases the specimens. Once the mixture hardens the puck is removed from the mold. The mounted specimens are then taken through a grinding and polishing process using an automatic polisher to eventually receive a mirror-like finish on the specimens. This allows for images to be taken and examine internal part defects or porosity. The automatic polisher used for this process is the Metprep 3, pictured in Figure 26. The polishing procedure can be located in Table 6 .

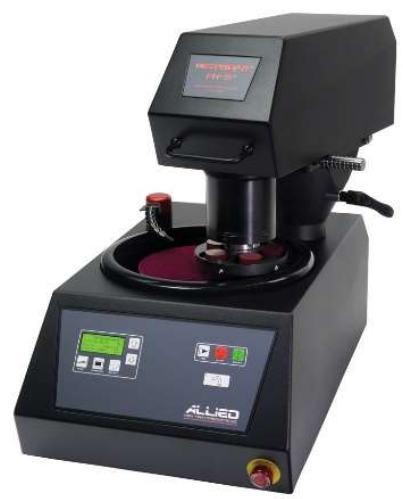

Figure 26. Allied High-Tech Metprep 3 Automatic Polisher used to prepare samples. 
Table 6. Metallurgical sample preparation guide from Allied High-Tech Polishing Procedures.

\begin{tabular}{|c|c|c|c|c|c|c|c|}
\hline & Step & 1 & 2 & 3 & 4 & 5 & 6 \\
\hline \multirow{5}{*}{ 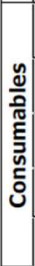 } & $\begin{array}{c}\text { Abrasive Size } \\
\text { (P-Grading) }\end{array}$ & $\begin{array}{l}180 \text { Grit } \\
(P-180)\end{array}$ & $\begin{array}{l}320 \text { Grit } \\
(P-400)\end{array}$ & $\begin{array}{l}600 \text { Grit } \\
(P-1200)\end{array}$ & $6 \mu \mathrm{m}$ & $1 \mu \mathrm{m}$ & $0.04 \mu \mathrm{m}$ \\
\hline & \multirow{3}{*}{$\begin{array}{c}\text { Carrier } \\
\text { Polishing Cloth }\end{array}$} & $\begin{array}{l}\text { Silicon } \\
\text { Carbide }\end{array}$ & $\begin{array}{l}\text { Silicon } \\
\text { Carbide }\end{array}$ & $\begin{array}{l}\text { Silicon } \\
\text { Carbide }\end{array}$ & $\begin{array}{c}\text { Poly } \\
\text { Diamond }\end{array}$ & $\begin{array}{c}\text { Poly } \\
\text { Diamond }\end{array}$ & $\begin{array}{l}\text { Colloidal } \\
\text { Silica }\end{array}$ \\
\hline & & $\begin{array}{c}\text { Abrasive } \\
\text { Disc }\end{array}$ & $\begin{array}{c}\text { Abrasive } \\
\text { Disc }\end{array}$ & $\begin{array}{c}\text { Abrasive } \\
\text { Disc }\end{array}$ & $\begin{array}{c}\text { Glycol } \\
\text { Suspension }\end{array}$ & $\begin{array}{c}\text { Glycol } \\
\text { Suspension }\end{array}$ & Suspension \\
\hline & & - & - & - & DiaMat & White Label & Final A \\
\hline & \multirow{5}{*}{\begin{tabular}{|c|} 
Coolant \\
Platen Speed \\
(RPM) / Direction * \\
Sample Speed \\
(RPM) \\
Force $($ Ibf/N) ** \\
Time $(\mathrm{min})+$
\end{tabular}} & Water & Water & Water & GreenLube & GreenLube & Water $+\dagger$ \\
\hline \multirow{4}{*}{ 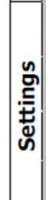 } & & $300 /$ Comp & $300 /$ Comp & $300 /$ Comp & 150/Comp & 150/Comp & 150/Comp \\
\hline & & 150 & 150 & 150 & 150 & 150 & 150 \\
\hline & & $5 / 22$ & $5 / 22$ & $5 / 22$ & $5 / 22$ & $5 / 22$ & $4 / 18$ \\
\hline & & 1 & 1 & 1 & 4 & 3 & 1 \\
\hline
\end{tabular}

\section{a. Density Measurement}

Once polished to mirror finish, five micrographs were taken at different locations on the polished surface using an optical microscope, pictured in Figure 26. Once taken the image was saved as a tif file. Fraction porosity was determined by first converting to binary image, standard thresholding, and pixel counting method using ImageJ software [74]. Density of the sample was estimated by calculating the average of all measurements and precision determined through standard deviation of these five measurements.

\section{b. Microstructure Examination}

Concluding density measurement, the polished surface was etched using Kallings Reagent \#2, an acidic based mixture of copper chloride, hydrochloric acid, and ethanol used to bring out the microstructure of steel. This process would be conducted under a fume hood with proper personal protection equipment such as gloves, safety goggles, and a mask. The reagent would be placed unto the surface of the sample using a disposable plastic dropper. The solution would remain on the surface for 15-30 seconds followed by a removal of the liquid into a glass 
container and a flushing of the surface with isopropyl alcohol and cleaning using an alcohol wipe. The liquid waste was properly disposed of in a labeled plastic container and the solid waste into its own labeled container.

\section{Surface Roughness Testing}

The surface roughness measurement serves multiple purposes. The first is due to the nature of fatigue testing and how surface defects tend to be a source of fatigue failure. The surface roughness of the specimen has a direct correlation to the fatigue life of the specimen. Another is to determine what surface treatment quality the test specimens are under (i.e. polished, machined, etc.). This understanding aides in fatigue life prediction calculations as well as determining if the surface treatment operation meets standard. Surface roughness measurements were taken using the profilometer Mitutoyo SJ210, displayed in Figure 27. This particular instrument utilizes a stylus which is moved across the surface of the specimen. The displacement of the stylus is recorded and calculated into a surface roughness measurement. For these specimens a small fixture was created to hold the specimens in place and create a repeatable testing setup. As the Profilometer only moves along one axis, the testing device could only measure the roughness of the grip section as it couldn't account for the continuous radial contour. The surface roughness measurements output the $R_{a}, R_{q}$, and $R_{z} . R_{a}$ is the average roughness across the surface and is a typical value used to determine the surface roughness and compare to other measurements. $\mathrm{R}_{\mathrm{q}}$ is the root mean square deviation of the profile and is often used in conjunction with the $R_{a}$ measurement. The final output is the $R_{z}$ which is the maximum height of a surface roughness peak. When examining a machining process it is best to observe the $R_{a}$ and $R_{z}$ together. The machining process should be consistent (low $R_{a}$ ) but may still have large peaks (high $\mathrm{R}_{z}$ ) from the intrinsic properties of machining. The testing 
fixture is depicted in Figure 28 below and was fabricated using a desktop fused filament fabrication, FFF, AM machine in PLA polymer.

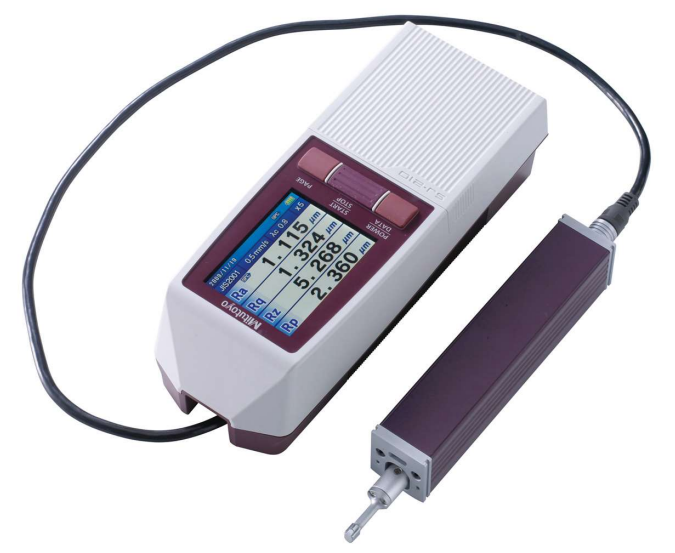

Figure 27. SJ210 profilometer used for surface roughness measurements.

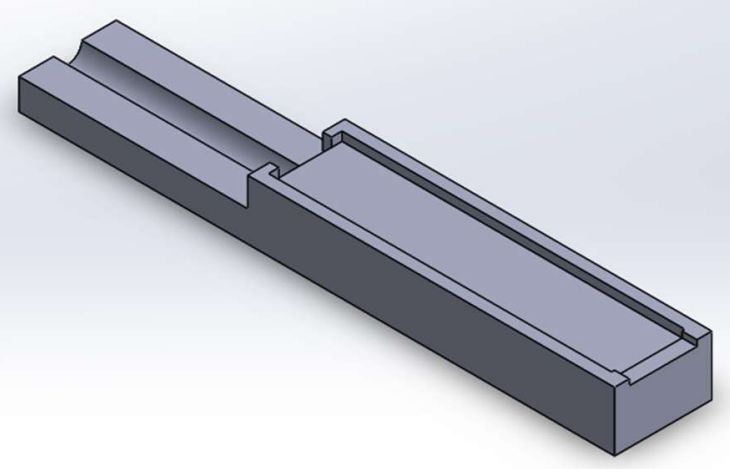

Figure 28. Fatigue bar surface roughness testing fixture.

\section{Tensile Testing}

Tensile testing was performed on an Instron $50 \mathrm{kN}$ test machine (Model: 5569A) using ASTM E8-16 standard tensile testing method. The samples were placed into the crosshead grips on the machine and tightened. Following this an Instron extensometer was attached to the gauge length with high strength rubber bands. This functions to easily attach and remove the extensometer as well as ensure the knife edges of the measurement device to do not slip. The extensometer measures strain of the specimens referencing the original gauge length of the 
testing equipment, $12.5 \mathrm{~mm}$ gauge length, and the displacement of the knife edges as the tensile specimen yields. The $50 \mathrm{kN}$ load cell measures the load on the specimen as it is pulled in tension to failure. The stress is calculated as a function of the load and the cross-sectional area of the specimen, measured for each sample and input for the test. The stress and strain raw data are used to generate the commonly used stress v. strain curve as a way to observe mechanical performance and behavior. Figure 29 below is an image of the Instron model used for tensile testing.

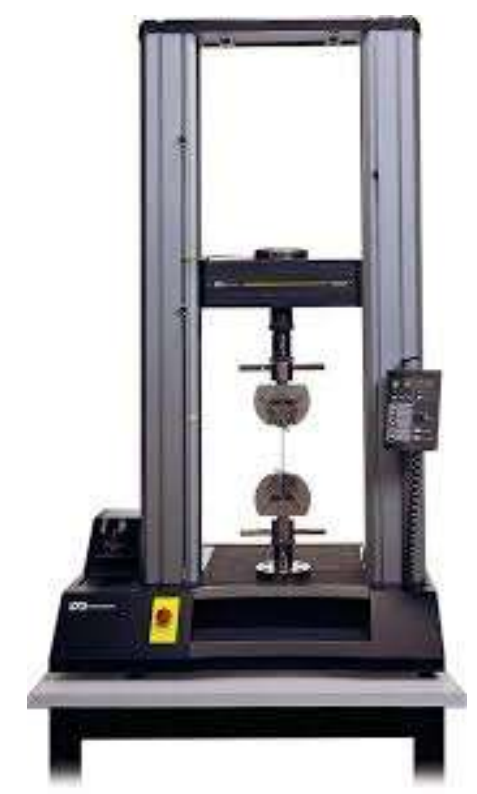

Figure 29. Instron 5569a model tensile and compression tester used in study.

9. Hardness Testing

The hardness of the samples was evaluated by performing Vickers micro-hardness measurements on the polished sections using Shimadzu's HMV-G21. At least 10 measurements were taken diagonally from each sample using a load of $980.67 \mathrm{mN}$ (100 gf) with a $10 \mathrm{~s}$ holding time. The hardness values point to mechanical performance and is an important benchmark to meet standard for industry use. This data is also used in conjunction 
with the tensile data to ensure the data is consistent across both testing platforms as there is a strong relationship between the two mechanical testing methods. Figure 30 below is model used to test Vickers micro-hardness in this study.

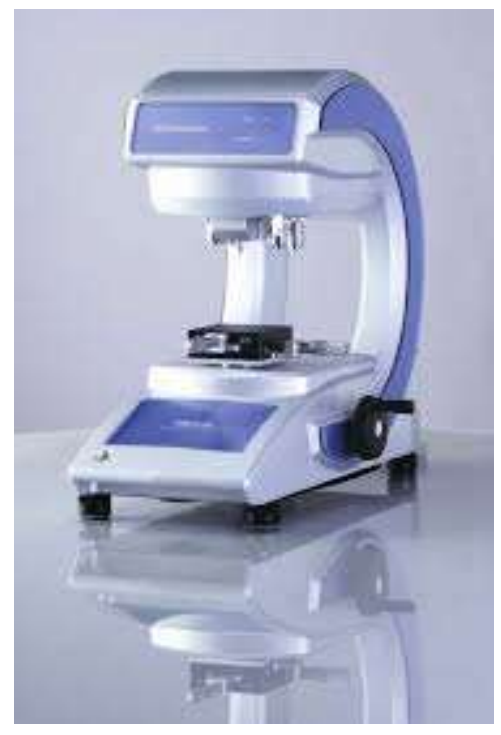

Figure 30. Vickers micro-hardness testing device used in this study.

10. Fatigue Testing

All specimens were tested on the same machine with only two testing parameters altered during testing, frequency and maximum alternating stress.

\section{a. Testing Fixture}

The machine used for testing was an Instron E10000, Figure 31. This machine has the capacity to test to $\pm 10 \mathrm{kN}$ with a frequency of $50 \mathrm{~Hz}$. However, it is recommended by the manufacturer to test larger stress or strain amplitudes at lower frequencies to ensure machine lifetime and reliability in data. The grips allow for a variety of grip section diameters and are controlled through the use of pneumatics. The crosshead location is adjustable based upon the height of the specimen. 


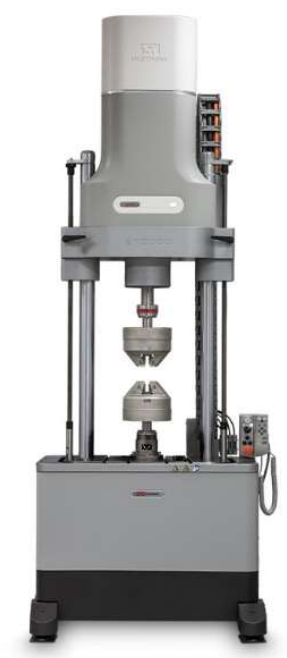

Figure 31. Instron E10000 fatigue testing device used in this study.

\section{b. Procedure}

The first step to fatigue tests were to load the sample into the machine. Move the crosshead into position so that the sample will fit into the grips. Next using cushioned clamps, as not to harm the specimen, place the sample within the collet. Lower the top crosshead down over the top of the grip section, both grips should be within the collet. Activate the pneumatic device

that closes the grips and holds the specimen. At this point the specimen is loaded. The following steps will be to setup a testing profile in the Instron Wavematrix software. There are three inputs needed for testing. The first is ramp loading, the second is load amplitude, and the third is frequency. Ramp loading is based from the maximum alternating stress and $\mathrm{R}$ value. As the fatigue testing equipment operates with load inputs, the desired stress level will need to be chosen then the load calculated based from the minimum cross-sectional area in the continual radius gauge section. Ramp load is the load at the mean stress level. Once this is identified and input, the next step is to provide the amplitude or the difference in load from the 
ramp load to the maximum alternating stress load equivalent. The final step is to select a testing frequency. Concluding this, the test is ready to commence.

\section{c. Testing Parameters}

Only two factors were changed as the specimens were tested for different lifetimes: frequency and maximum alternating stress. All tests were conducted at a $\mathrm{R}$ value equal to 0.1 . Meaning that the mean stress and minimum alternating stress were both functions of the maximum alternating stress. If a shorter lifetime was desired to test the maximum alternating stress was increased. The purpose for altering the frequency was due to the manufacturing warning to test higher amplitudes at a lower frequency to ensure machine life and reliable data. For all tests conducted with a maximum alternating stress lower than $500 \mathrm{MPa}$ the frequency was set at 50 $\mathrm{Hz}$ and for any tests higher it was tested at $30 \mathrm{~Hz}$.

\section{Microscopy}

The optical microscope, an Olympus BX53, was used to image the polished surfaces of the specimens and powders used for various density measurement methods. This included observing and imaging the etched surfaces of the specimens to observe the microstructure. This method was also used to observe fracture initiation points of the specimens.

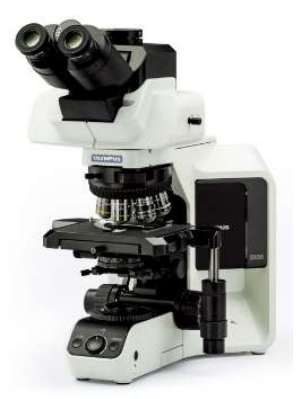

Figure 32. Olympus BX53 optical light microscope used in this study. 


\section{RESULTS}

\section{Powder Characterization}

The 17-4 PH stainless steel argon atomized AM powder selected for this study had powder characterization and testing results indicative of a high quality powder to be used for SLM fabrication methods. The following subsections elaborate on the characterization results obtained in this study.

\section{a. Flowability}

The flowability data obtained from the six separate characterization methods implemented is provided in Table 7.

Table 7. Flowability results for the 17-4 PH stainless steel powder used for this study.

\begin{tabular}{cccccc}
\hline $\begin{array}{c}\text { Apparent Density Tap Density } \\
(\%)\end{array}$ & $\begin{array}{c}\text { Hausner } \\
(\%)\end{array}$ & $\begin{array}{c}\text { Angle of repose } \\
\left({ }^{\circ}\right)\end{array}$ & $\begin{array}{c}\text { Avalanche angle } \\
\left({ }^{\circ}\right)\end{array}$ & $\begin{array}{c}\text { Hall flow } \\
(\mathrm{s})\end{array}$ \\
\hline 54 & 59 & 1.10 & 32 & 22 & 19.3 \\
\hline
\end{tabular}

The apparent and tap densities were calculated relative to the true density of 17-4 PH stainless steel, $7.75 \mathrm{~g} / \mathrm{cm}^{3}$. These values were used in the calculation of the Hausner ratio, which with a value less than 1.25 is well within the range of good flowability. Angle of repose has a higher slumping angle than that of the avalanche angle, which is to be expected as angle of repose is a static performance test and avalanche angle testing is dynamic. The Hall flowmeter time is also consistent with powders which demonstrate good flowability. 


\section{b. Powder Size Distribution Analysis}

Key particle size data from the light refractory testing using the Microtrac and the sieve analysis conducted in the lab are presented in Table 8 .

Table 8. Microtrac and sieve analysis data for particle size analysis.

\begin{tabular}{|c|c|c|c|c|}
\hline \multirow{2}{*}{$\begin{array}{l}\text { Microtrac } \\
\mathrm{D}_{50}(\mu \mathrm{m})\end{array}$} & \multirow{2}{*}{$\begin{array}{c}\text { Microtrac } \\
\mathrm{D}_{10}(\mu \mathrm{m})\end{array}$} & \multicolumn{3}{|c|}{ Sieve Analysis } \\
\hline & & $<38 \mu \mathrm{m}$ & $38-75 \mu \mathrm{m}$ & $>75 \mu \mathrm{m}$ \\
\hline 41.4 & 29.6 & 10.0 & 89.3 & 0.3 \\
\hline
\end{tabular}

The $\mathrm{D}_{50}$ and $\mathrm{D}_{10}$ values are diameters for which $50 \%$ and $10 \%$ of the powder is smaller than the given value. The key values from the Microtrac are consistent with the sieve analysis. The particle size distribution in Figure 33 is also consistent with data gathered in the sieve analysis, which is describes the differential and cumulative particle size distribution from the Microtrac. An expected gaussian distribution of particle size is observed.

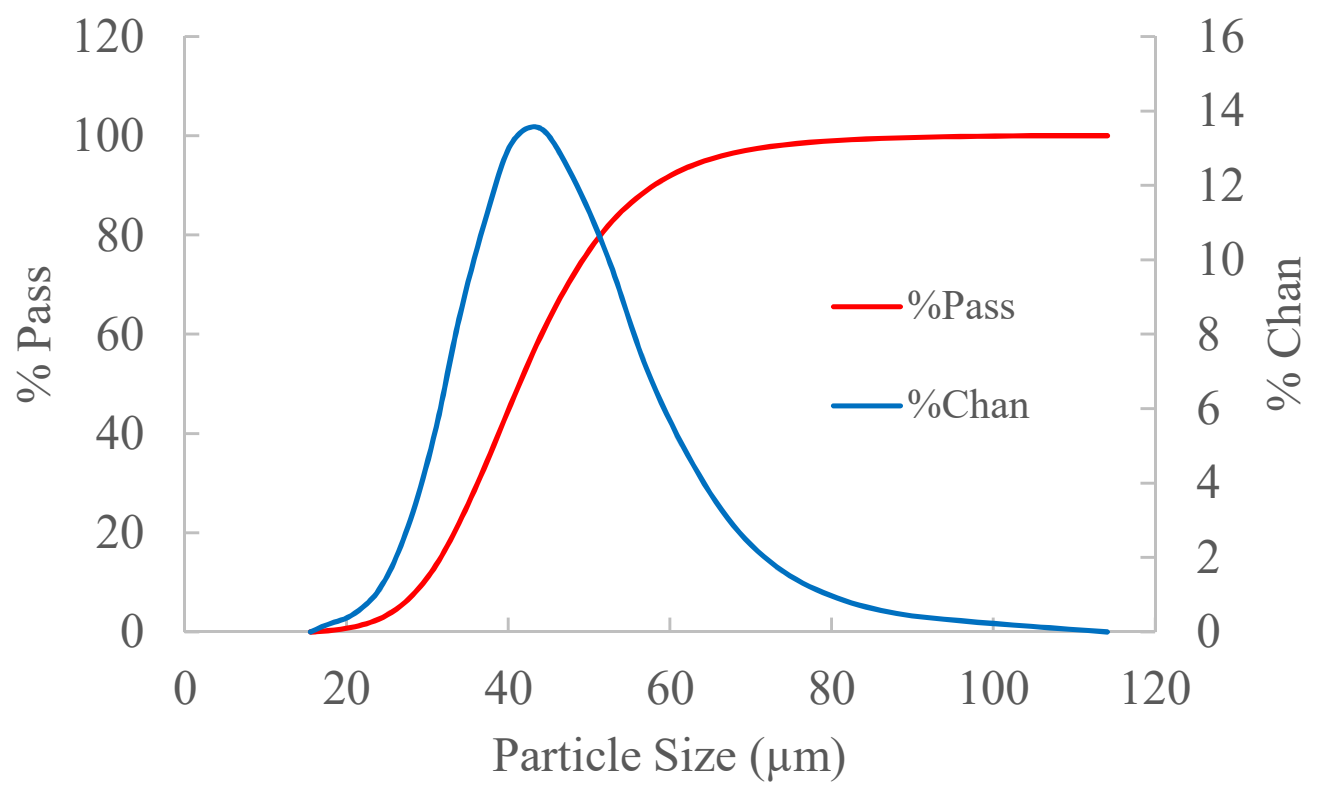

Figure 33. Particle size analysis and distribution. 


\section{Internal Powder Porosity}

Table 9 contains the results of all porosity measurements including as-built coupons and internal particle porosity.

Table 9. Porosity measurements for as-built coupons and powder particles.

\begin{tabular}{ccc}
\hline & \% porosity* & \\
\hline Coupon XY & Coupon YZ & Particle \\
$0.10(.01)$ & $0.10(.03)$ & $0.29(.27)$ \\
\hline
\end{tabular}

*average of five measurements (standard deviation)

There is a significant uncertainty in the particle porosity measurements based on the variability of the five image fields used for these values. However, the powder retains a density $>99 \%$ within two standard deviations.

3. Metallographic Sample Analysis

The part density and microstructural analysis results gathered will be reviewed within the following subsections.

\section{a. Density Measurements}

Table 9, above, contains the part density data gathered through sectioning, polishing, and imaging of the parts. In both the $\mathrm{XY}$ and $\mathrm{YZ}$ planes the overall porosity measured within the specimens was approximately $0.10 \%$ with low deviation. The similarity in porosity between the $\mathrm{XY}$ and $\mathrm{YZ}$ planes indicates a relatively even distribution of pores throughout the fabricated part. Figure 34, below, is one of the images taken of the polished surface using light microscopy. 


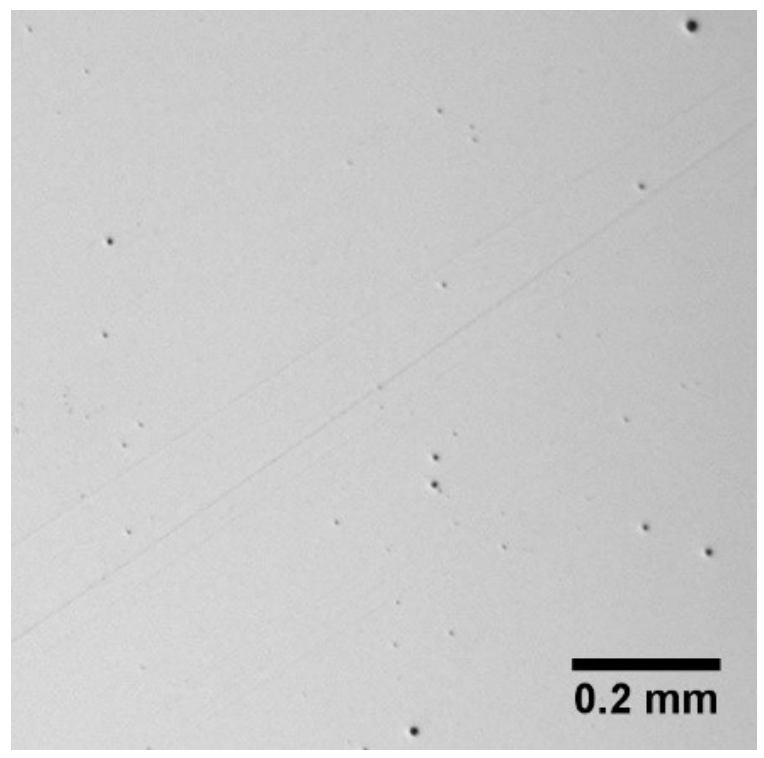

Figure 34. Polished surface of AM powder with observable porosity.

The porosity present in the photograph is small and rather spherical, this indicates that the parameters used for part fabrication are optimized for removal of lack of fusion porosity.

b. Microstructural Examination

The variable thermal treatments: as-built, direct hardened, and solutionized and hardened, did have variations in the microstructure present. Figure 35, below, is a micrograph taken of the etched as-built surface of the AM material. 


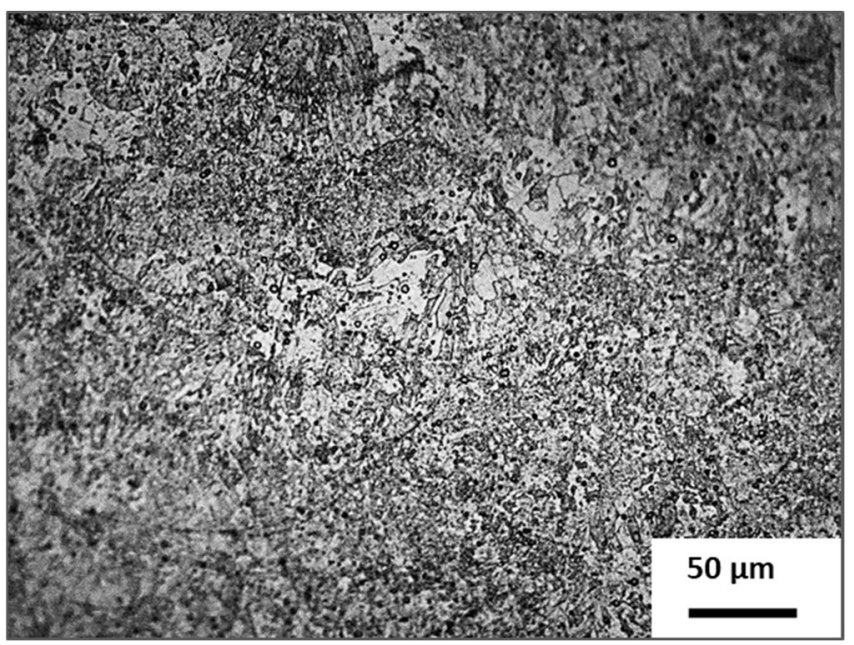

Figure 35. As-built microstructure of AM coupon.

The as-built microstructure of the 17-4 PH AM material comes out as dominantly martensitic, with fine granular structures prevalent in the image. The slightly lighter and larger particles are retained $\delta$ ferrite which did not fully transform into martensite during the fabrication process. This as-built microstructure indicates an ability for further successful hardening thermal treatments to improve the mechanical properties of the material. Figure 36, is the microstructure of the AM material post H900 direct hardening thermal treatment. Visually, the material looks relatively the same as it did prior to the thermal treatment. The retained $\delta$ ferrite is still present as the temperatures involved with the direct hardening is not elevated enough to transform the microstructure to full martensite. However, it is observed that the martensite present is now much finer than before, which is to be expected with this type of treatment. The finer martensitic microstructure will improve the mechanical strength of the material. 


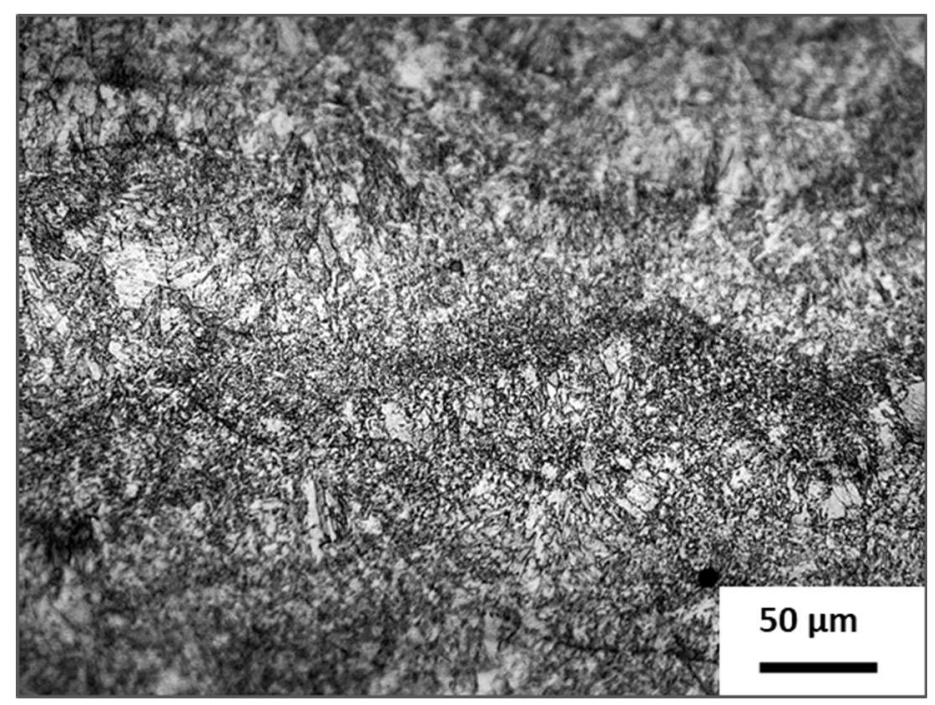

Figure 36. Direct H900 hardening microstructure of AM coupon.

The solutionized and hardened microstructure is provided in Figure 37. There is a definite observed difference between this microstructure and the as-built and direct harden AM microstructures.

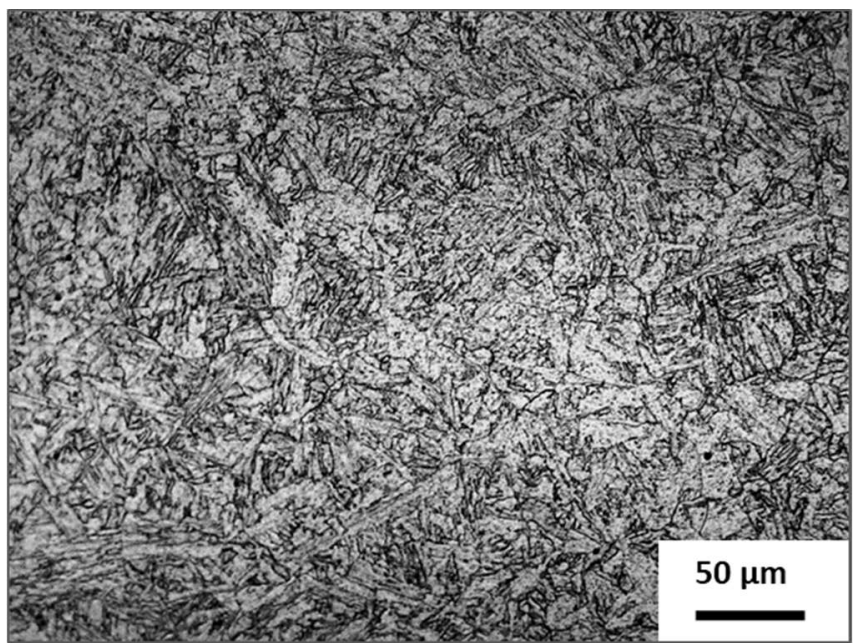

Figure 37. Solutionized and H900 hardened microstructure of AM coupon.

The full transformation of the $\delta$ ferrite into martensite has homogenized the microstructure. Figure 38 is the microstructure of the wrought material post direct harden thermal treatment. 


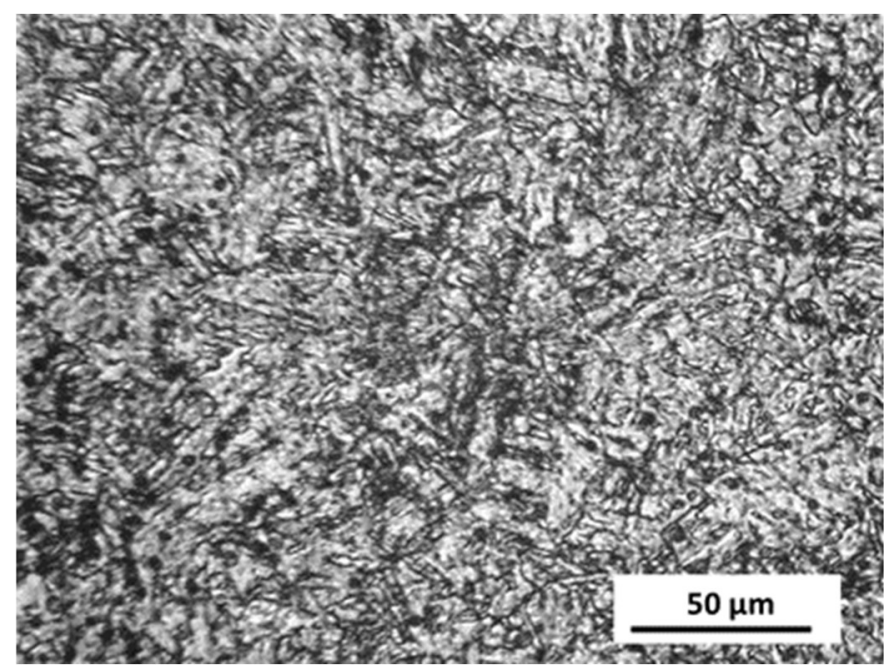

Figure 38. Direct H900 hardened microstructure of wrought 17-4 PH material.

This microstructure is also fully martensitic matching most closely to the solutionized and hardened AM material. This is expected as the wrought material goes through a solutionized step prior to the manufacturer shipping the material.

\section{Surface Roughness Testing}

The data summary of the surface roughness measurements is presented in Table 10. The average surface roughness, $\mathrm{R}_{\mathrm{a}}$ (defined in material and methodology), is similar in all samples after the same machining operation used to form the shape of the samples. However, the $\mathrm{R}_{\mathrm{a}}$ for the as-built and direct hardening AM samples are slightly higher from the wrought and solutionizing and hardened AM sample sets. This is attributed to variation in the machining process as chipping of the samples during turning did not always occur and occasionally left rings of material that needed to be removed by hand. This could have slightly damaged the surface in the process. This was similarly found in the other two means of surface roughness measurement, $\mathrm{R}_{\mathrm{q}}$ and $\mathrm{R}_{\mathrm{z}}$. Figure 39 are graphical depictions of the actual surface roughness profile of the specimens. These figures cover the full $10 \mathrm{~mm}$ sample surface tested as well as a range in $\mu \mathrm{m}$ that provides a detailed examination of the surface profile. All of the AM 
specimens look similar in the examined profiles, however in the wrought specimen significantly less noise is observed compared to the AM specimens. This is attributed to the layering fabrication method used in SLM.

Table 10. Surface roughness measurement property summary.

\begin{tabular}{|c|c|c|c|c|}
\hline \multirow{2}{*}{ Material } & \multirow{2}{*}{ Condition } & \multirow{2}{*}{ Factor } & \multicolumn{2}{|c|}{$\begin{array}{l}\text { Surface Roughness } \\
\text { Measurement }(\mu \mathrm{m})\end{array}$} \\
\hline & & & AVG & SD \\
\hline \multirow{9}{*}{$\mathbf{A M}$} & \multirow{3}{*}{ As-Built } & $\mathrm{Ra}$ & 0.474 & 0.063 \\
\hline & & $\mathrm{Rq}$ & 0.583 & 0.070 \\
\hline & & $\mathrm{Rz}$ & 3.357 & 0.449 \\
\hline & \multirow{3}{*}{$\begin{array}{l}\text { Direct H900 } \\
\text { Hardening }\end{array}$} & $\mathrm{Ra}$ & 0.457 & 0.133 \\
\hline & & $\mathrm{Rq}$ & 0.571 & 0.144 \\
\hline & & $\mathrm{Rz}$ & 3.124 & 0.467 \\
\hline & \multirow{3}{*}{$\begin{array}{c}\text { Solutionizing } \\
\quad+\text { H900 } \\
\text { Hardening }\end{array}$} & $\mathrm{Ra}$ & 0.402 & 0.125 \\
\hline & & $\mathrm{Rq}$ & 0.498 & 0.154 \\
\hline & & $\mathrm{Rz}$ & 2.711 & 0.778 \\
\hline \multirow{3}{*}{ Wrought } & \multirow{3}{*}{$\begin{array}{l}\text { Direct H900 } \\
\text { Hardening }\end{array}$} & $\mathrm{Ra}$ & 0.398 & 0.023 \\
\hline & & $\mathrm{Rq}$ & 0.490 & 0.027 \\
\hline & & $\mathrm{Rz}$ & 2.653 & 0.153 \\
\hline
\end{tabular}

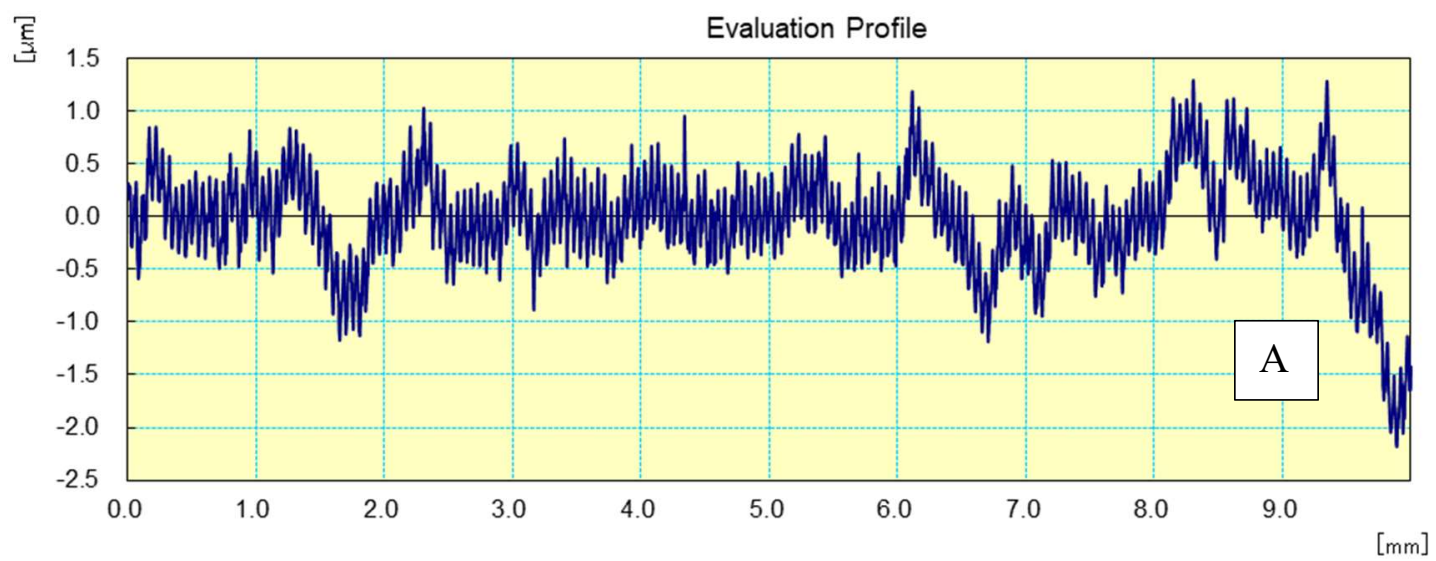



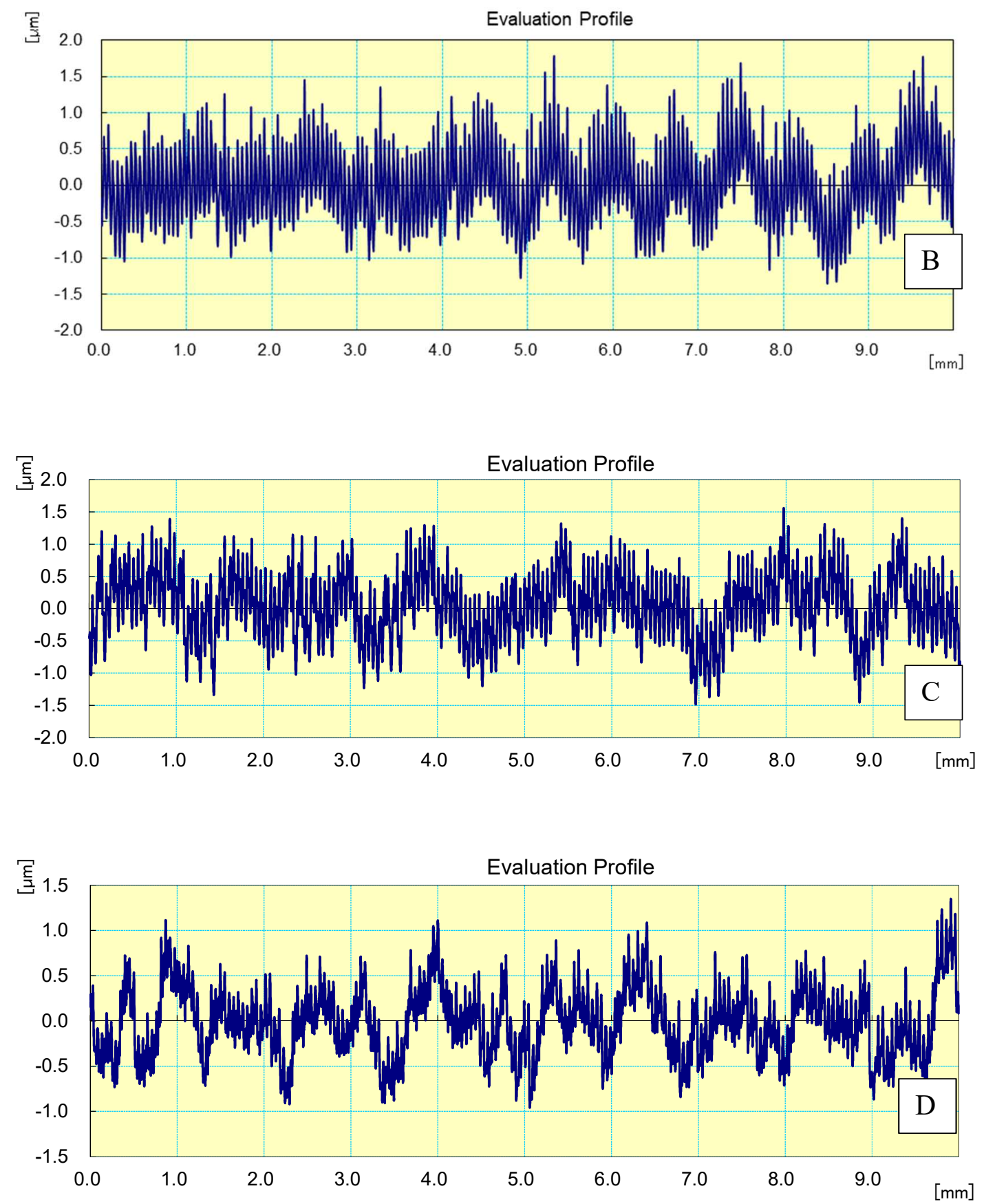

Figure 39. Surface roughness profile (a) As-Built, (b) H900, (c) S+H900, and (d) Wrought H900.

\section{Tensile Testing}

A typical engineering stress strain curve is represented in Figure 40 for all thermal treatment material variations. The AM samples tested were only fabricated in the vertical direction to 
match the fabrication direction of the fatigue samples and receive a reliable yield and ultimate stress approximation.

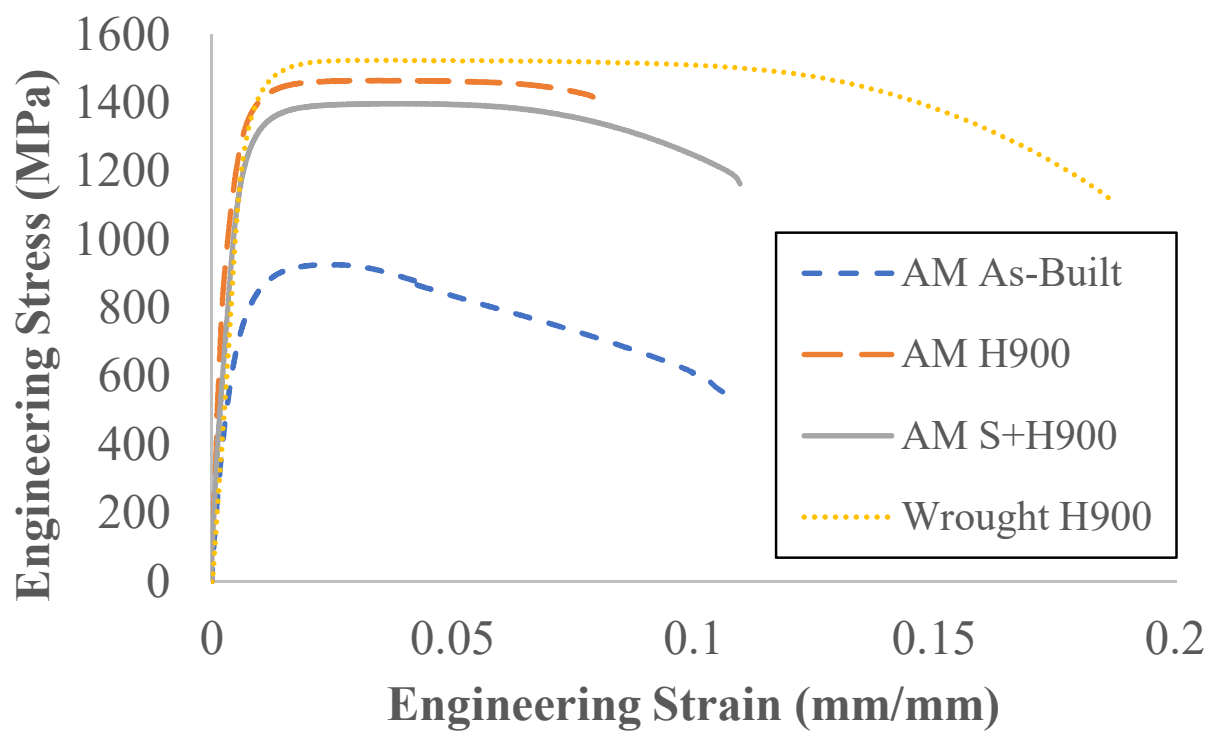

Figure 40. Tensile testing performance.

The tensile strength performance of the materials is as anticipated. The performance of the asbuilt AM material demonstrates a significantly lower yield and ultimate stress than all of the thermally treated specimens. As the as-built material came out predominantly martensitic, upon direct hardening the mechanical strength vastly improved and similar results are demonstrated in the solutionized and hardened material. The wrought direct hardened specimens had a superior overall performance compared to all the materials tested. The elongation of the AM specimens remained nearly consistent between all thermal treatments at approximately $10 \%$ which meets material specification.

A summary of the mechanical properties tested in this study is presented within Table 11. There is minimal variation among the three specimens tested in each thermal treatment and material category indicating repeatability and reliability in mechanical performance. 
Table 11. Summary of Mechanical Properties of Tensile Tests and Micro-Vickers Hardness.

\begin{tabular}{ccccc}
\hline & $\begin{array}{c}\text { Yield strength, 0.2\% } \\
\text { elastic offset }(\mathrm{MPa})\end{array}$ & $\begin{array}{c}\text { Ultimate tensile } \\
\text { strength }(\mathrm{MPa})\end{array}$ & $\begin{array}{c}\text { Total } \\
\text { elongation }(\%)\end{array}$ & $\begin{array}{c}\text { Micro-Vickers } \\
\text { hardness (HV) }\end{array}$ \\
\hline AM As-Built & $856 \pm 23$ & $917 \pm 27$ & $11.0 \pm 0.6$ & $333.0 \pm 5$ \\
AM H900 & $1389 \pm 7$ & $1467 \pm 11$ & $9.4 \pm 1$ & $461.9 \pm 5$ \\
AM S+H900 & $1322 \pm 2$ & $1401 \pm 9$ & $10.0 \pm 0.5$ & $440.7 \pm 10$ \\
$\begin{array}{c}\text { Wrought } \\
\text { H900 }\end{array}$ & $1371 \pm 52$ & $1523 \pm 18$ & $17.3 \pm 1.2$ & $480.2 \pm 13$ \\
\hline
\end{tabular}

6. Hardness Testing

The results of the micro-Vickers hardness testing are in Table 11. The values found support the found yield and ultimate strengths from the tensile results, as observed in Figure 41, with the thermally treated samples having similar values, but the wrought H900 direct hardened being the highest followed by the AM H900 direct hardened and AM solutionized and H900 hardened.

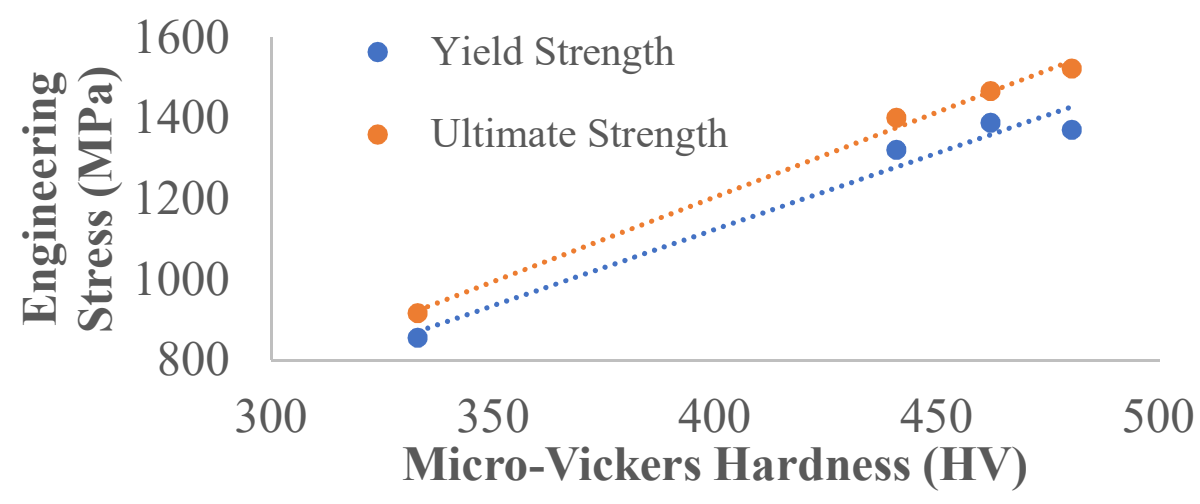

Figure 41. Relationship of Micro-Vickers Hardness to Yield and Ultimate Strength.

7. Fatigue Testing

The S-N curve for the fatigue tests performed in this study is represented in Figure 42. The specimen result encircled in red and the run out specimens were not included in the logarithmic 
trend line of the sample performance. There was also one as-built specimen which failed at a low cycle which was not included in the test results, information in Appendix 3. The trend lines were applied in the graphing program and extrapolated out to $10^{7}$ life cycles where an endurance limit line was manually added. There is some evidence for the lines location from the run out testing performance indicated from the arrows drawn out from the specimens once the $10^{7}$ life cycle had been reached.

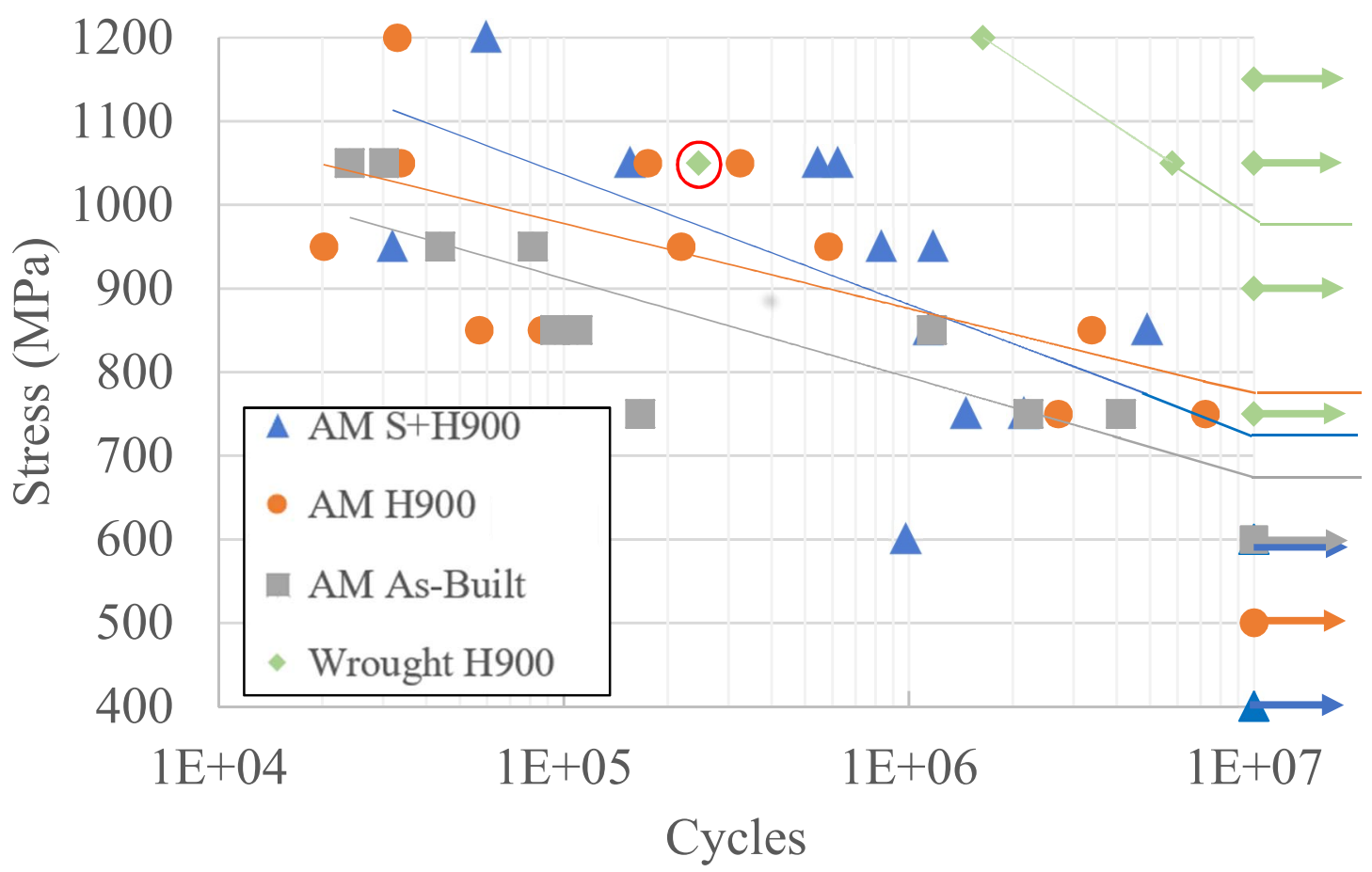

Figure 42. S-N curve of fatigue tested specimens.

There is significant scatter of the specimen performance, typical of fatigue testing. However, there is little difference between the AM specimens besides a slightly higher overall performance of the thermally treated samples. 


\section{Fracture Initiation Locations}

All images of the fracture location images are located in in Appendix 3. A few notable images for reference are in Figure 43 below. The failure initiation locations are encircled in red.
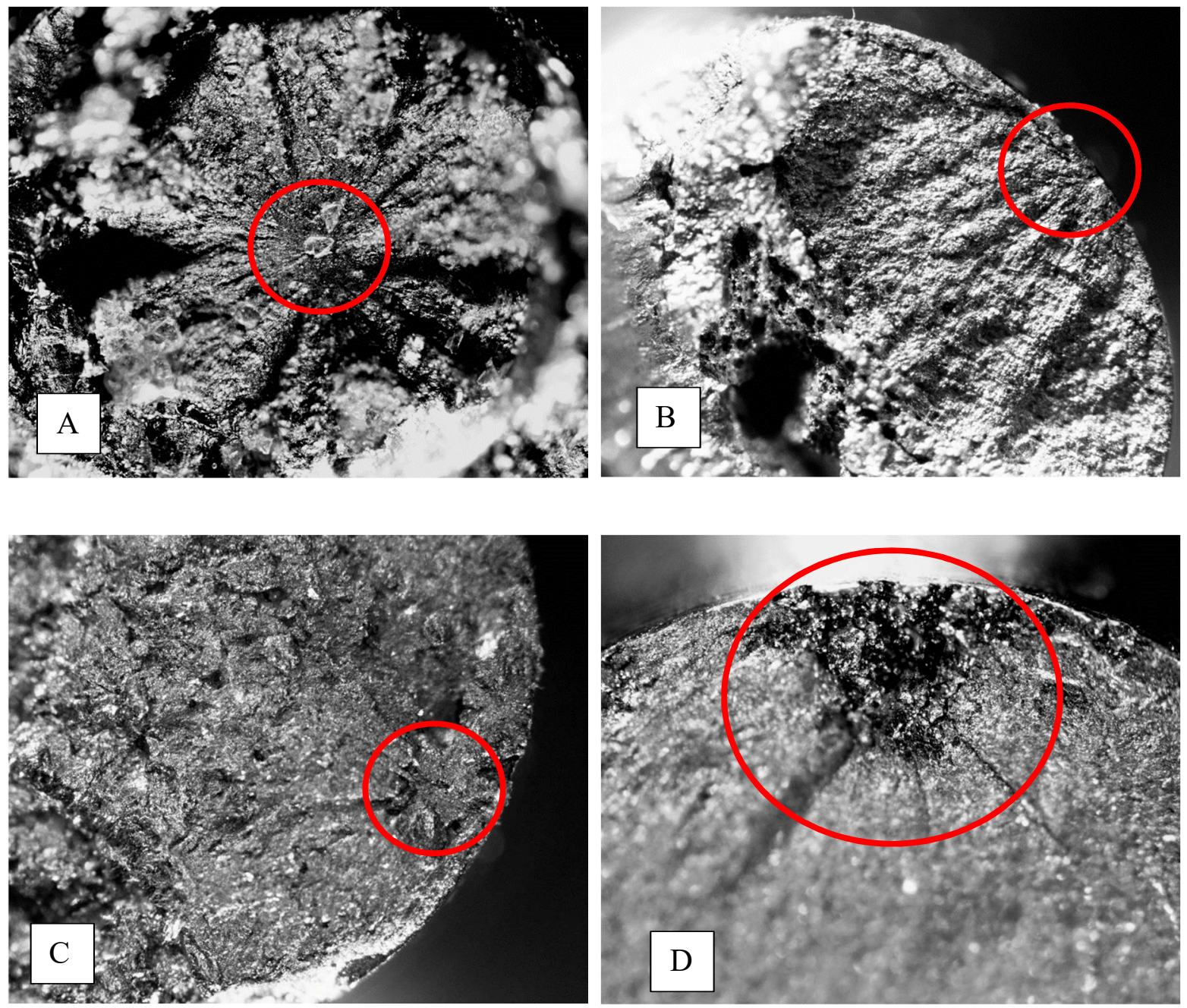

Figure 43. Fracture initiation locations (a) internal porosity, (b) surface defect, (c) sub-surface porosity, and (d) unmelted powder/major defect.

The majority of the failure initiation locations for the AM specimens were at the surface and caused by surface defect or sub-surface porosity. This failure mode is typical of stainless steel fatigue testing. Few were caused by major defects such unmelted powder, but these resulted in a significant decrease in fatigue life compared to a sample with the same testing conditions. 
The typical failure mode is present within in the specimens with a defect that initiates the failure surrounded by micro-cracking, a section of material that slowly fractures followed by a fast fracture. 


\section{DISCUSSION}

\section{Powder Characteristics}

The AM powder demonstrated a high level of flowability. With a low Hausner ratio (1.10) and smooth flow through the standard Hall Flowmeter funnel, this powder is well within the means of good flowability. The powder had an angle of repose measurement was slightly above $30^{\circ}$. Typically a measurement of $40^{\circ}$ or higher indicates powder cohesion and poor flowability while a measurement of approximately $30^{\circ}$ indicates good flowability. It is known that the avalanche angle and angle of repose are correlated. As the avalanche angle is a dynamic powder flowability measuring tool, a lower value is suspected and is meant to simulate the spreading of powder. This value also indicates superior flowability.

It is known that particle size distribution has a direct effect on the flowability of a powder. The two methods, particle size analysis as well as powder sieve test provide similar results and lead to the same conclusion that the powder used to fabricate these specimens is within the intended particle size and is the proper distribution for an SLM type fabrication method. The sieve analysis poses that approximately $10 \%$ of the particles are $<38 \mu \mathrm{m}$ and $\mathrm{D}_{10}$ is below this value. As this powder is a typical size range SLM powder, i.e. manufacturer particle size of 15-45 $\mu \mathrm{m}$, it is expected that nearly $90 \%$ of the powder would be within the size of $38-75 \mu \mathrm{m}$ with little powder exceeding this size range and that the $\mathrm{D}_{50}$ is approximately $40 \mu \mathrm{m}$. Figure 33 shows a typical gaussian distribution for the particle size detailing the percentage of material 
at certain particle sizes as well as the percent of material that has passed through at particular particle sizes.

\section{Thermal Treatment and Microstructure}

It has been observed in previous studies [71] that the as-built microstructure can vary widely among powders of even the same grade material. In this case, 17-4 PH stainless steel, it has been observed to have austenitic, ferritic, and martensitic microstructures. In this as-built case the AM material has a dominant martensitic microstructure with some retained ferrite. This indicates that the material can be directly hardened for an improvement of mechanical properties. The direct hardening microstructure is similar to that of the as-built, with a slightly finer martensitic structure. This is because the H900 hardening temperature is not enough to transform the ferrite to austenite then to martensite. It is further observed that the AM powder exhibited inhomogeneous grain size distribution by having coarse columnar grains whereas, Wrought-H900 has more homogeneous grain size distribution. A further thermal treatment was used to homogenize the microstructure through a solutionizing and hardening step for separate specimens. The solutionizing step completely homogenized the microstructure, with the elevated temperature, converting the available martensite and ferrite to the parent grain austenite. Upon air quenching, providing a slower cooling rate than the fabrication process, the thermally treated specimen was converted fully to a fine martensitic grain structure. This grain structure aligned more with that of the wrought-H900 specimen.

\section{Thermal Treatment and Mechanical Properties}

The tensile performance of the specimens was heavily influenced by the state of the specimens in regard to thermal treatment. The as-built sample performance was the lowest of all the specimens tested, which for many AM parts is to be expected. As-built had a slightly longer 
elongation than the other AM specimens, but a significantly lower yield and ultimate stress of approximately $500 \mathrm{MPa}$ difference between the specimens. The performance of the as-built samples is typical, however, of tensile testing. The direct hardening step of the specimens vastly improved the mechanical yield and ultimate strength. However, the elongation of the specimens was not improved by this process compared to the as-built, in fact it was reduced.

The direct hardened specimens performed most similar to the wrought H900 material, with slightly lower strength (difference in ultimate of approximately $50 \mathrm{MPa}$ ) and significantly lower elongation. The solutionized and hardened specimens performed slightly lower than the directly hardened samples (difference in ultimate of approximately $60 \mathrm{MPa}$ ) and had a similar elongation. This reduction in strength, while small is attributed to slight over aging of material. The hardness values corresponded well to the yield and ultimate strength of all specimens as observed in Figure 41. These measurements will be further used in analysis of the fatigue specimens.

\section{Thermal Treatment and Fatigue}

Typically it is expected that with improved yield strength of a material, there will also be an improvement in the fatigue performance of the specimens as these two properties are often connected. It has been observed in this study that there are measurable improvements in the yield strength of the as-built material post thermal treatments (approximately $500 \mathrm{MPa}$ for both hardening steps performed). With this vast improvement in performance it is expected that there will be a distinct difference between the as-built materials and that of the hardened AM and wrought specimens. However, this is not what is observed within the data. What is instead found is that there is little difference between the three thermally unique categories of AM specimens, with significant scatter present. 


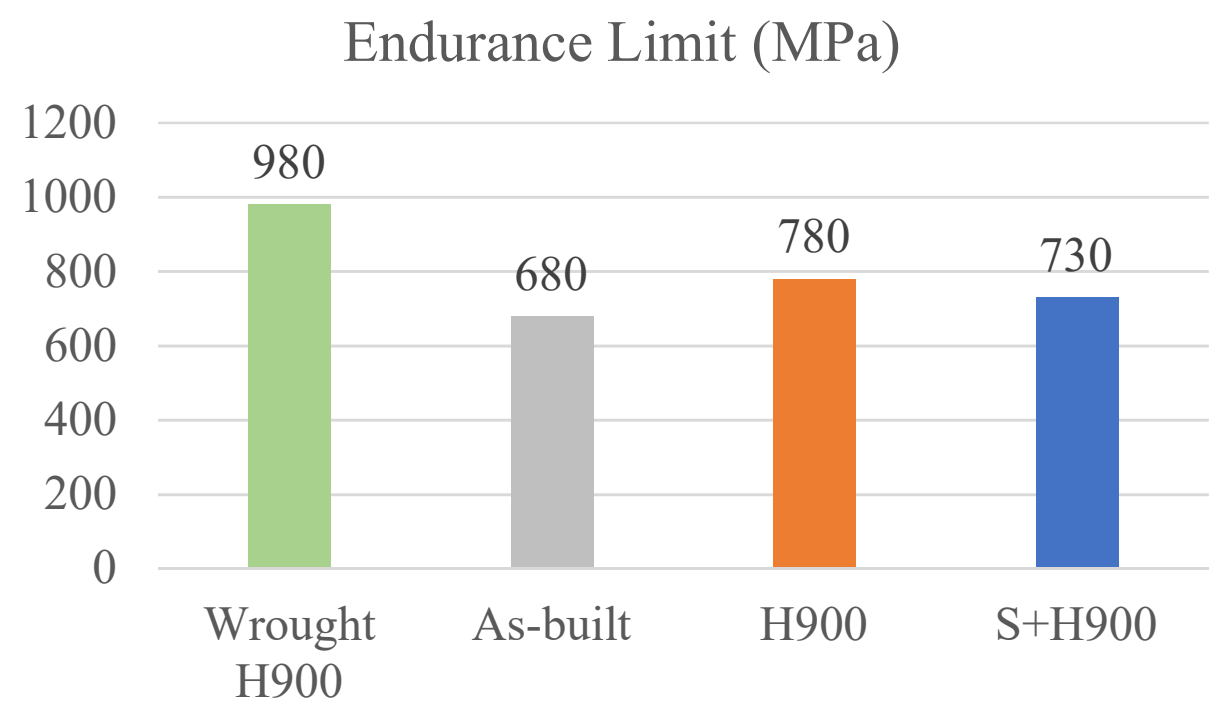

Figure 44. Endurance limit of the specimens tested.

All of the specimens experience a high level of scatter. The trend of logarithmic fatigue life and the extrapolated endurance limit reflects the scatter in Figure 42. Many of the samples deviate from the logarithmic trend line. Figure 44 displays all of the specimens tested with the respective extrapolated endurance limit. It is observed that all three of the AM materials have relatively similar endurance limits that are significantly below the wrought. Due to such significant scatter throughout there are no clear conclusions or definitive statements that can be made concerning the superiority of one AM specimen type over another, only that all underperformed compared to wrought material and that they performed in a relatively similar manner.

To predict the endurance limit of a specimen there is brief equation used, provided below.

$$
S_{e}=\frac{1}{2} S_{u}
$$

Where $S_{e}$ is the expected endurance limit and $S_{u}$ is the ultimate strength of the material [75]. It is worth noting that according to the AMS specification of mechanical properties for 17-4 
$\mathrm{PH}$, available in Table 2, that the ultimate strength requirement is $1310 \mathrm{MPa}$. According to Equation 2 the predicted endurance limit is $655 \mathrm{MPa}$. According to Figure 44, this implies that the as-built material, while not meeting strength specifications does meet this predictor for endurance limit. Also the direct harden material does meet specification for strength, elongation, and the predicted ultimate strength. Furthermore, the ratio of the extrapolated endurance limit and the ultimate strength of our specimens should yield 0.5 to understand the performance of each specimen. Figure 45 is a chart displaying the calculated values from the experimental data gathered.

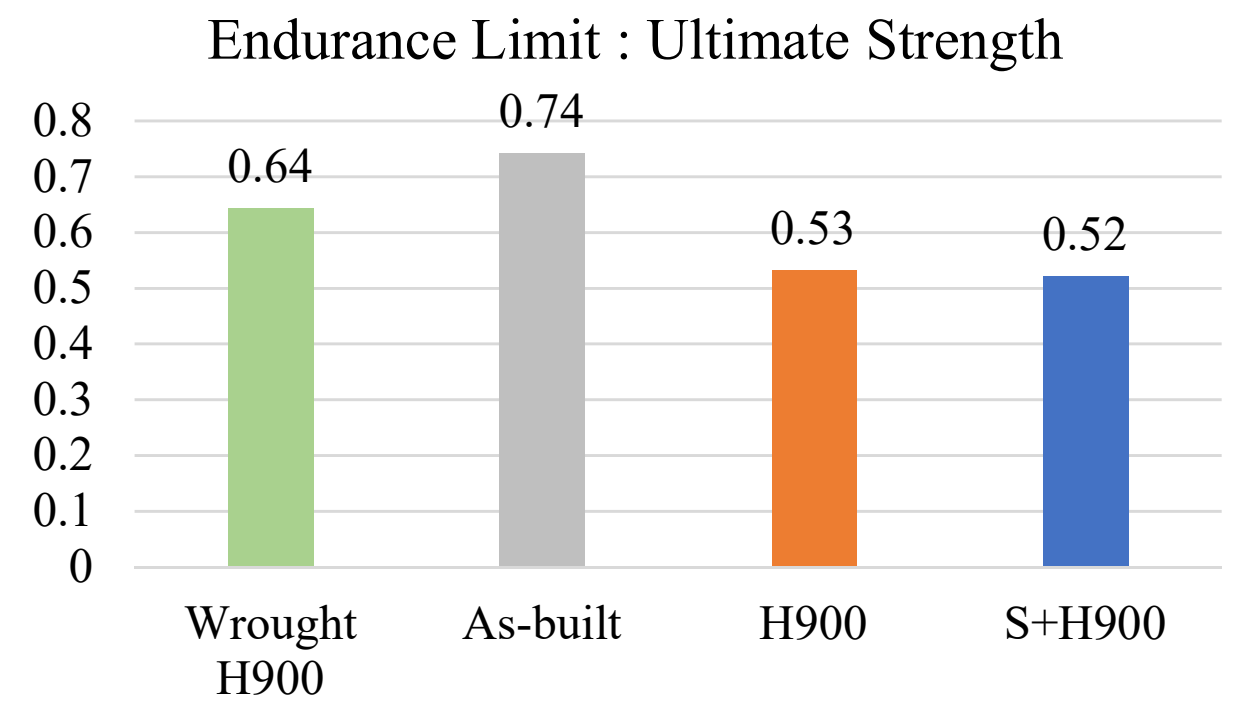

Figure 45. Ratio of endurance limit to ultimate strength.

From this calculation it is found that the while the hardened AM specimens underperformed relative to the wrought, those specimens are nearer the expected value of the ratio of endurance limit to ultimate strength. The wrought and as-built specimens performed better than anticipated given the predictive relation. This implies that the material is not necessarily underperforming given the standard, only comparatively to the wrought specimen with a similar ultimate strength to the hardened AM materials. 
An attempt to further normalize the data provided in Figure 42, is available in Figure 46. The data was normalized by removing data with large defect areas and specimens that fractured well above the minimum diameter of the rounded gauge length section. Upon removing of specimens there is significantly less scatter, implying that premature failure is indeed defect driven. However, while scatter was reduced, the endurance limits became further clustered and even produced a more significant gap between the specimens and the wrought material justifying the previous statements.

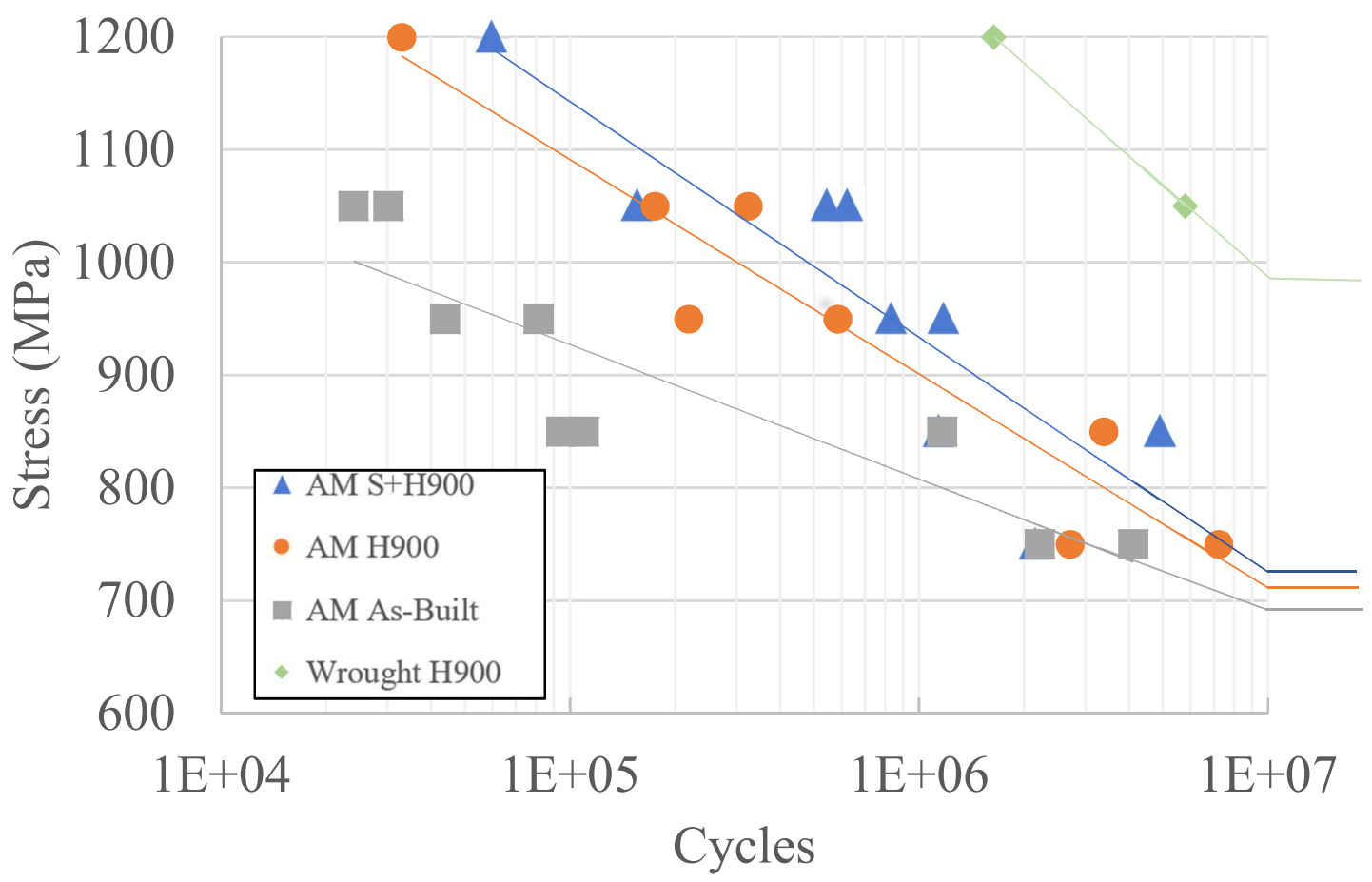

Figure 46. Normalized fatigue data.

This result was also found in a previous study [61], where thermally treated 17-4 PH stainless steel SLM specimens were tested. Similar to this study the fabrication process parameters were designed with the intent to optimize for full densification. It was observed that the as-built specimens clustered with the thermally treated specimens despite an increase in mechanical 
strength post thermal treatment. The same was also found for another SLM study using 630 stainless steel [76]. In one study using SLM to fabricate 17-4 PH stainless steel specimens the as-built actually outperformed the thermally treated specimens [77].

\section{Defects and Fatigue}

As stated, there were results from previous studies that were similar to that of this study. That despite improvement of mechanical properties post thermal treatment the fatigue life of the post-processed AM parts were similar to that of as-built and underperformed significantly compared to wrought. It was also found in those studies, as it was in this, that the first order limiting factor of the AM specimen fatigue life are the intrinsic defects experienced during the AM fabrication process such as the ones observed in Figure 43. In Appendix 3, it is found that cause of failure for all AM specimens is sub-surface and surface defect oriented. Predominantly the cause of failure is porosity close to the machined surface.

As a reminder, these specimens were machined from bulk cylindrical shapes. So, any porosity observed from near the surface is not a result of process setting such as a contour setting; this is porosity within the bulk of the specimen. The density measurements taken from the coupons, fabricated to observe the porosity of the specimens, are provided in Table 9.

The particle porosity measurements are located there as well. A higher level of particle porosity was observed than within the specimens, suggesting a causation for the porosity becoming entrapped within the fabricated part. The observed pores within the specimens are relatively small in size and spherical, matching some of the observed defects within the fracture surface observation. However, there are some observed lack of fusion porosity and unsintered powder defects at fracture initiation locations that are not observed in the images taken during 
microscopy. It is unknown why there was no observation of this type of defect in the polished surface of the coupons as the same fabrication parameters were used.

In a recent study conducted that had similar results to this study, [61], it was also found that specimens fabricated vertically underperformed compared to the wrought materials. Their reference marker was a comparison to how the horizontal specimens performed. As there was no horizontal specimens fabricated or tested, there are no conclusions that can be drawn concerning the fabrication orientation. However, there was a result that suggested that the fabrication method coupled with the orientation of loading (i.e. loading parallel with the build direction) was the cause of failure in Figure 47.
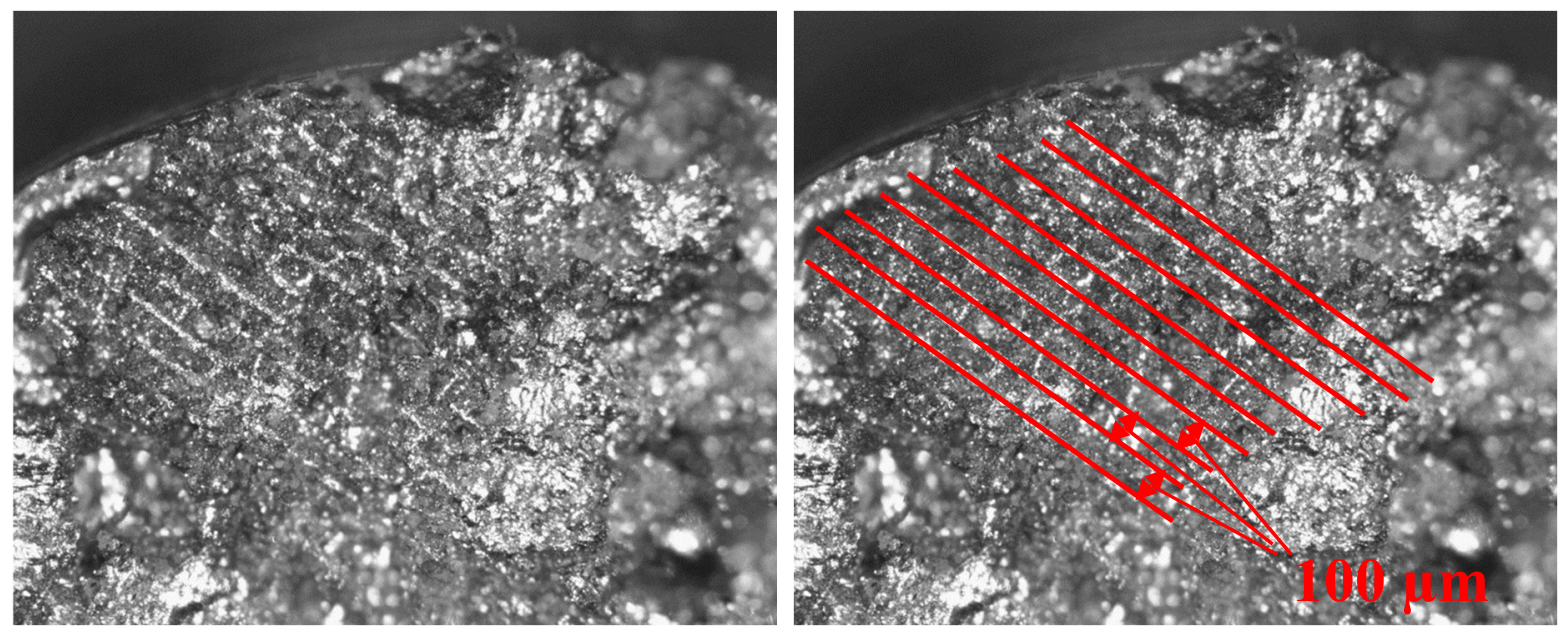

Figure 47. Observed scanning strategy near fracture location.

Figure 47 shows failure along the scanning strategy used in the fabrication of the specimen. This affirmed by the repeating observed lines in the specimen (highlighted in red) and the measured distance between the lines being the approximate manufacturer stated beam diameter of $100 \mu \mathrm{m}$. This was the only specimen where the failure was seemingly caused by the scanning strategy defect, or this was the only detectable of this type of failure. The specimen in question 
was a directly hardened AM specimen, implying that the thermal treatment did not rid the sample of this defect.

\section{Defects and Defect Area Analysis}

It was found that a majority of the failures were caused internal or sub surface defects such as voids, porosity, or unsintered powder. In Table 12, below, the defect area was measured via fracture surface examination and the images taken for that process, located in Appendix 3. The cause of the fracture was identified, and the defect area was measured using Image $\mathrm{J}$ analysis tools.

Table 12. Defect area measurements.

\begin{tabular}{|c|c|c|c|}
\hline $\begin{array}{c}\text { Material } \\
\text { State }\end{array}$ & Sample & $\begin{array}{l}\text { Stress } \\
\text { (MPa) }\end{array}$ & $\begin{array}{c}\text { Defect Area } \\
\left(\mathrm{mm}^{\wedge} 2\right)\end{array}$ \\
\hline \multirow{7}{*}{$\mathbf{A M} \mathbf{S}+\mathbf{H}$} & 2 & 600 & 0.416 \\
\hline & 4 & 750 & 0.009 \\
\hline & 9 & 950 & 0.007 \\
\hline & 11 & 950 & 0.002 \\
\hline & 12 & 1050 & 0.002 \\
\hline & 13 & 1050 & 0.011 \\
\hline & 14 & 1050 & 0.002 \\
\hline \multirow{8}{*}{ AM H900 } & 2 & 750 & 0.001 \\
\hline & 3 & 750 & 0.006 \\
\hline & 7 & 850 & 0.001 \\
\hline & 8 & 950 & 0.003 \\
\hline & 10 & 950 & 0.001 \\
\hline & 11 & 1050 & 0.003 \\
\hline & 12 & 1050 & 0.001 \\
\hline & 13 & 1050 & 0.002 \\
\hline \multirow{7}{*}{$\begin{array}{c}\text { AM } \\
\text { As-built }\end{array}$} & 1 & 750 & 0.012 \\
\hline & 2 & 750 & 0.002 \\
\hline & 3 & 750 & 0.003 \\
\hline & 5 & 850 & 0.002 \\
\hline & 6 & 850 & 0.002 \\
\hline & 7 & 850 & 0.001 \\
\hline & 8 & 950 & 0.001 \\
\hline
\end{tabular}


Besides sample 2 of the AM solutionized and H900 hardened (AM S+H), the other samples had a relatively small defect area. When examined there was no clear trend relating the size of the defect area to the total number of cycles for a given maximum alternating stress, at the surface level. To further examine possible relationships, an approximate stress intensity factor was calculated in an attempt to draw conclusions. The stress intensity factor is used in fracture mechanics to predict the intensity of the stress at a defect. This factor, often denoted $K$, is dependent on sample geometry size and location of defect, and the magnitude of the applied load. There are several methods used to calculate the stress intensity factor of a specimen, however due to the spherical nature of the porosity and many of the defects observed, the widely used "penny" approximation method was used. The method simplifies much of the calculation by approximating the stress intensity factor located at the top of a penny shaped crack in an infinite domain which is under a uniaxial applied load [78]. A representation of this method is observed below in Figure 48.

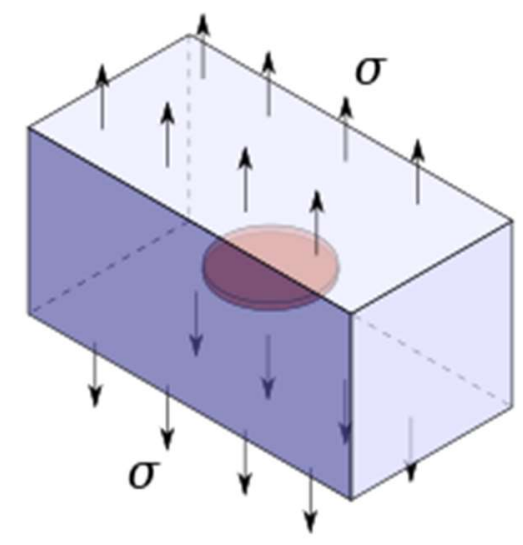

Figure 48. Penny-shaped crack in an infinite domain stress intensity approximation.

The equation used for calculation of the stress intensity factor, $K$, is

$$
K=\frac{2}{\pi} \sigma \sqrt{\pi a}
$$


where $a$ is the crack radius and $\sigma$ is the applied uniaxial stress. For the purposes of this study the area of the "penny" surface for a given defect is assumed to be the measured area of defect in Table 12 and the crack radius will be calculated. The applied uniaxial stress in the above formula will be the maximum alternating stress in the test for each specimens. The approximate stress intensity factor was calculated and is provided in below.

\begin{tabular}{cccccc}
\hline $\begin{array}{c}\text { Material } \\
\text { State }\end{array}$ & Sample & $\begin{array}{c}\text { Stress } \\
(\mathbf{M P a})\end{array}$ & $\begin{array}{c}\text { Defect } \\
\text { Area } \\
\left(\mathbf{m m} \mathbf{2}^{\wedge}\right)\end{array}$ & $\boldsymbol{a} \mathbf{( m m )}$ & $\begin{array}{c}\mathbf{K} \\
(\mathbf{M P a} \sqrt{ } \mathbf{m})\end{array}$ \\
\hline & 2 & 600 & 0.416 & 0.103 & 6.86 \\
& 4 & 750 & 0.009 & 0.015 & 3.29 \\
AM S+H & 9 & 950 & 0.007 & 0.013 & 3.91 \\
& 11 & 950 & 0.002 & 0.007 & 2.86 \\
& 12 & 1050 & 0.002 & 0.007 & 3.16 \\
& 13 & 1050 & 0.011 & 0.017 & 4.84 \\
& 14 & 1050 & 0.002 & 0.007 & 3.16 \\
\hline & 2 & 750 & 0.001 & 0.005 & 1.90 \\
AM H900 & 3 & 750 & 0.006 & 0.012 & 2.97 \\
& 7 & 850 & 0.001 & 0.005 & 2.15 \\
& 10 & 950 & 0.003 & 0.009 & 3.16 \\
& 11 & 1050 & 0.001 & 0.005 & 2.40 \\
& 12 & 1050 & 0.001 & 0.009 & 3.50 \\
& 13 & 1050 & 0.002 & 0.005 & 2.66 \\
AM & 1 & 750 & 0.012 & 0.007 & 3.16 \\
\hline As-built & 2 & 750 & 0.002 & 0.007 & 3.53 \\
& 3 & 750 & 0.003 & 0.009 & 2.26 \\
& 5 & 850 & 0.002 & 0.007 & 2.56 \\
& 6 & 850 & 0.002 & 0.007 & 2.56 \\
& 7 & 850 & 0.001 & 0.005 & 2.15 \\
& 8 & 950 & 0.001 & 0.005 & 2.40 \\
\hline
\end{tabular}

The maximum stress intensity factors were calculated in the solutionized and hardened AM specimens. There are only two primary data points, in that group, that could be considered significant outliers among the calculated $K$ values: specimens 2 and 13. Specimen 2, is an 
outlier due to the location and cause of break. Observed in Appendix 3, specimen 2 broke far from the middle of the curved region in the gauge length implying that the true maximum alternating stress would be lower than the calculated testing stress as the area at location of break. This indicates a lower true alternating stress and a lower $K$ value in turn. Also, in both specimens 2 and 13 major defects were observed, among the largest in fact of all specimens. The remainder of the calculated $K$ values were calculated to be a relatively consistent value among all test specimens. To understand the effect of the stress intensity factor on the lifetime of the specimens, the calculated stress intensity factor was plotted along with cycles to failure, provided in Figure 49.

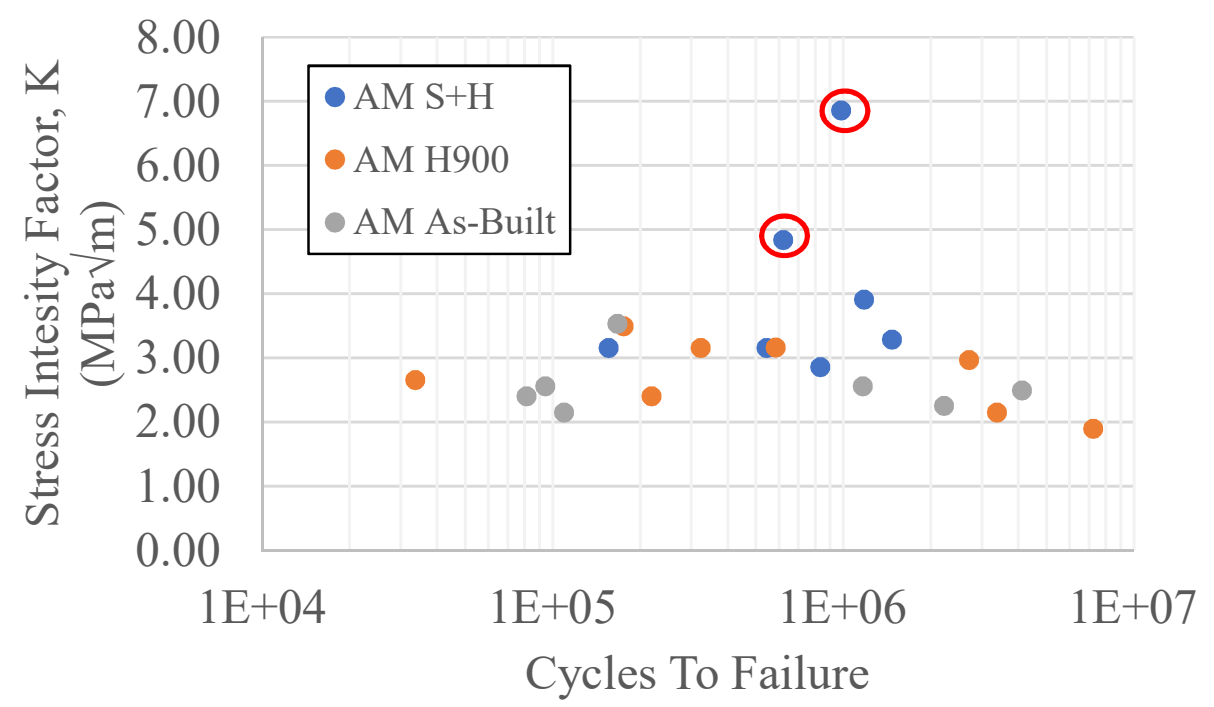

Figure 49. Stress intensity factor relationship to cycles to failure.

Despite the two major outliers mentioned previously (circled in red) the trend is relatively constant among the specimens. This implies that while these internal defects are a major source of failure among the specimens, there is no significant reduction or change in the lifetime for a given stress concentration value. 


\section{CONCLUSION}

In the present study, 17-4 PH stainless steel specimens were fabricated vertically using SLM for the purposes of understanding varying thermal treatments on fatigue behavior. The material was fully characterized in the powder state and fabricated state. Prior to fatigue testing, other mechanical property testing, tensile and hardness, was carried out to understand how the thermal treatment effects these characteristics. Certain material properties were examined as well such as the microstructure of the different specimens prior to and post thermal treatment. The uniaxial fatigue testing was conducted for the specimens and analyzed to determine any possible trends in the data. The following conclusions were determined:

- The as-built microstructure of the AM specimens was highly martensitic indicating the ability for direct hardening to improve mechanical properties.

- The as-built AM specimens were able to be both solutionized and directly hardened for a vast improvement in tensile (yield and ultimate) strength and hardness values.

- Despite a vast improvement in the yield and ultimate strengths of the thermally treated specimens there was little difference in the fatigue life and endurance limits for any given alternating stress between the as-built, direct harden, and solutionized and hardened samples. The wrought specimens vastly out-performed the AM specimens.

- It was discovered that AM fatigue specimen failure was highly defect driven with the major causes being internal porosity, unsintered powder, scanning strategy, and surface 
- defects. This conclusion was drawn, despite fabrication parameters optimized for density.

- The calculated stress intensity factor, $K$, showed little effect, exemplifying a constant trend, on the cycles to failure for the test specimens.

While the testing conditions were unique, with examining multiple thermal treatments and a 17-4 PH stainless steel powder that comes as-built near full martensitic, the results were similar to past studies conducted utilizing SLM and investigating fatigue. Future work may involve seeking to reduce the defect driven conclusion through the process of hot isostatic pressing or investigating other surface treatments such as shot or laser peening and electro-polishing. 


\section{REFERENCES}

1. $\quad$ Stephens, R.I., Metal Fatigue in Engineering. 2001: Wiley.

2. Roylance, D., Fatigue. Department of Material Science and Engineering at Cambridge Massachusetts Institue of Technology, 1 May 2001.

3. Bhat, S. and R. Patibandla, Metal Fatigue and Basic Theoretical Models: A Review, Alloy Steel - Properties and Use. 22 December, 2011.

4. News, B. 1954: 'Metal fatigue' caused Comet Crashes. 2005; Available from: http://news.bbc.co.uk/onthisday/hi/dates/stories/october/19/newsid_3112000/3112466 .stm.

5. Materials, A.S.f.T.a., ASTM F2792-12a, in Standard Terminology for Additive Manufacturing Technologies, vol. 10.04.

6. Zhai, Y., D.A. Lados, and J.L. LaGoy, Additive Manufacturing: Making Imagination the Major Limitation. JOM, 2014. 66(5): p. 808-816.

7. Frazier, W.E., Metal Additive Manufacturing: A Review. Journal of Materials Engineering and Performance, 2014. 23(6): p. 1917-1928.

8. $\quad$ Associates, W., Wohlers Report 2018. 2018.

9. Duda, T. and L.V. Raghavan, 3D Metal Printing Technology. IFAC-PapersOnLine, 2016. 49(29): p. 103-110.

10. Petrick, I.J. and T.W. Simpson, 3D Printing Disrupts Manufacturing: How Economies of One Create New Rules of Competition. Research-Technology Management, 2013. 56(6): p. 12-16.

11. Dodziuk, H., Applications of $3 D$ printing in healthcare. Kardiochirurgia i torakochirurgia polska $=$ Polish journal of cardio-thoracic surgery, 2016. 13(3): p. 283293.

12. Nickels, L., AM and aerospace: an ideal combination. Metal Powder Report, 2015. 70(6): p. 300-303.

13. Aston, R. $3 D$ Printing done right. Available from: https://www.boeing.com/features/innovation-quarterly/nov2017/feature-thoughtleadership-3d-printing.page.

14. Holmes, M. Boeing Ventures Invests in New 3-D Alloy Printing Company. 8 August 2018; Available from: www.satellitetoday.com/innovation/2018/08/08/boeingventures-invests-in-new-3-d-alloy-printing-company/.

15. Council, N.R., 3D Printing in Space. 2014, Washington, DC: The National Academies Press. 106.

16. Slotwinski, J.A., et al., Characterization of Metal Powders Used for Additive Manufacturing. Journal of research of the National Institute of Standards and Technology, 2014. 119: p. 460-493.

17. Vock, S., et al., Powders for powder bed fusion: a review. Progress in Additive Manufacturing, 2019. 
18. Averyanova, M., P. Bertrand, and B. Verquin, Studying the influence of initial powder characteristics on the properties of final parts manufactured by the selective laser melting technology. Virtual and Physical Prototyping, 2011. 6(4): p. 215-223.

19. Galicki, D., et al., Localized Changes of Stainless Steel Powder Characteristics During Selective Laser Melting Additive Manufacturing. Metallurgical and Materials Transactions A, 2019. 50(3): p. 1582-1605.

20. Zielinski, J., et al., Influence of Powder Bed Characteristics on Material Quality in Additive Manufacturing. BHM Berg- und Hüttenmännische Monatshefte, 2017. 162(5): p. 192-198.

21. Tan, J.H., W.L.E. Wong, and K.W. Dalgarno, An overview of powder granulometry on feedstock and part performance in the selective laser melting process. Additive Manufacturing, 2017. 18: p. 228-255.

22. Sutton, A.T., et al., Powder characterisation techniques and effects of powder characteristics on part properties in powder-bed fusion processes. Virtual and Physical Prototyping, 2017. 12(1): p. 3-29.

23. Geldart, D., et al., Characterization of Powder Flowability Using Measurement of Angle Of Repose. China Particuology, 2006. 4: p. 104-107.

24. Baitimerov, R., et al., Influence of Powder Characteristics on Processability of AlSil2 Alloy Fabricated by Selective Laser Melting. Materials (Basel, Switzerland), 2018. 11(5): p. 742.

25. Muñiz-Lerma, J.A., et al., A Comprehensive Approach to Powder Feedstock Characterization for Powder Bed Fusion Additive Manufacturing: A Case Study on AlSi7Mg. Materials (Basel, Switzerland), 2018. 11(12): p. 2386.

26. Murphy, T.F., METALLOGRAPHIC TESTING OF POWDERS INTENDED FOR USE IN ADDITIVE MANUFACTURING. International Journal of Powder Metallurgy, 2016. 52(1).

27. Snow, Z., R. Martukanitz, and S. Joshi, On the development of powder spreadability metrics and feedstock requirements for powder bed fusion additive manufacturing. Additive Manufacturing, 2019. 28: p. 78-86.

28. Strondl, A., et al., Characterization and Control of Powder Properties for Additive Manufacturing. JOM, 2015. 67(3): p. 549-554.

29. Belorus, A.O., K. Bespalova, and Y.M. Spivak. Morphology and internal structure of porous silicon powders in dependence on the conditions of post-processing. in 2016 IEEE NW Russia Young Researchers in Electrical and Electronic Engineering Conference (EIConRusNW). 2016.

30. Horio, T., M. Yasuda, and S. Matsusaka, Effect of particle shape on powder flowability of microcrystalline cellulose as determined using the vibration shear tube method. International Journal of Pharmaceutics, 2014. 473(1): p. 572-578.

31. Spierings, A.B., Comparison of density measurement techniques for additive manufactured metallic parts. Rapid Prototyping Journal, 2011. 17(5): p. 380-386.

32. Lowell, S. and J.E. Shields, Powder surface area and porosity. Vol. 2. 2013: Springer Science \& Business Media.

33. Arreguin, J., Powder Characterization Methods. 2019, GE Additive: Additive Manufacturing Users Group Conference.

34. Azom. Stainless Steel - Grade 17-4 (UNS S17400). 2018; Available from: https://www.azom.com/article.aspx?ArticleID $=6778$. 
35. Murr, L.E., et al., Microstructures and Properties of 17-4 PH Stainless Steel Fabricated by Selective Laser Melting. Journal of Materials Research and Technology, 2012. 1(3): p. 167-177.

36. Mahmoudi, M., et al., Mechanical properties and microstructural characterization of selective laser melted 17-4 PH stainless steel. Rapid Prototyping Journal, 2017. 23(2): p. 280-294.

37. Cheruvathur, S., E.A. Lass, and C.E. Campbell, Additive Manufacturing of 17-4 PH Stainless Steel: Post-processing Heat Treatment to Achieve Uniform Reproducible Microstructure. JOM, 2016. 68(3): p. 930-942.

38. Sun, Y., R.J. Hebert, and M. Aindow, Effect of heat treatments on microstructural evolution of additively manufactured and wrought 17-4PH stainless steel. Materials \& Design, 2018. 156: p. 429-440.

39. Steel, A. 17-4 PH Stainles Steel Product Bulletin. 2018; Available from: https://www.aksteel.com/sites/default/files/2018-01/174ph201706.pdf.

40. Yadollahi, A., et al., Mechanical and Microstructural Properties of Selective Laser Melted 17-4 PH Stainless Steel. 2015.

41. Vunnam, S., et al., Effect of Composition on as-built microstrucutre of SLM-processed 17-4 PH stainless steel. Additive Manufacturing Journal, Submitted 2019.

42. Dobson, S., Powder Variation and Mechanical Properties for SLM 17-4ph Stainless Steel. Solid Freeform Fabrication Symposium, 2019.

43. Shunmugavel, M., A. Polishetty, and G. Littlefair, Microstructure and Mechanical Properties of Wrought and Additive Manufactured Ti-6Al-4V Cylindrical Bars. Procedia Technology, 2015. 20: p. 231-236.

44. Wu, J.H. and C.K. Lin, Tensile and fatigue properties of 17-4 PH stainless steel at high temperatures. Metallurgical and Materials Transactions a-Physical Metallurgy and Materials Science, 2002. 33(6): p. 1715-1724.

45. Rack, H. and D. Kalish, The strength, fracture toughness, and low cycle fatigue behavior of 17-4 PH stainless steel. Metallurgical and Materials Transactions B, 1974. 5(7): p. 1595-1605.

46. Kamaya, M. and M. Kawakubo, Mean stress effect on fatigue strength of stainless steel. International Journal of Fatigue, 2015. 74: p. 20-29.

47. Vincent, L., J.-C. Le Roux, and S. Taheri, On the high cycle fatigue behavior of a type 304L stainless steel at room temperature. International Journal of fatigue, 2012. 38: p. 84-91.

48. Schönbauer, B.M., K. Yanase, and M. Endo, The influence of various types of small defects on the fatigue limit of precipitation-hardened 17-4PH stainless steel. Theoretical and Applied Fracture Mechanics, 2017. 87: p. 35-49.

49. Romano, S., et al., Fatigue properties of AlSilOMg obtained by additive manufacturing: Defect-based modelling and prediction of fatigue strength. Engineering Fracture Mechanics, 2018. 187: p. 165-189.

50. Li, P., et al., Critical assessment of the fatigue performance of additively manufactured Ti-6Al-4V and perspective for future research. International Journal of Fatigue, 2016. 85: p. 130-143.

51. Rafi, H.K., T.L. Starr, and B.E. Stucker, A comparison of the tensile, fatigue, and fracture behavior of Ti-6Al-4V and 15-5 PH stainless steel parts made by selective 
laser melting. The International Journal of Advanced Manufacturing Technology, 2013. 69(5-8): p. 1299-1309.

52. Mower, T.M. and M.J. Long, Mechanical behavior of additive manufactured, powderbed laser-fused materials. Materials Science and Engineering: A, 2016. 651: p. 198213.

53. Gordon, J., et al., Enhancement in fatigue performance of metastable austenitic stainless steel through directed energy deposition additive manufacturing. Materials \& Design, 2019. 168: p. 107630.

54. Gordon, J.V., et al., Fatigue crack growth anisotropy, texture and residual stress in austenitic steel made by wire and arc additive manufacturing. Materials Science and Engineering: A, 2018. 724: p. 431-438.

55. Yadollahi, A. and N. Shamsaei, Additive manufacturing of fatigue resistant materials: Challenges and opportunities. International Journal of Fatigue, 2017. 98: p. 14-31.

56. Yadollahi, A., et al., Data demonstrating the effects of build orientation and heat treatment on fatigue behavior of selective laser melted 17-4 PH stainless steel. Data in Brief, 2016. 7: p. 89-92.

57. Shrestha, R., et al. Effect of Build Orientation on the Fatigue Behavior of Stainless Steel 316L Manufactured Via A Laser-Powder Bed Fusion Process. in 27th Annual Solid Frefform Fabrication Symposium Proceedings. 2016.

58. Meneghetti, G., D. Rigon, and C. Gennari, An analysis of defects influence on axial fatigue strength of maraging steel specimens produced by additive manufacturing. International Journal of Fatigue, 2019. 118: p. 54-64.

59. Spierings, A.B., T.L. Starr, and K. Wegener, Fatigue performance of additive manufactured metallic parts. Rapid Prototyping Journal. 19(2): p. 88-94.

60. Chastand, V., et al., Fatigue characterization of Titanium Ti-6Al-4V samples produced by Additive Manufacturing. Procedia Structural Integrity, 2016. 2: p. 3168-3176.

61. Yadollahi, A., et al., Effects of building orientation and heat treatment on fatigue behavior of selective laser melted 17-4 PH stainless steel. International Journal of Fatigue, 2017. 94: p. 218-235.

62. Molaei, R. and A. Fatemi, Fatigue Design with Additive Manufactured Metals: Issues to Consider and Perspective for Future Research. Procedia Engineering, 2018. 213: p. $5-16$.

63. Shamsaei, N. and J. Simsiriwong, Fatigue behaviour of additively-manufactured metallic parts. Procedia Structural Integrity, 2017. 7: p. 3-10.

64. Domfang Ngnekou, J.N., et al., Fatigue properties of AlSilOMg produced by Additive Layer Manufacturing. International Journal of Fatigue, 2019. 119: p. 160-172.

65. Meneghetti, G., et al., Influence of build orientation on static and axial fatigue properties of maraging steel specimens produced by additive manufacturing. Procedia Structural Integrity, 2017. 7: p. 149-157.

66. Yadollahi, A., et al., Fatigue Behavior Of Selective Laser Melted 17-4 Ph Stainless Steel, in Solid Freeform Fabrication Symposium. 2015: Austin TX. p. 721-731.

67. Kasperovich, G. and J. Hausmann, Improvement of fatigue resistance and ductility of TiAl6V4 processed by selective laser melting. Journal of Materials Processing Technology, 2015. 220: p. 202-214. 
68. Irrinki, H., et al., Effects of particle characteristics on the microstructure and mechanical properties of 17-4 PH stainless steel fabricated by laser-powder bed fusion. Powder Technology, 2018. 331: p. 192-203.

69. Wang, Y., J. Bergstrom, and C. Burman, Four-point bending fatigue behaviour of an iron-based laser sintered material. International Journal of Fatigue, 2006. 28(12): p. 1705-1715.

70. Masuo, H., et al., Influence of defects, surface roughness and HIP on the fatigue strength of Ti-6Al-4V manufactured by additive manufacturing. International Journal of Fatigue, 2018. 117: p. 163-179.

71. Vunnam, S., et al., Effect Of Powder Chemical Composition On Microstructures And Mechanical Properties Of L-Pbf Processed 17-4 Ph Stainless Steel In The As-Built And Hardened-H900 Conditions. Solid Freeform Fabrication 2019 Proceedings, 2019.

72. Conesa, C., et al., Characterization of Flow Properties of Powder Coatings Used in the Automotive Industry. KONA Powder and Particle Journal, 2004. 22: p. 94-106.

73. MATLAB. 2019; Version R2019a:[Available from: https://www.mathworks.com/.

74. Rasband, W.S. ImageJ. 1997-2018; Available from: https://imagej.nih.gov/ij/.

75. Beardmore, R. Metal Fatigue and Endurance. 2010; Available from: https://web.archive.org/web/20120415084023/http://www.roymech.co.uk/Useful_Tab les/Fatigue/Fatigue.html.

76. Akita, M., et al., Defect-dominated fatigue behavior in type 630 stainless steel fabricated by selective laser melting. Materials Science \& Engineering A, 2016. 666: p. 19-26.

77. Yadollahi, A., et al. Fatigue behavior of selective laser melted 17-4 PH stainless steel. in Proceedings of 26th International Solid Freeform Fabrication Symposium, Austin, $T X .2015$.

78. Anderson, T.L., Fracture mechanics: fundamentals and applications. 2017: CRC press. 


\section{APPENDIX}

\section{Figures}

Figure 1. Image of the Comet, taken before failure [4] .............................................................. 7

Figure 2. PBF machines widely used today. EOS M290 (L) \& Concept Laser M2 (R).................... 8

Figure 3. Cost vs. complexity between AM and Conventional fabrication methods [8].................... 10

Figure 4. (Top) traditional and (bottom) additively manufactured Airbus A350 XWB bracket.......... 11

Figure 5. (Left) traditional and (right) additively manufactured Boeing bracket............................. 12

Figure 6. Modes of crack extension: Mode I (a), Mode II (b), and Mode III (c). ............................. 20

Figure 7. Gas atomization of metallic material into powder. ....................................................... 30

Figure 8 . Tap density apparatus fabricated according to ASTM standard. ...................................... 31

Figure 9. Hall flowmeter and angle of repose testing apparatus. ..................................................... 32

Figure 10. MATLAB [72] code analyzes each video frame and calculates angle of the surface and

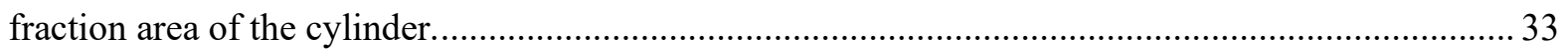

Figure 11. Microtrac S3500 particle size distribution testing device. ............................................. 34

Figure 12. Polished sections of atomized powder show gas entrapped within some particles............. 35

Figure 13. MATLAB[72] script measures internal porosity to receive density measurement............ 35

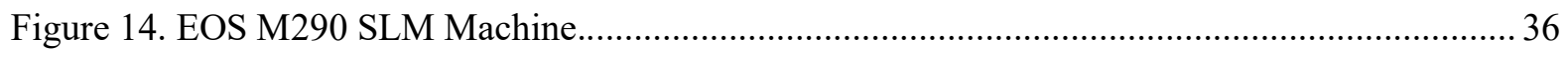

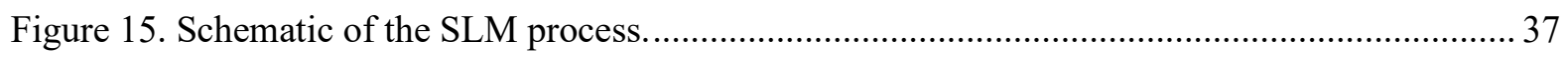

Figure 16. Completed build of fatigue bar samples on M290 ...................................................... 37

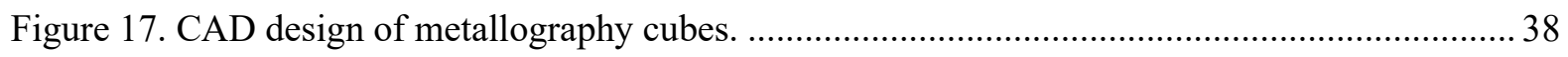

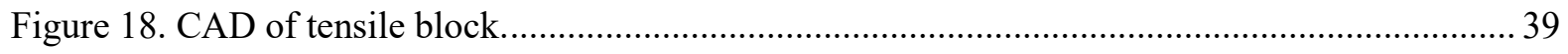

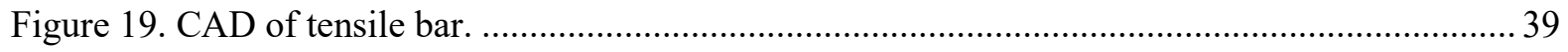




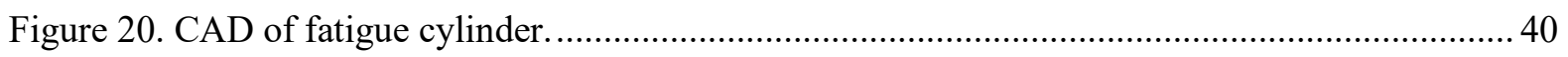

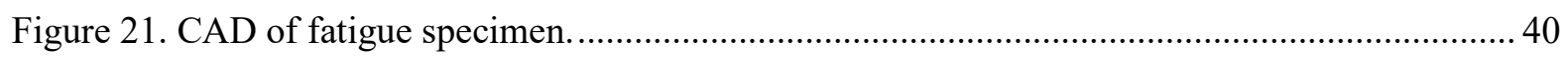

Figure 22. Paragon furnace used in study for thermal treatments. .............................................. 41

Figure 23. Specimen in lathe preparing for turning operation......................................................... 42

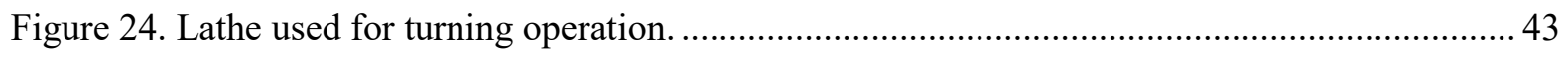

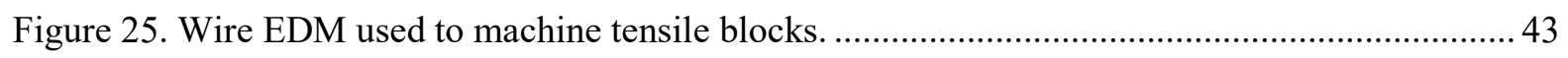

Figure 26. Allied High-Tech Metprep 3 Automatic Polisher used to prepare samples....................... 44

Figure 27. SJ210 profilometer used for surface roughness measurements...................................... 47

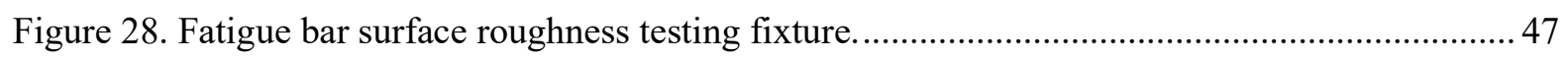

Figure 29. Instron 5569a model tensile and compression tester used in study............................... 48

Figure 30. Vickers micro-hardness testing device used in this study......................................... 49

Figure 31. Instron E10000 fatigue testing device used in this study.......................................... 50

Figure 32. Olympus BX53 optical light microscope used in this study........................................ 51

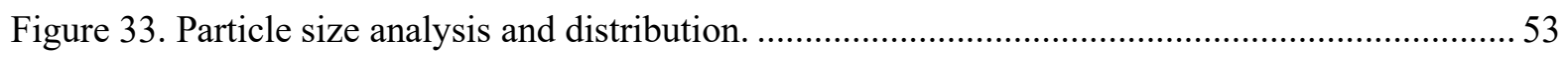

Figure 34. Polished surface of AM powder with observable porosity ............................................ 55

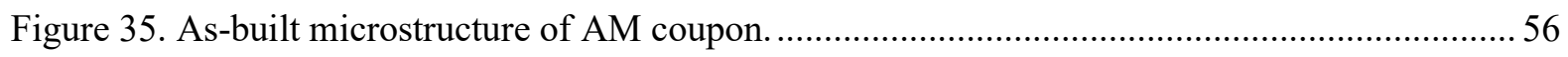

Figure 36. Direct H900 hardening microstructure of AM coupon. ............................................... 57

Figure 37. Solutionized and H900 hardened microstructure of AM coupon.................................... 57

Figure 38. Direct H900 hardened microstructure of wrought 17-4 PH material................................ 58

Figure 39. Surface roughness profile (a) As-Built, (b) H900, (c) S+H900, and (d) Wrought H900.... 60

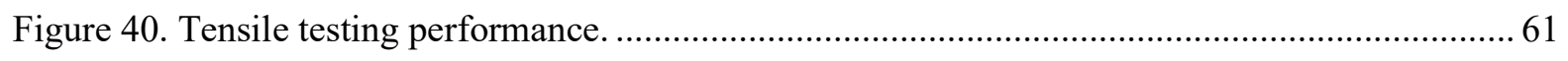

Figure 41. Relationship of Micro-Vickers Hardness to Yield and Ultimate Strength........................ 62

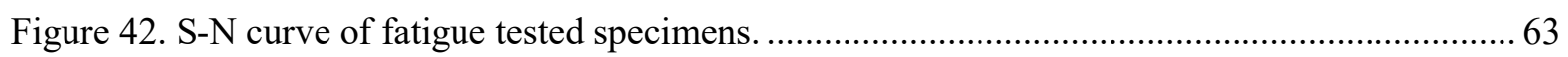

Figure 43. Fracture initiation locations (a) internal porosity, (b) surface defect, (c) sub-surface porosity,

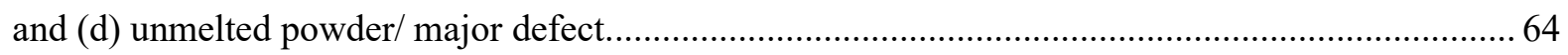


Figure 44. Endurance limit of the specimens tested.

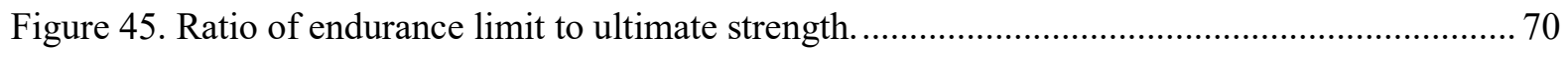

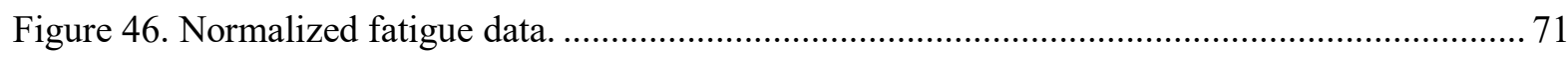

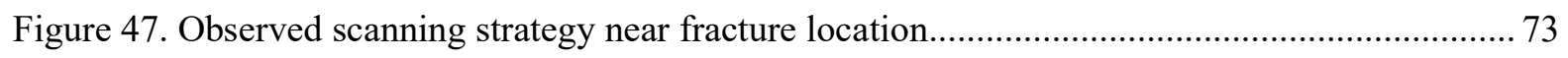

Figure 48. Penny-shaped crack in an infinite domain stress intensity approximation......................... 75

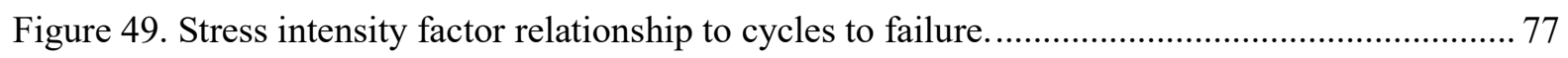

\section{Tables}

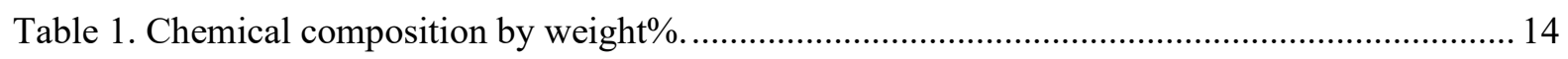

Table 2. Properties Acceptable for Material Specification............................................................. 16

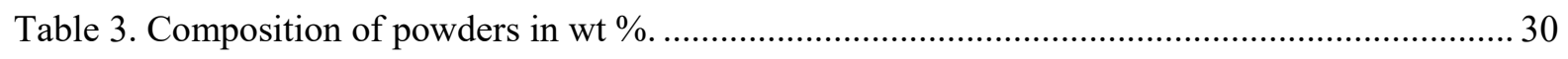

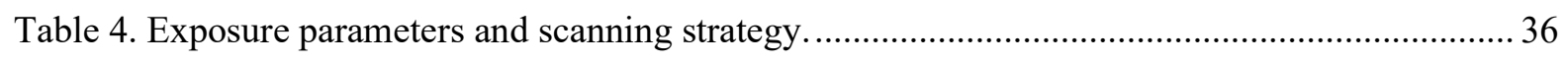

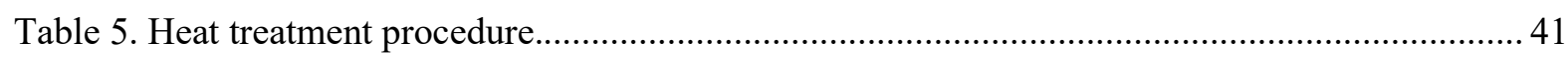

Table 6. Metallurgical sample preparation guide from Allied High-Tech Polishing Procedures......... 45

Table 7. Flowability results for the 17-4 PH stainless steel powder used for this study.................... 52

Table 8. Microtrac and sieve analysis data for particle size analysis. ............................................ 53

Table 9. Porosity measurements for as-built coupons and powder particles..................................... 54

Table 10. Surface roughness measurement property summary ..................................................... 59

Table 11. Summary of Mechanical Properties of Tensile Tests and Micro-Vickers Hardness............ 62

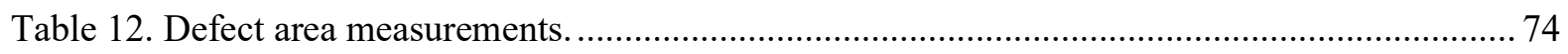


Sample Type: Additive Manufacturing

Sample Treatment: As-Built

Sample Number: 1

Max Testing Stress: $750 \mathrm{MPa}$

Failure (yes/no): Yes

Cycles to Failure: 166846

Failure Cause: Surface Defect

Area of Defect: $0.012 \mathrm{~mm}^{2}$
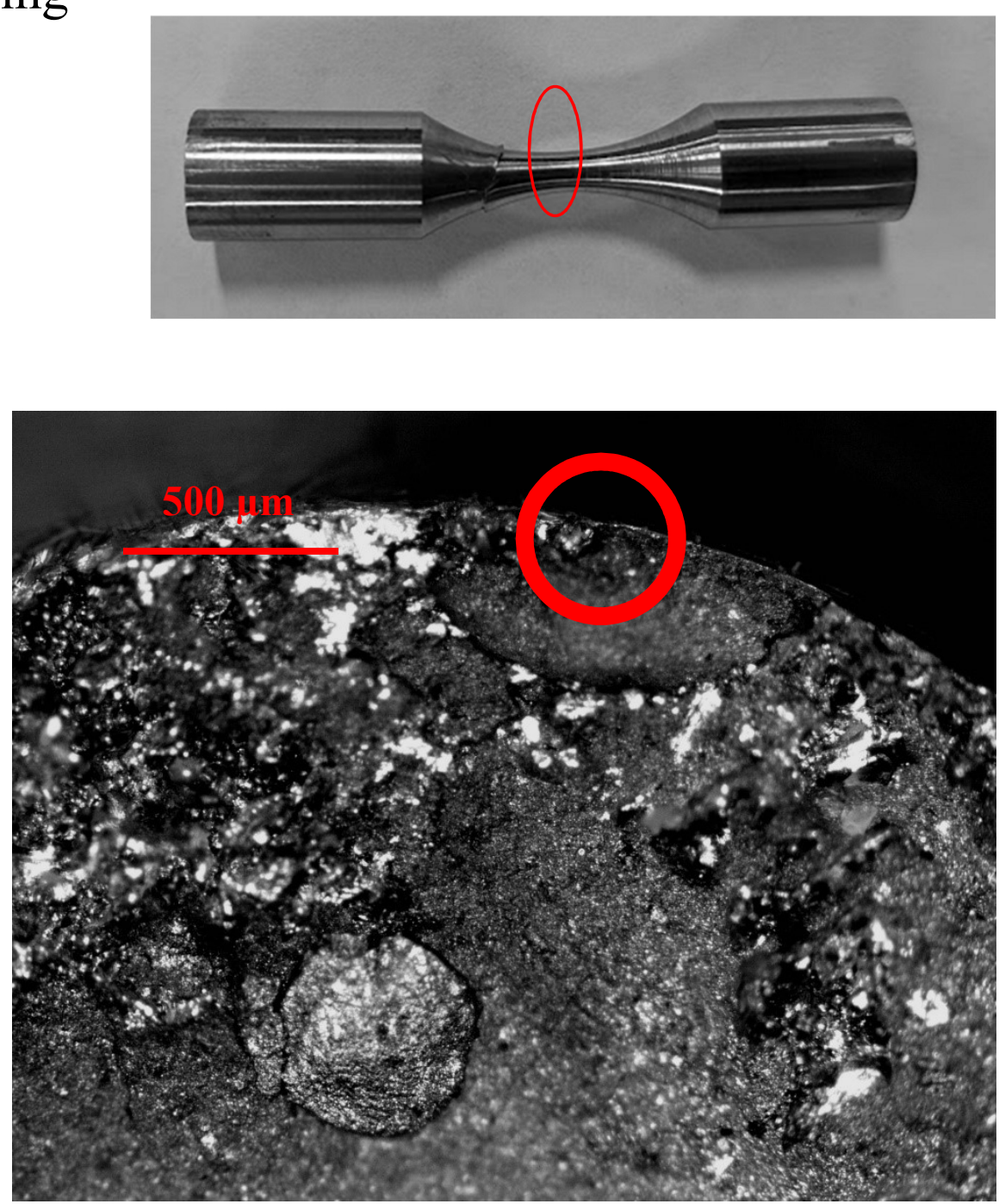
Sample Type: Additive Manufacturing Sample Treatment: As-Built

Sample Number: 2

Max Testing Stress: $750 \mathrm{MPa}$

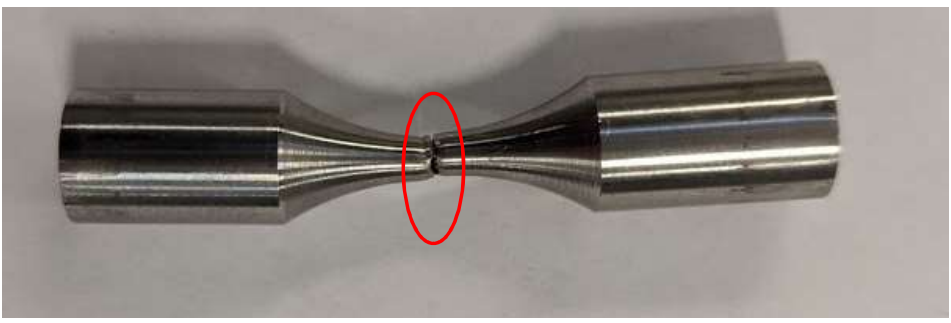

Failure (yes/no): Yes

Cycles to Failure: 22207

Failure Cause: Porosity

Area of Defect: $0.002 \mathrm{mn}$

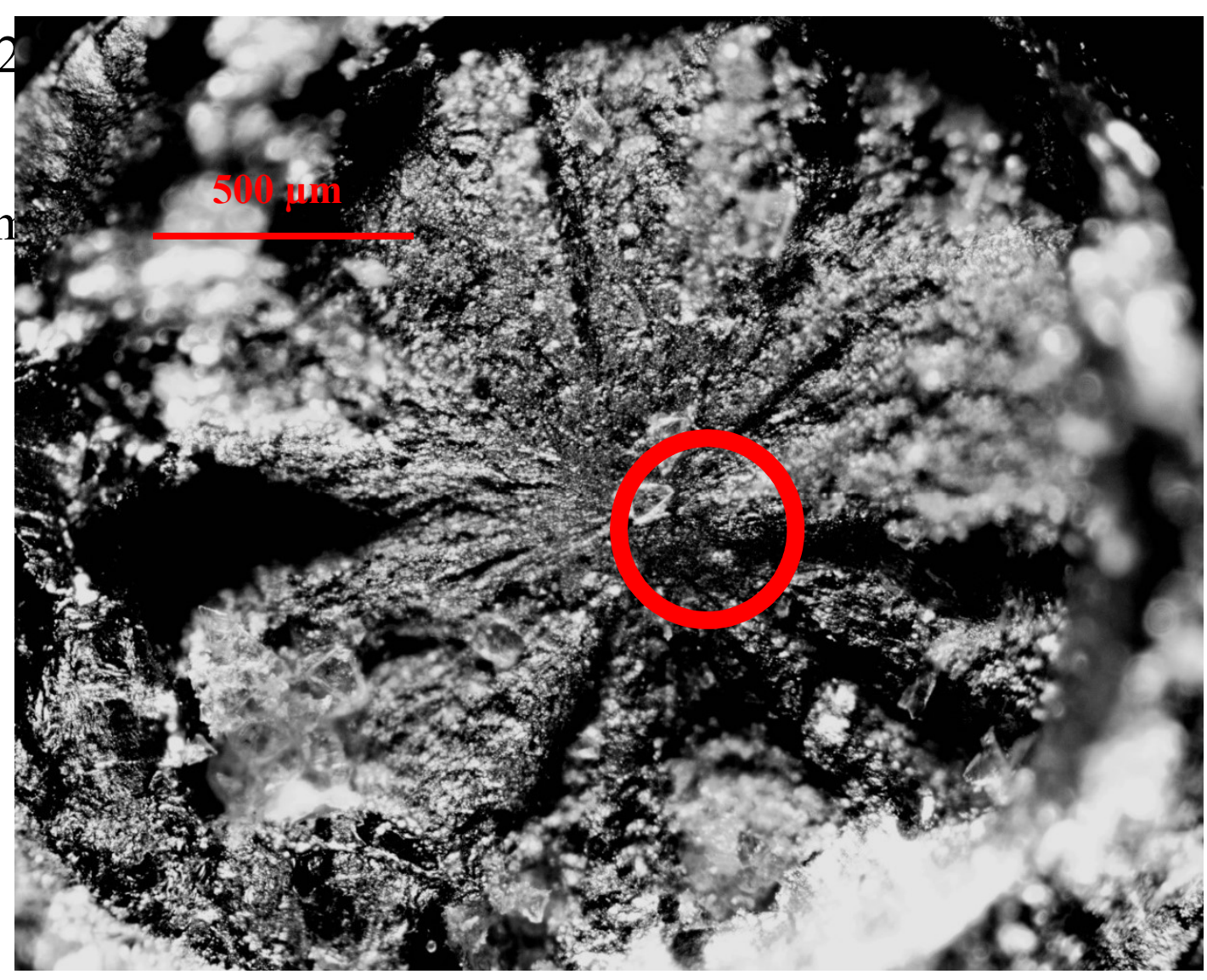


Sample Type: Additive Manufacturing

Sample Treatment: As-Built

Sample Number: 3

Max Testing Stress: $750 \mathrm{MPa}$

Failure (yes/no): Yes

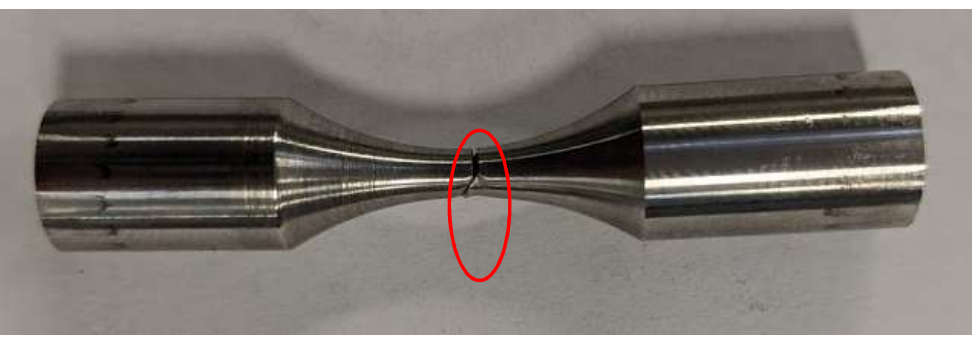

Cycles to Failure: 4117159

Failure Cause: Surface Porosity

Area of Defect: $0.003 \mathrm{~mm}^{2}$

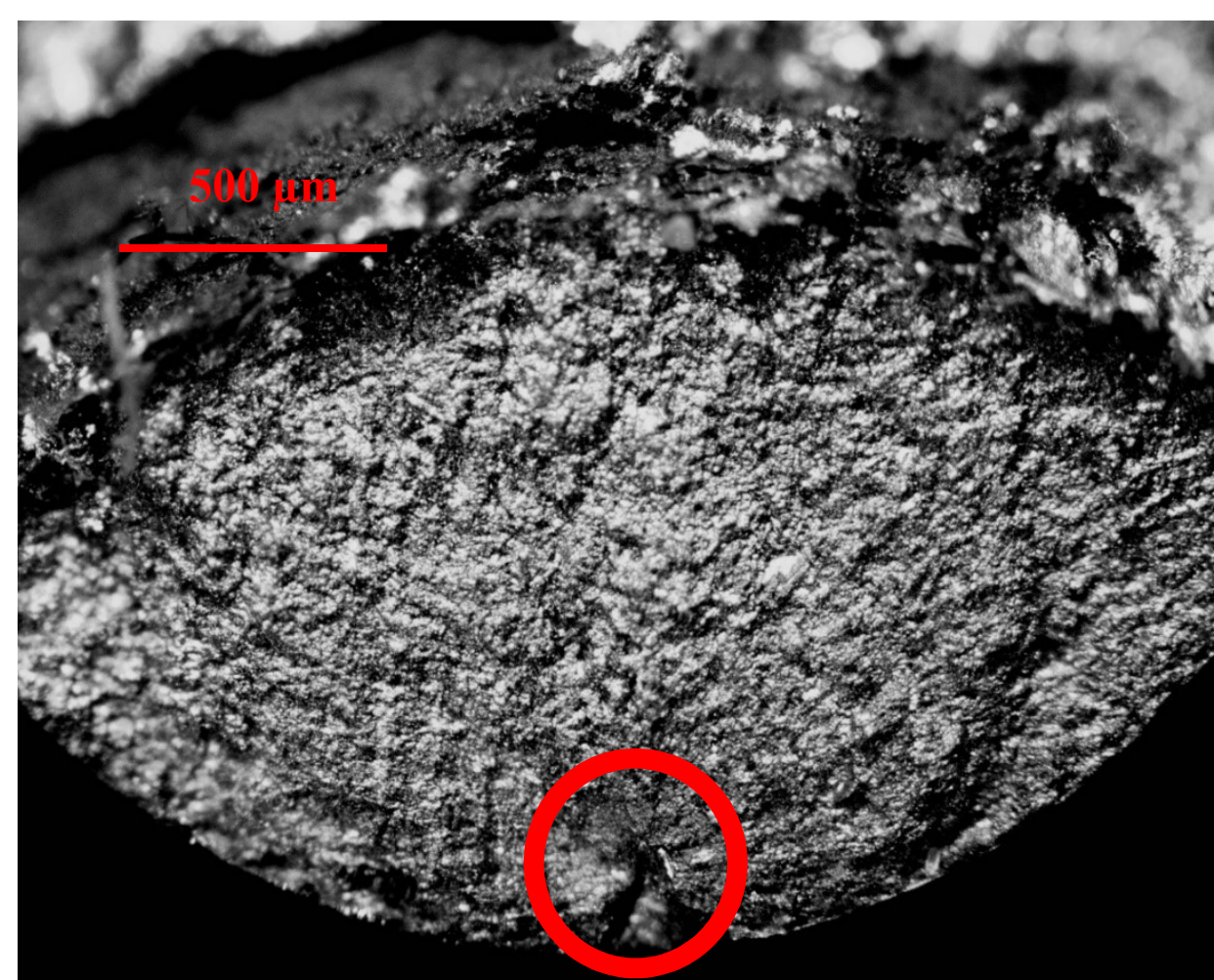


Sample Type: Additive Manufacturing Sample Treatment: As-Built

Sample Number: 4

Max Testing Stress: $1200 \mathrm{MPa}$

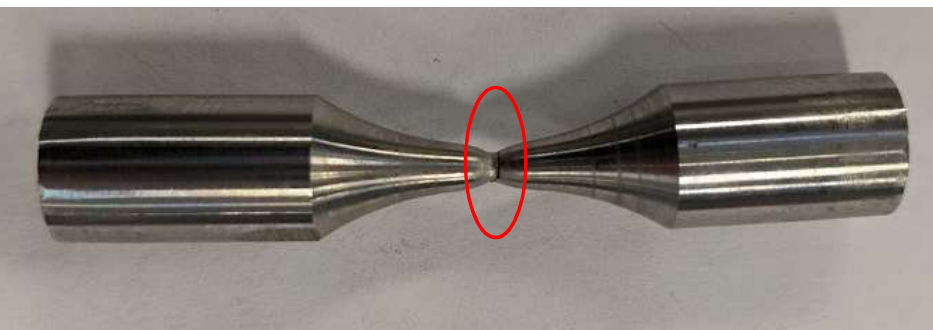

Failure (yes/no): Yes

Cycles to Failure: 41

Failure Cause: ?

Area of Defect: ?

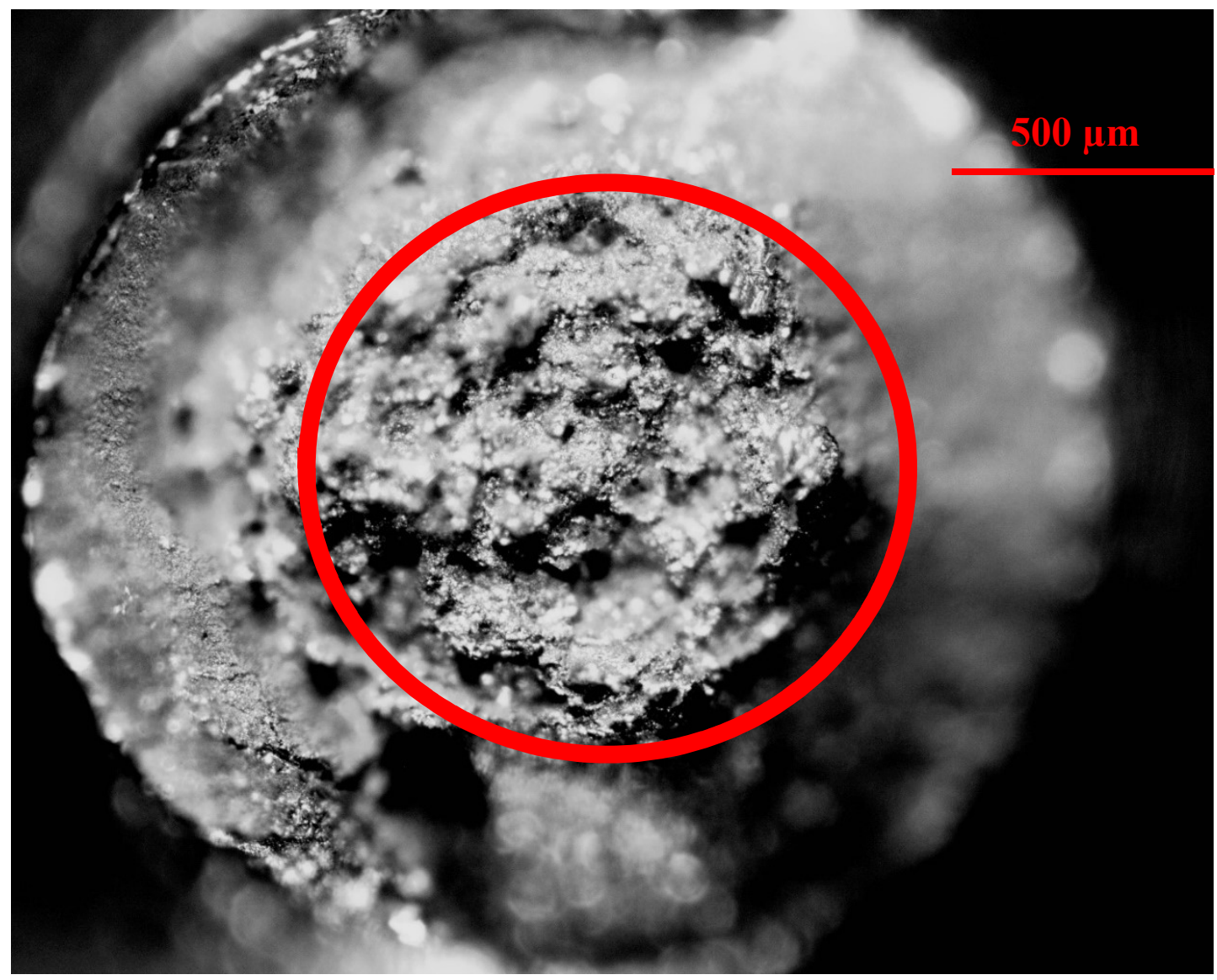


Sample Type: Additive Manufacturing

Sample Treatment: As-Built

Sample Number: 5

Max Testing Stress: $850 \mathrm{MPa}$

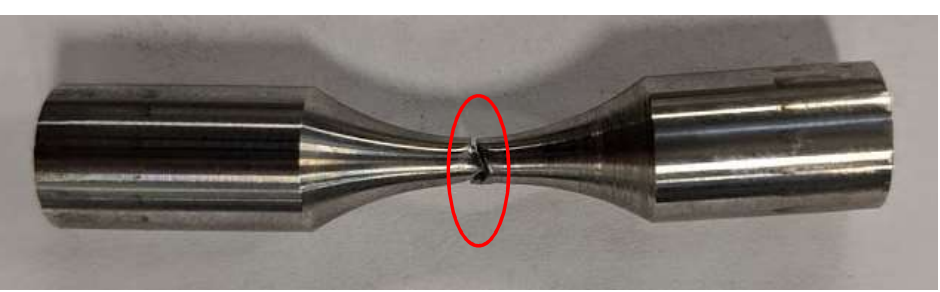

Failure (yes/no): Yes

Cycles to Failure: 116623

Failure Cause: Porosity

Area of Defect: $0.002 \mathrm{mn}$

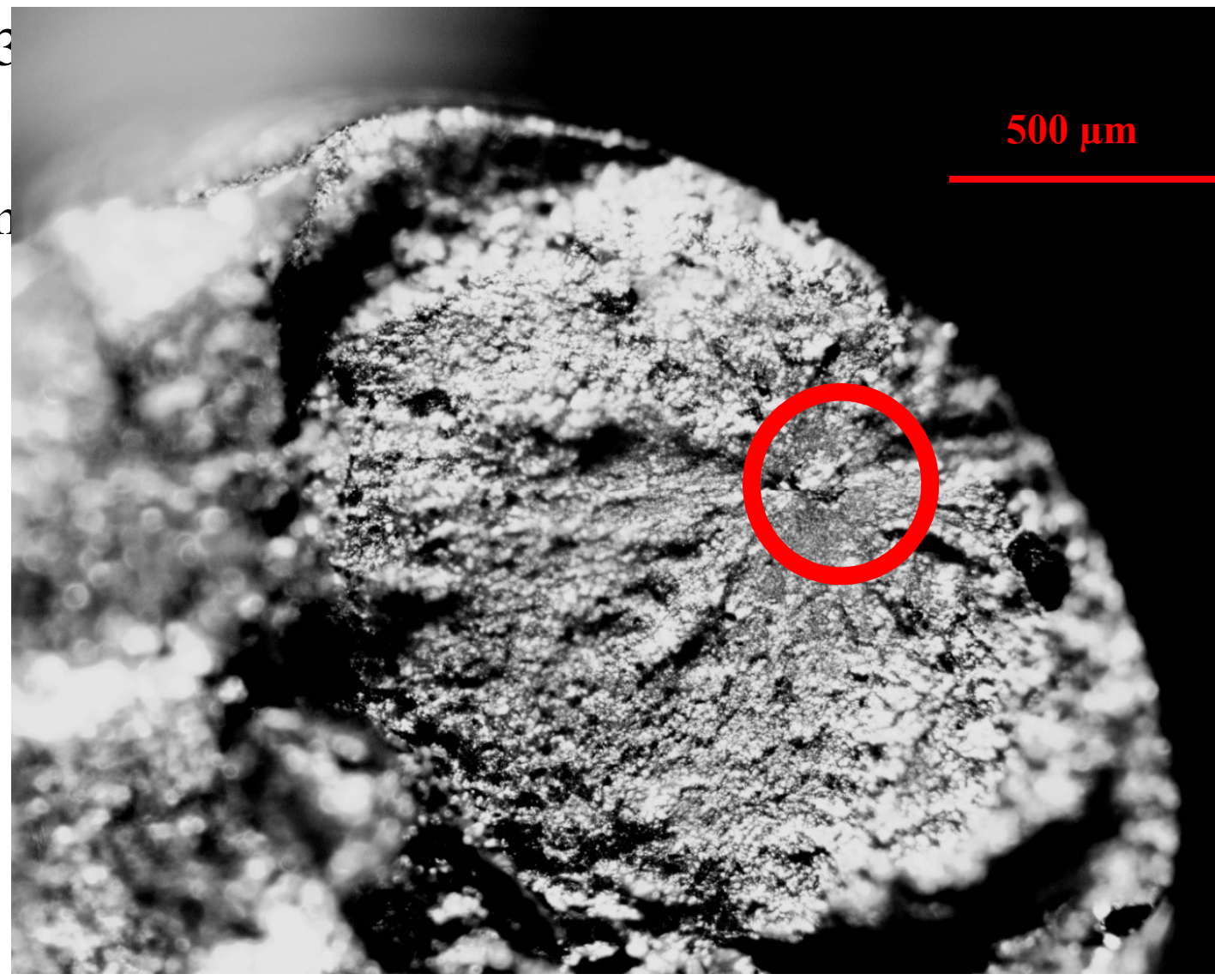


Sample Type: Additive Manufacturing

Sample Treatment: As-Built

Sample Number: 6

Max Testing Stress: $850 \mathrm{MPa}$

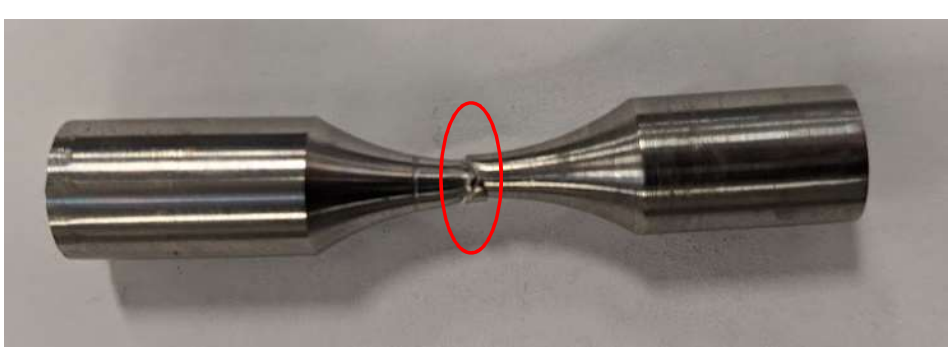

Failure (yes/no): Yes

Cycles to Failure: 94467

Failure Cause: Surface Porosit

Area of Defect: $0.002 \mathrm{~mm}^{2}$

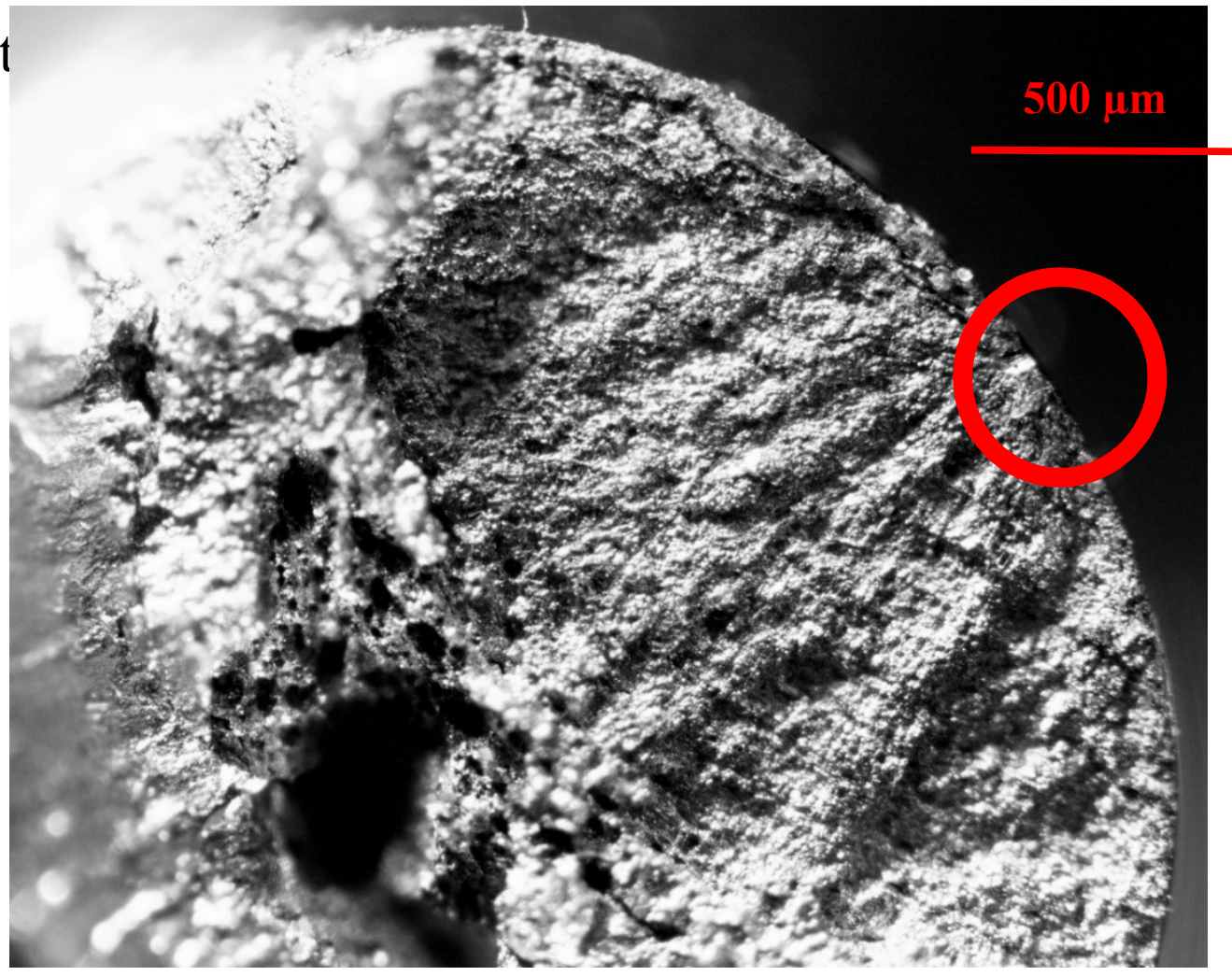


Sample Type: Additive Manufacturing Sample Treatment: As-Built Sample Number: 7

Max Testing Stress: $850 \mathrm{MPa}$

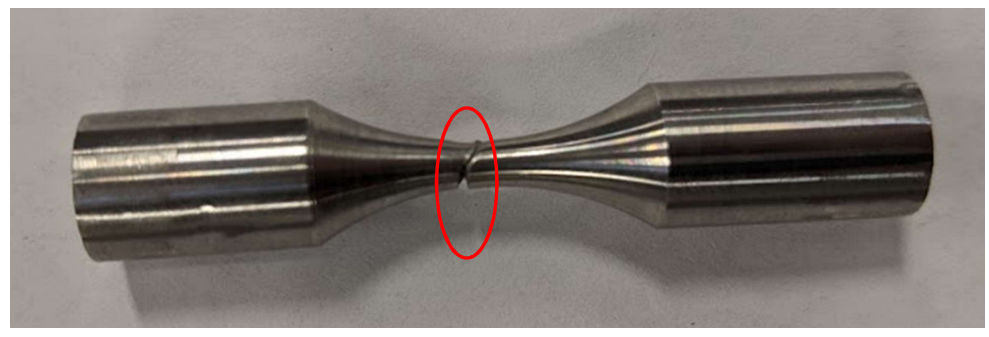

Failure (yes/no): Yes

Cycles to Failure: 109567

Failure Cause: Surface Porosi1 Area of Defect: $0.001 \mathrm{~mm}^{2}$

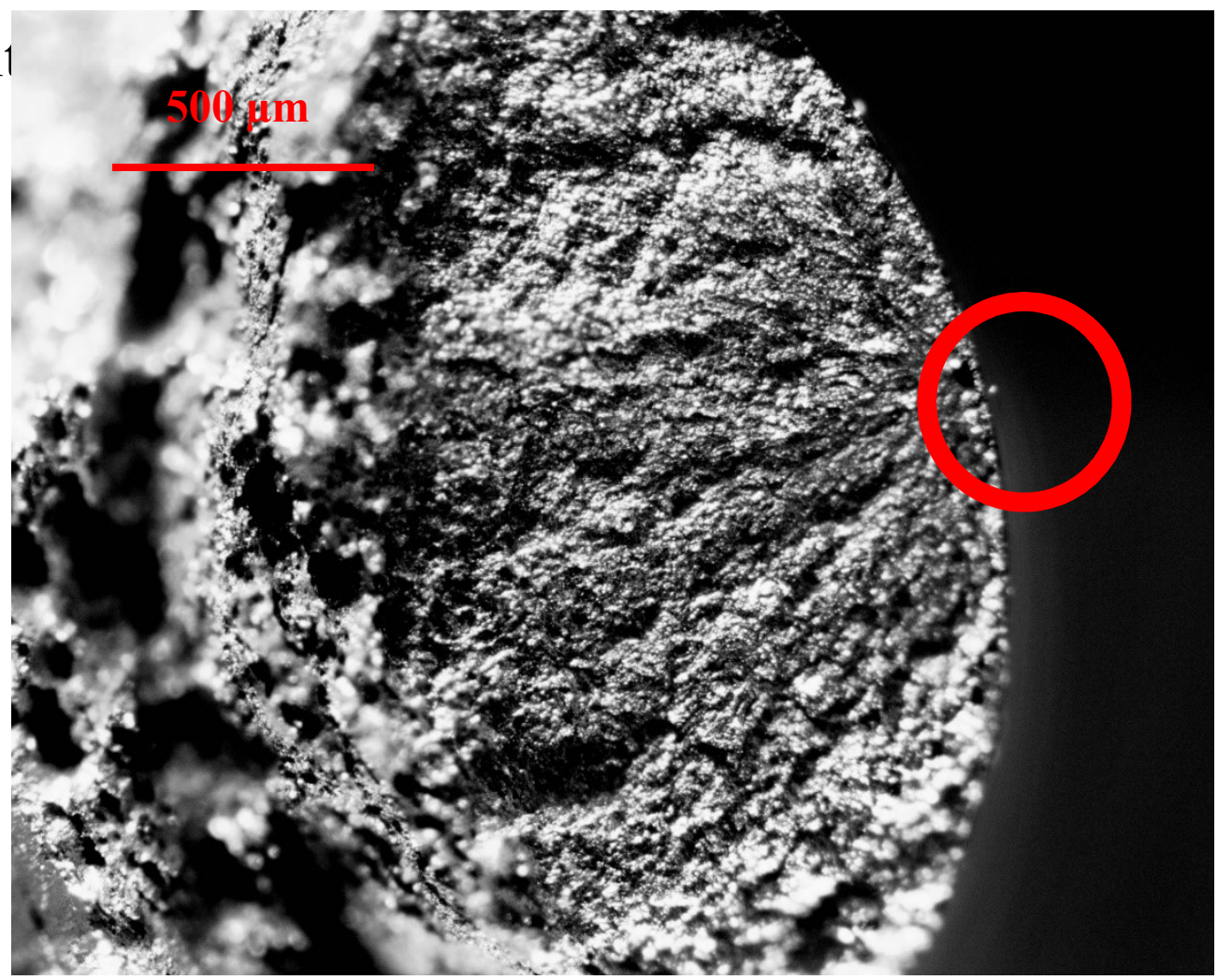


Sample Type: Additive Manufacturing Sample Treatment: As-Built

Sample Number: 8

Max Testing Stress: $950 \mathrm{MPa}$

Failure (yes/no): Yes

Cycles to Failure: 81345

Failure Cause: Surface Defer Area of Defect: $0.001 \mathrm{~mm}^{2}$

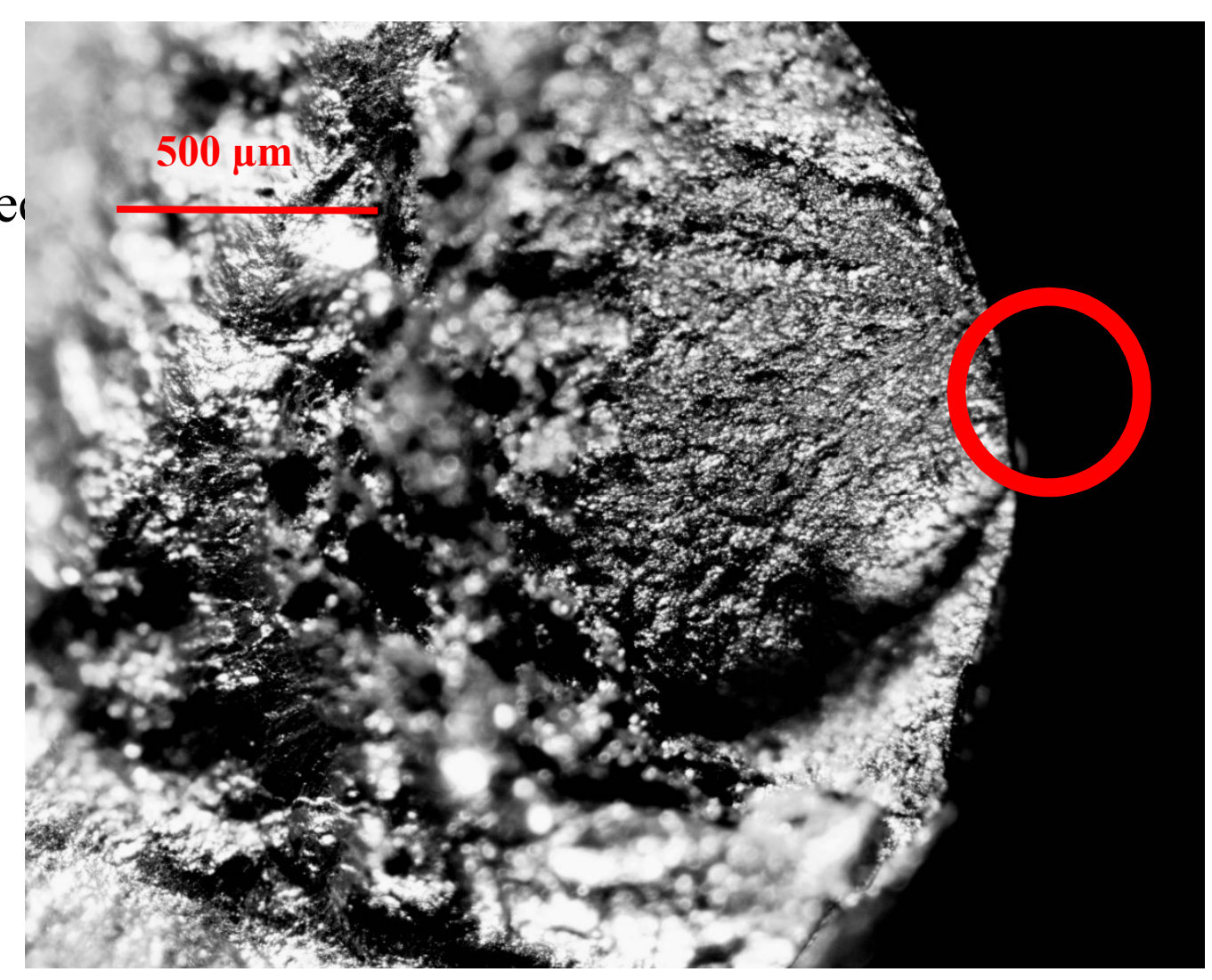


Sample Type: Additive Manufacturing Sample Treatment: As-Built Sample Number: 9

Max Testing Stress: $950 \mathrm{MPa}$ Failure (yes/no): Yes

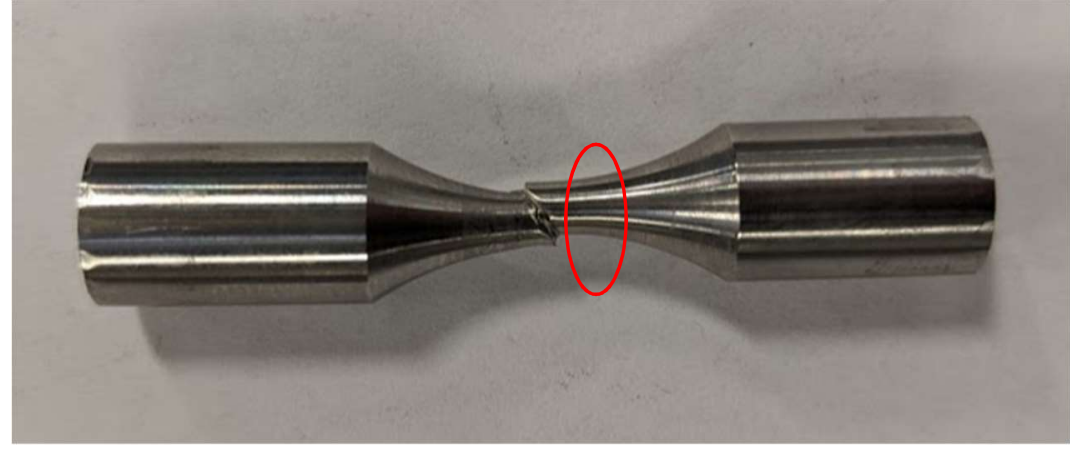

Cycles to Failure: 43871

Failure Cause: Surface Defect Area of Defect: DNF

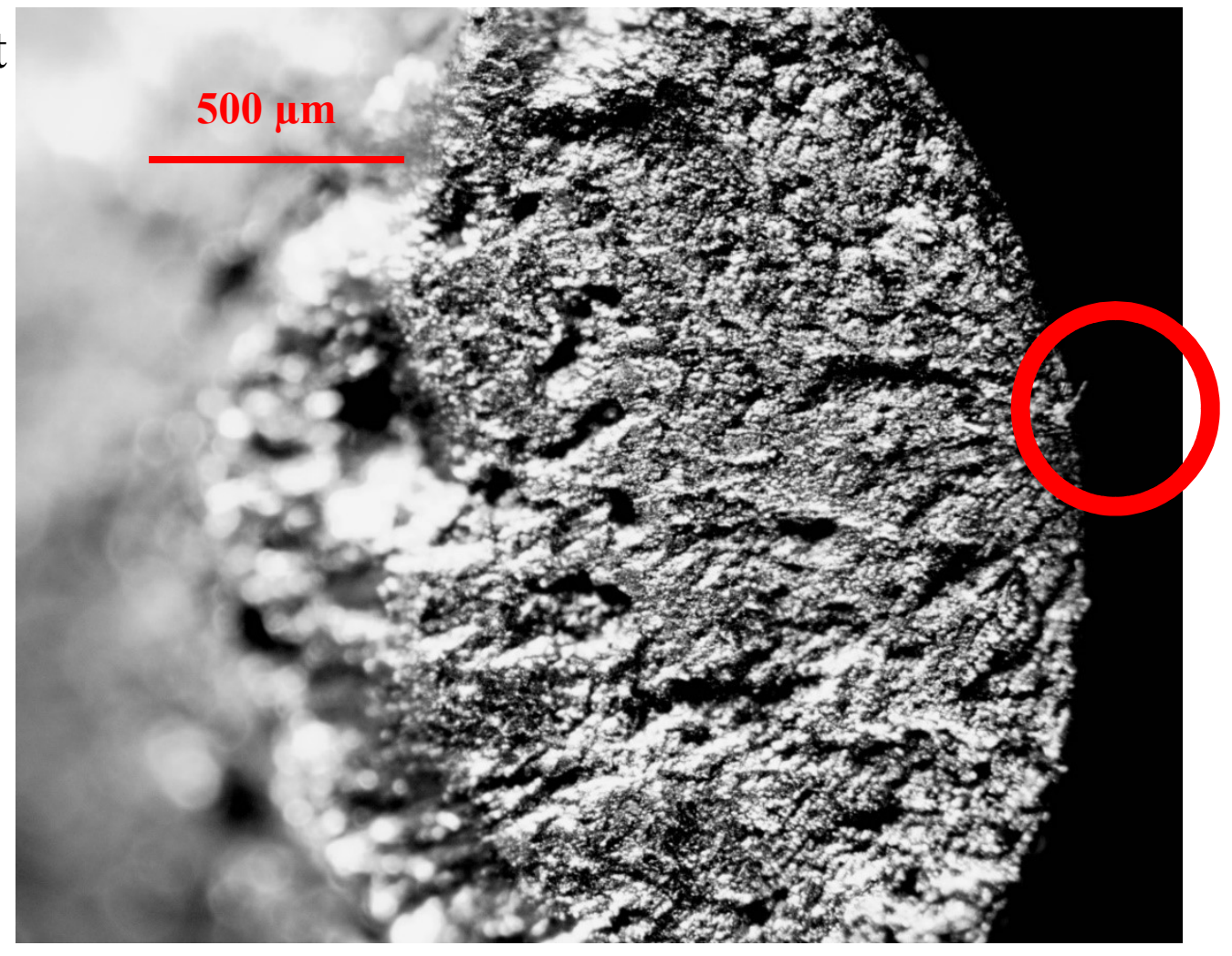


Sample Type: Additive Manufacturing

Sample Treatment: As-Built

Sample Number: 10

Max Testing Stress: $1050 \mathrm{MPa}$

Failure (yes/no): Yes

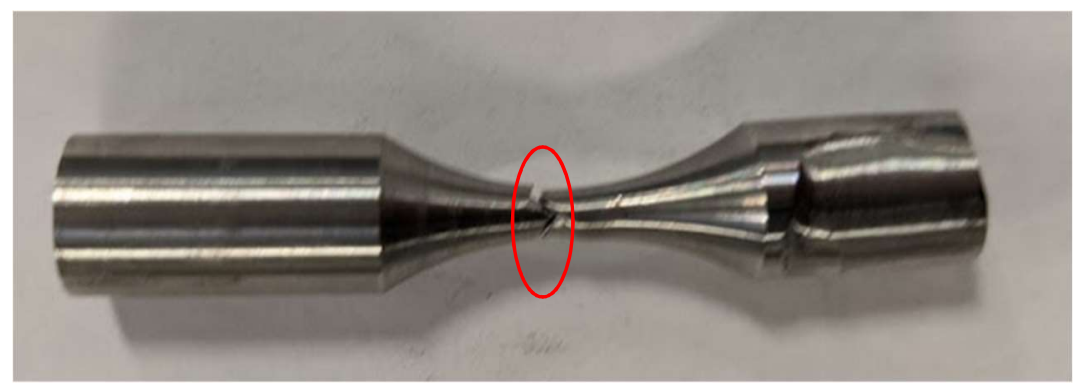

Cycles to Failure: 30195

Failure Cause: Surface Defect Area of Defect: DNF

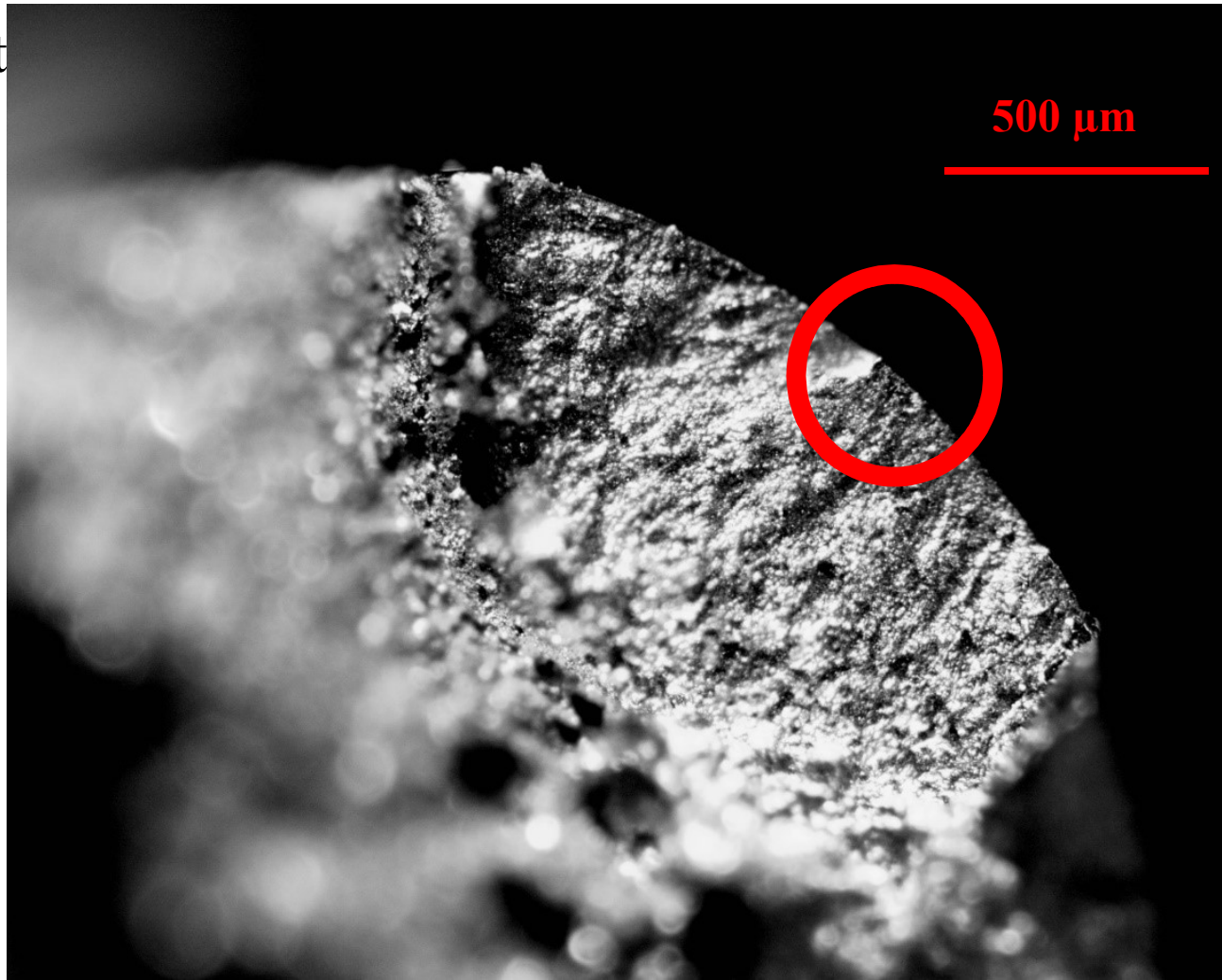


Sample Type: Additive Manufacturing Sample Treatment: As-Built Sample Number: 11

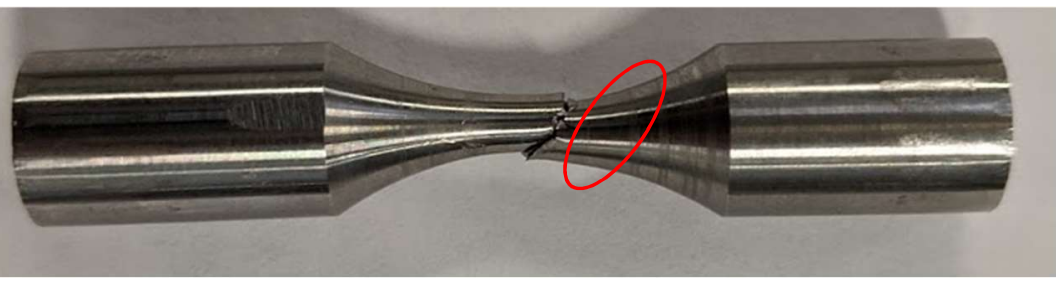
Max Testing Stress: $1050 \mathrm{MPa}$

Failure (yes/no): Yes Cycles to Failure: 23985 Failure Cause: Surface Defec Area of Defect: DNF

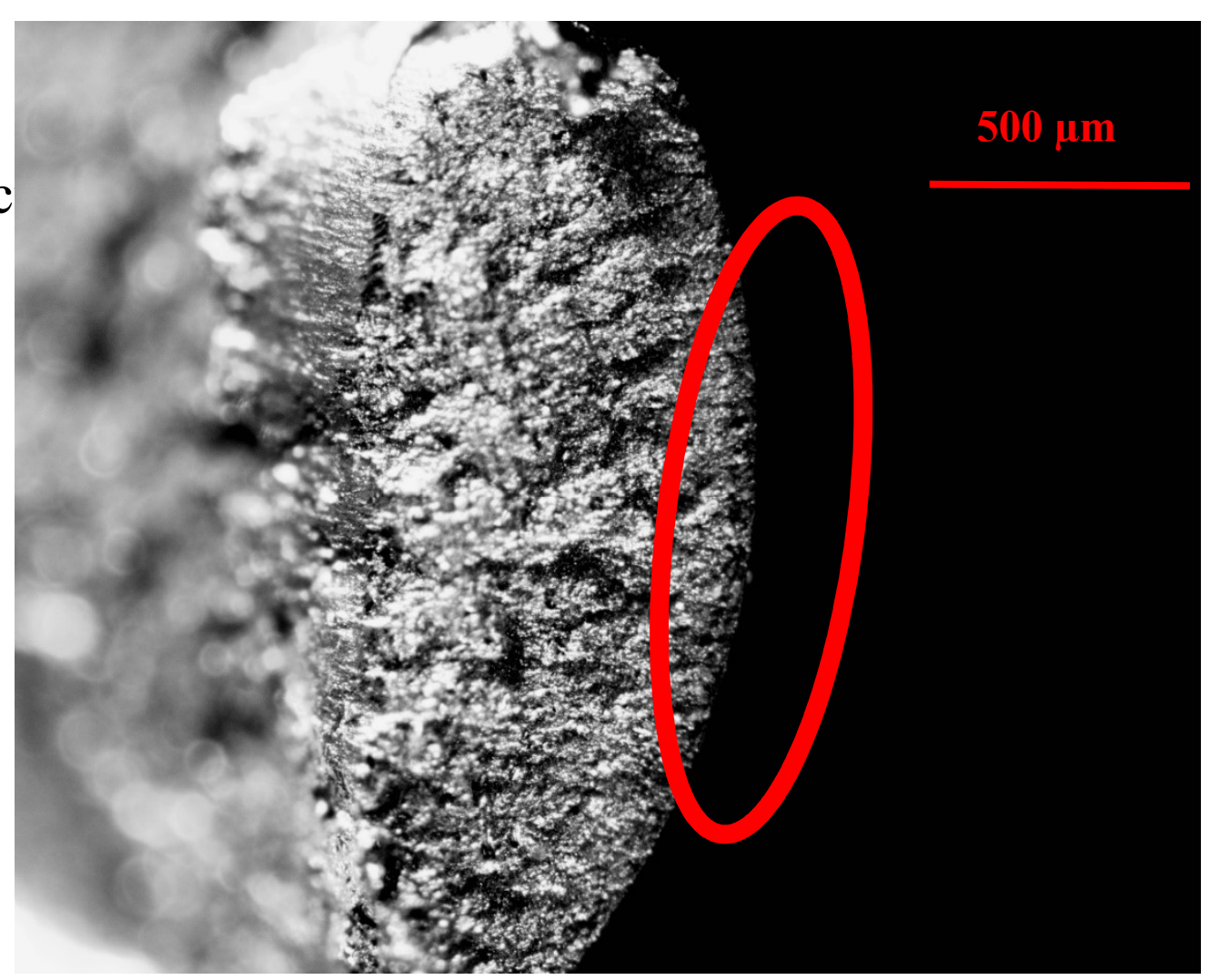


Sample Type: Additive Manufacturing

Sample Treatment: As-Built

Sample Number: 12

Max Testing Stress: $600 \mathrm{MPa}$

Failure (yes/no): No

Cycles to Failure: Run out

Failure Cause: N/A

Area of Defect: N/A 
Sample Type: Additive Manufacturing

Sample Treatment: H900 Direct Harden

Sample Number: 1

Max Testing Stress: $500 \mathrm{MPa}$

Failure (yes/no): No

Cycles to Failure: Run out

Failure Cause: N/A

Area of Defect: N/A 
Sample Type: Additive Manufacturing Sample Treatment: H900 Direct Harden Sample Number: 2

Max Testing Stress: $750 \mathrm{MPa}$

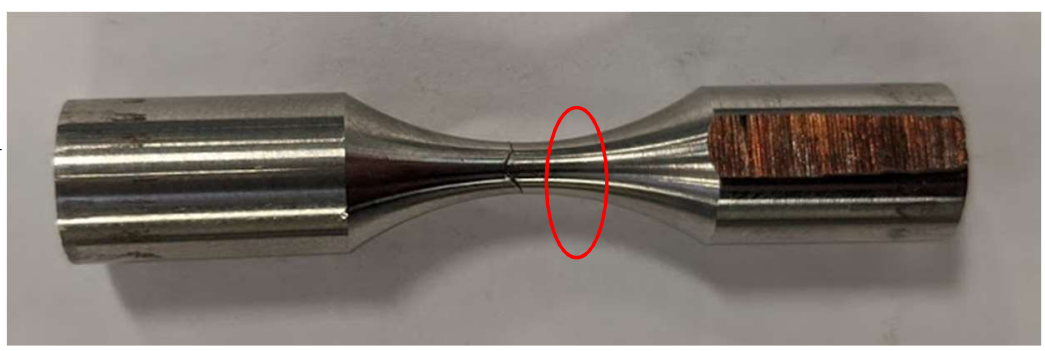

Failure (yes/no): Yes

Cycles to Failure: 7228279 Failure Cause: Porosity Area of Defect: $0.001 \mathrm{~mm}^{2}$

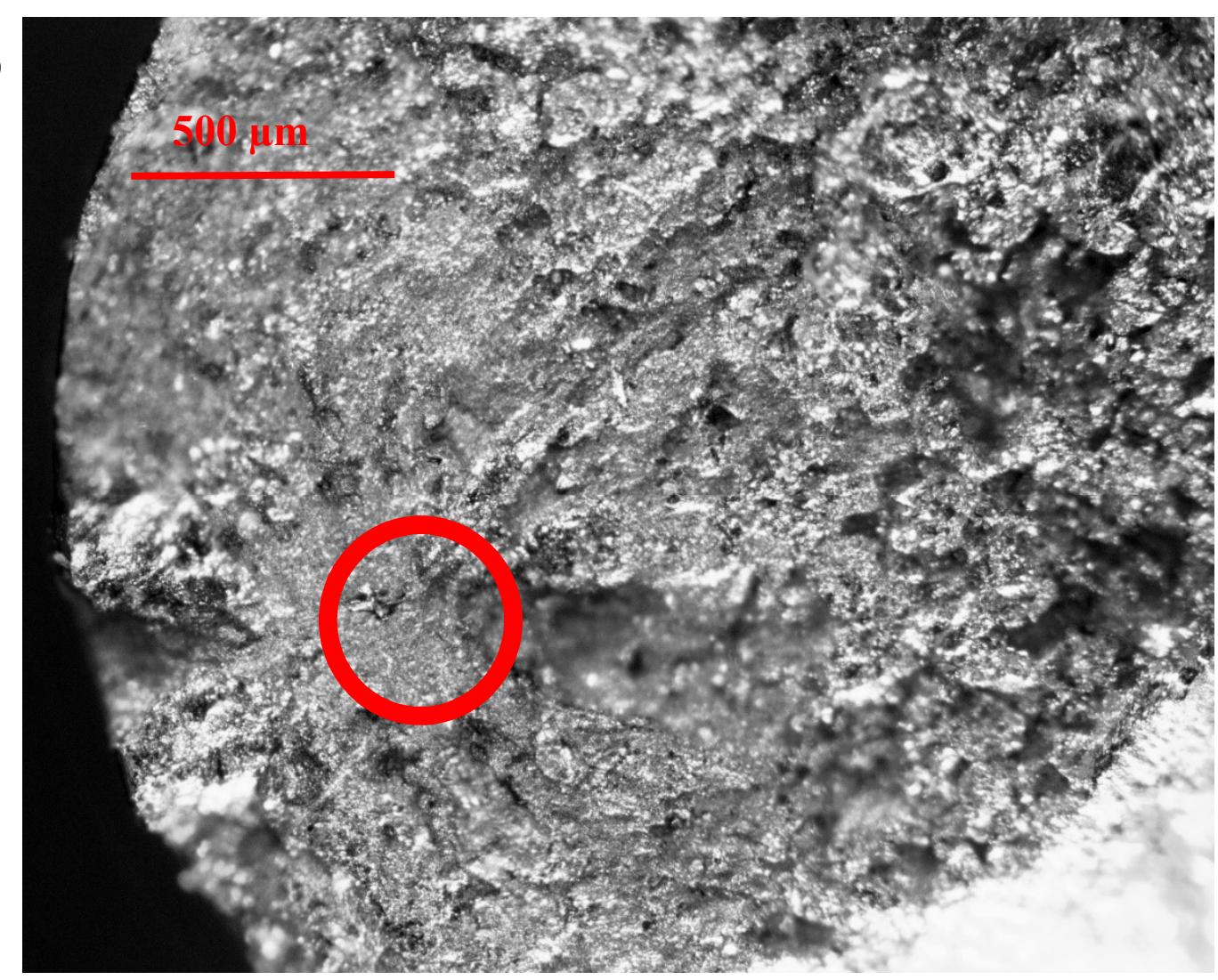


Sample Type: Additive Manufacturing Sample Treatment: H900 Direct Harden Sample Number: 3

Max Testing Stress: $750 \mathrm{MPa}$ Failure (yes/no): Yes

Cycles to Failure: 2707879 Failure Cause: Porosity Area of Defect: $0.006 \mathrm{~mm}^{2}$
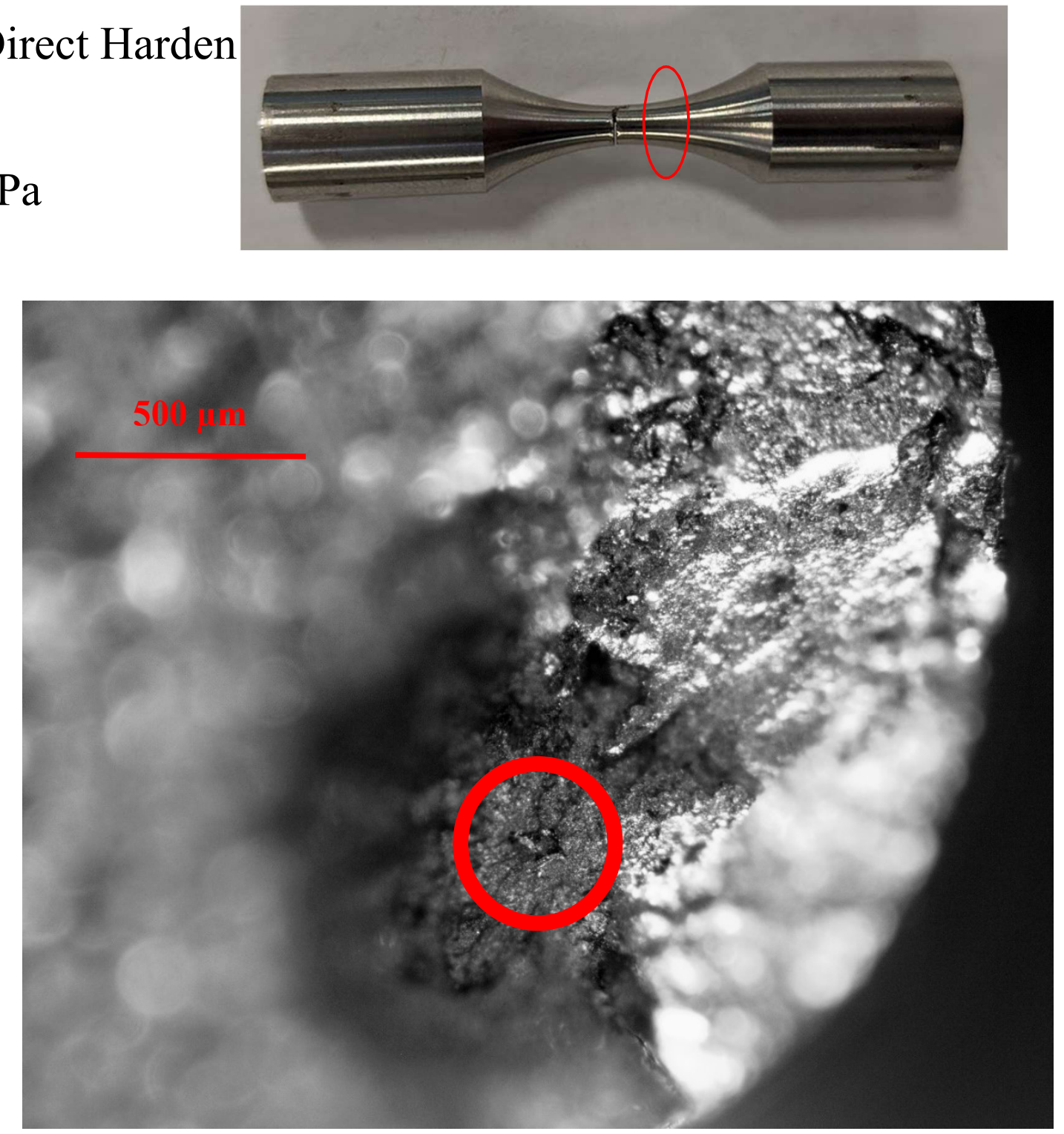
Sample Type: Additive Manufacturing Sample Treatment: H900 Direct Harden Sample Number: 4

Max Testing Stress: $1200 \mathrm{MPa}$

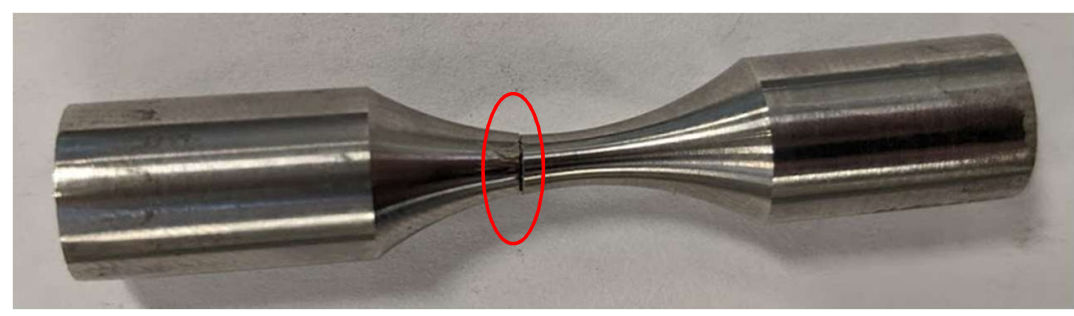

Failure (yes/no): Yes

Cycles to Failure: 32928

Failure Cause: Surface Porosity Area of Defect: $0.003 \mathrm{~mm}^{2}$

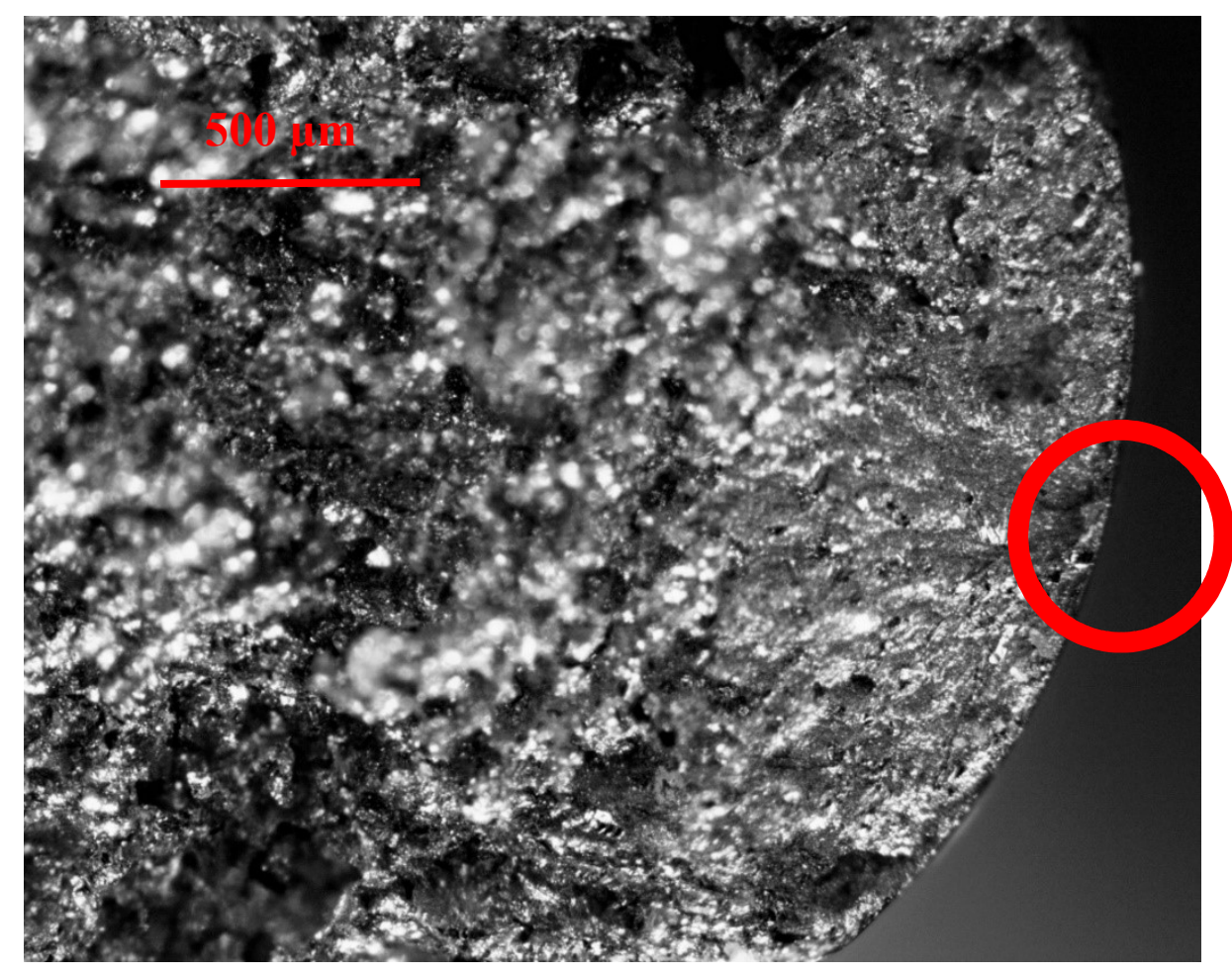


Sample Type: Additive Manufacturing

Sample Treatment: H900 Direct Harden

Sample Number: 5

Max Testing Stress: $850 \mathrm{MPa}$

Failure (yes/no): Yes

Cycles to Failure: 56900

Failure Cause: Surface Defect

Area of Defect: DNF
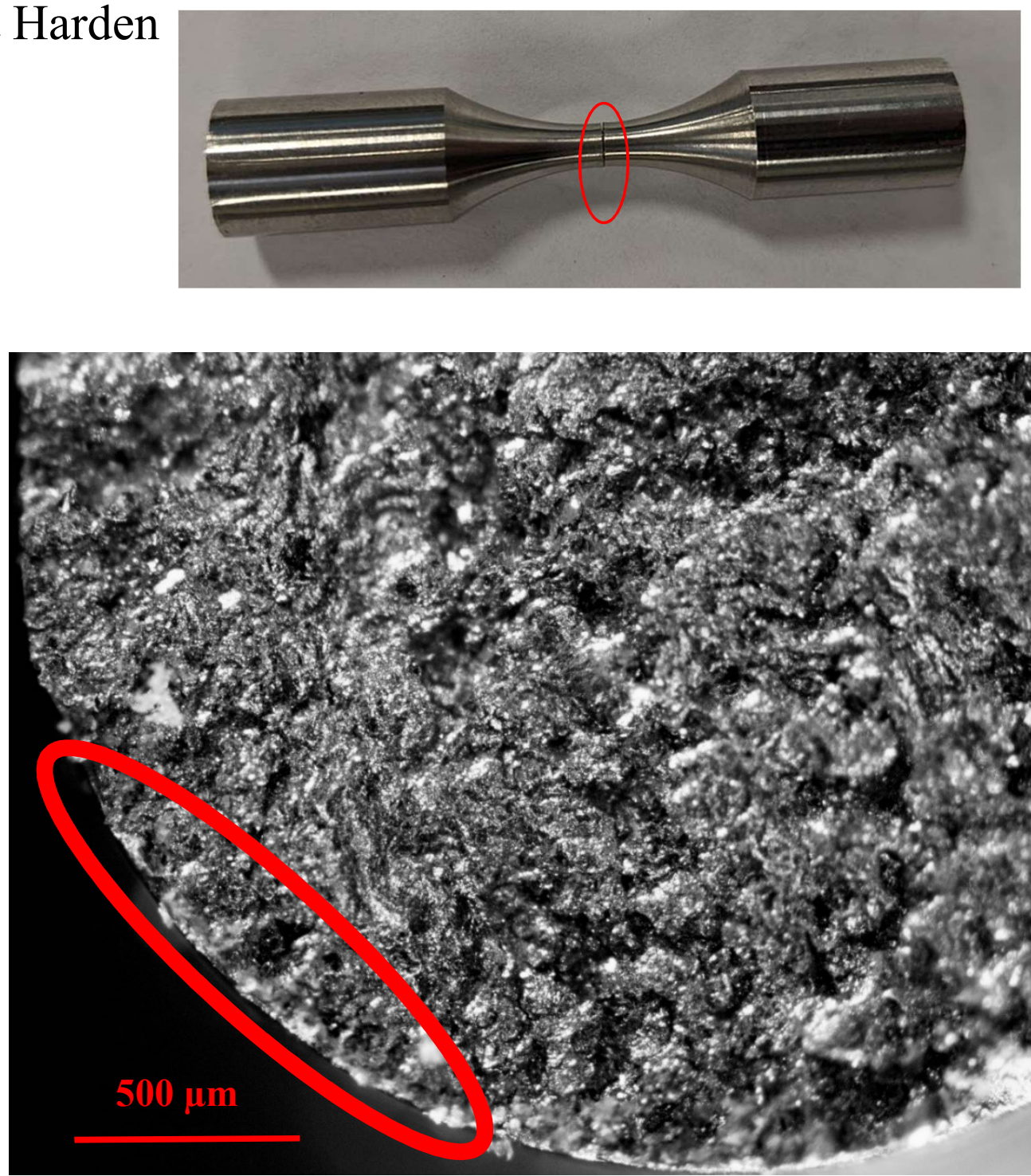
Sample Type: Additive Manufacturing Sample Treatment: H900 Direct Harden Sample Number: 6

Max Testing Stress: $850 \mathrm{MPa}$

Failure (yes/no): Yes

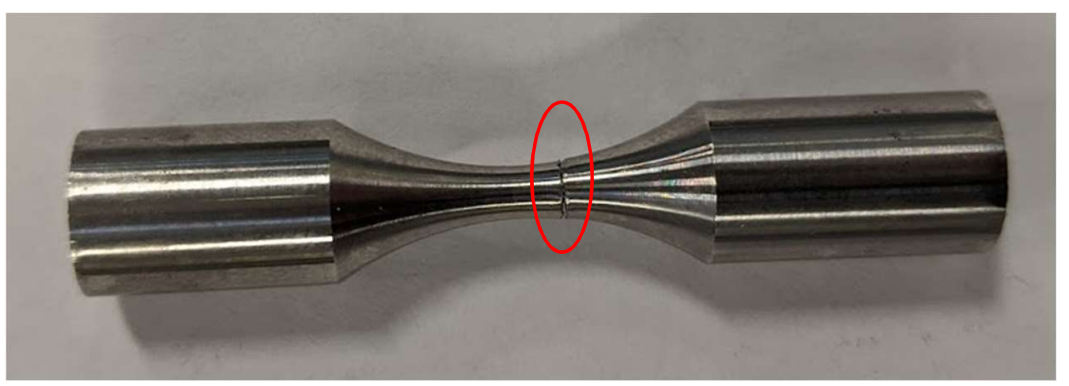

Cycles to Failure: 86494

Failure Cause: Surface Defec Area of Defect: DNF

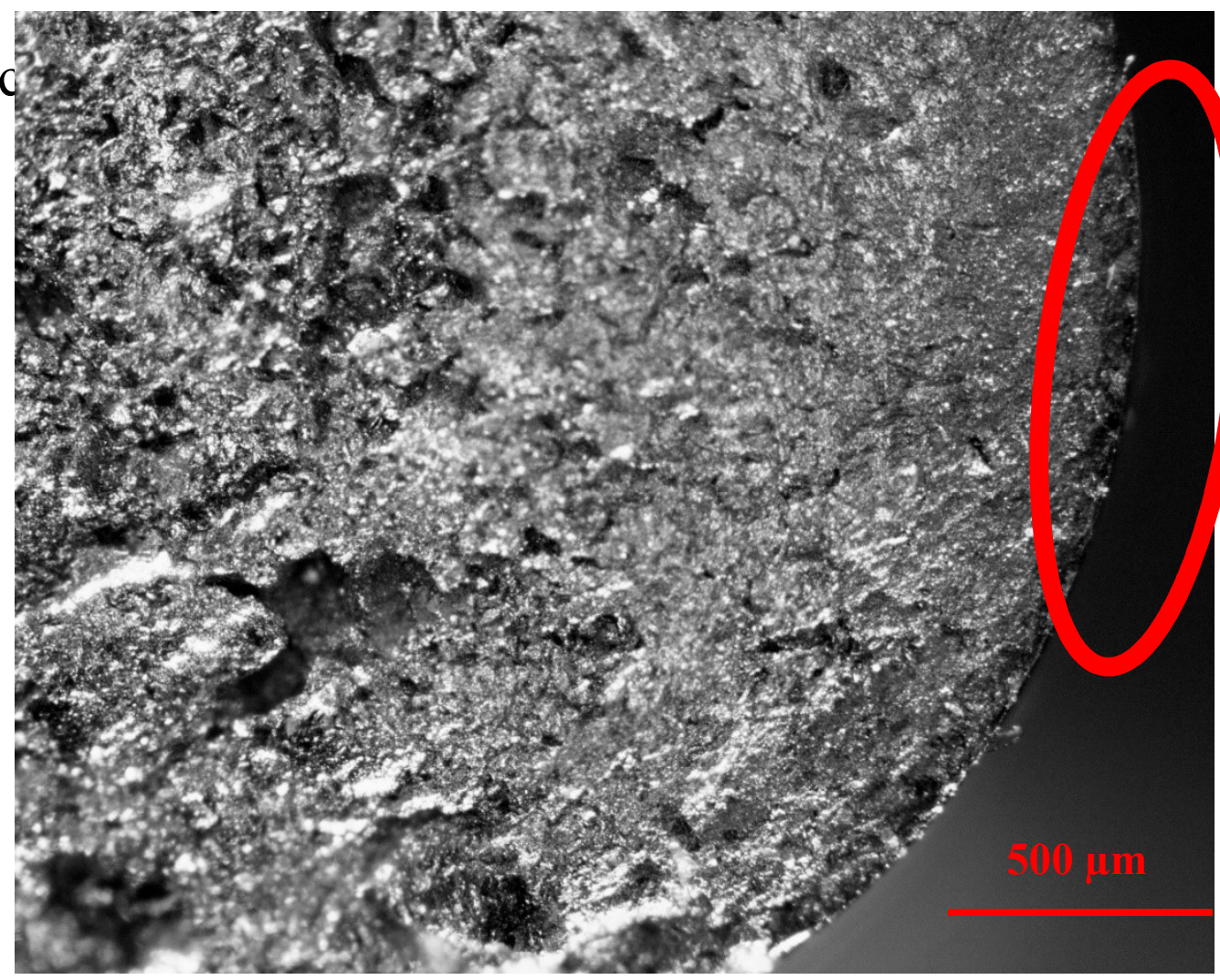


Sample Type: Additive Manufacturing

Sample Treatment: H900 Direct Harden

Sample Number: 7

Max Testing Stress: $850 \mathrm{MPa}$

Failure (yes/no): Yes

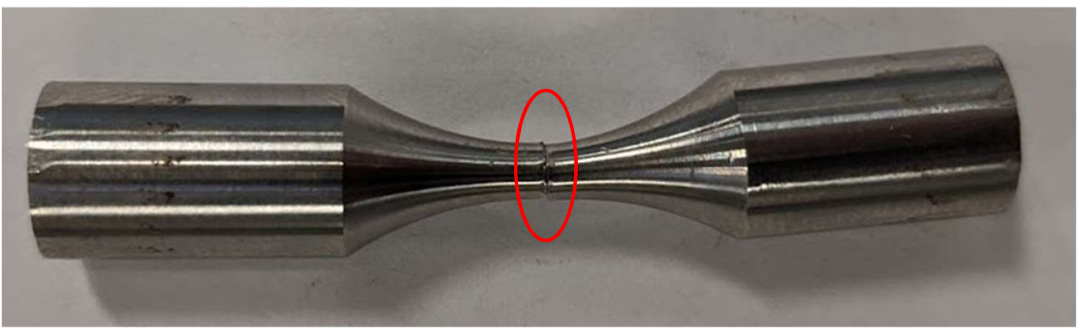

Cycles to Failure: 3379999

Failure Cause:

Surface Porosity/Porosity

Area of Defect: $0.001 \mathrm{~mm}^{2}$

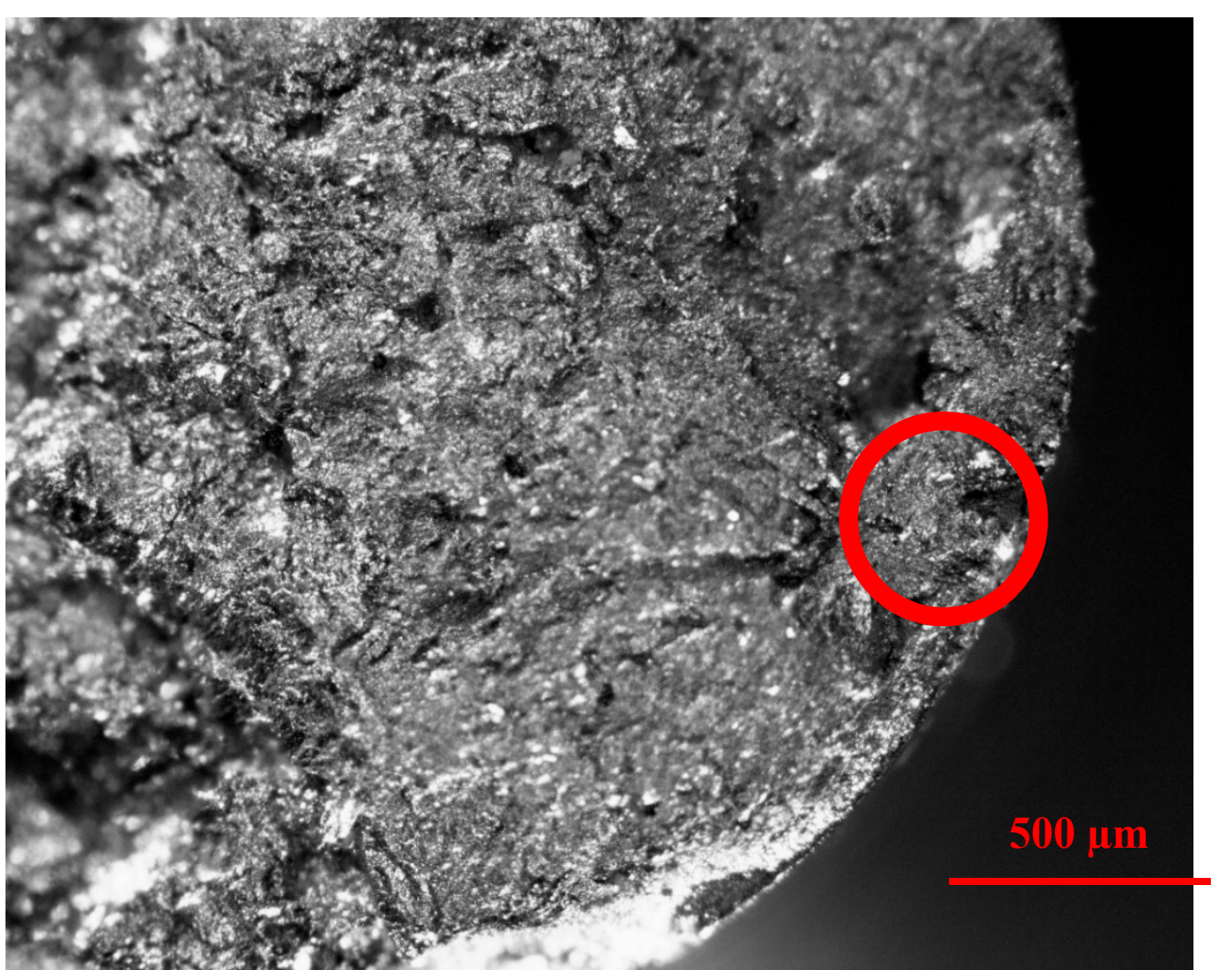


Sample Type: Additive Manufacturing Sample Treatment: H900 Direct Harden Sample Number: 8

Max Testing Stress: $950 \mathrm{MPa}$

Failure (yes/no): Yes

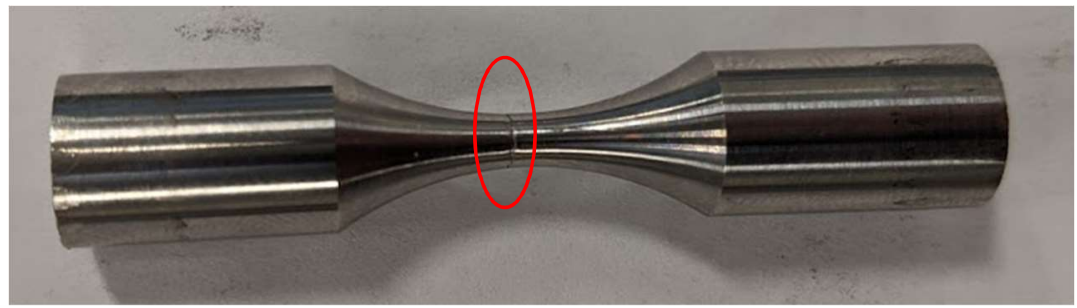

Cycles to Failure: 584651

Failure Cause: Surface Porosity Area of Defect: $0.003 \mathrm{~mm}^{2}$

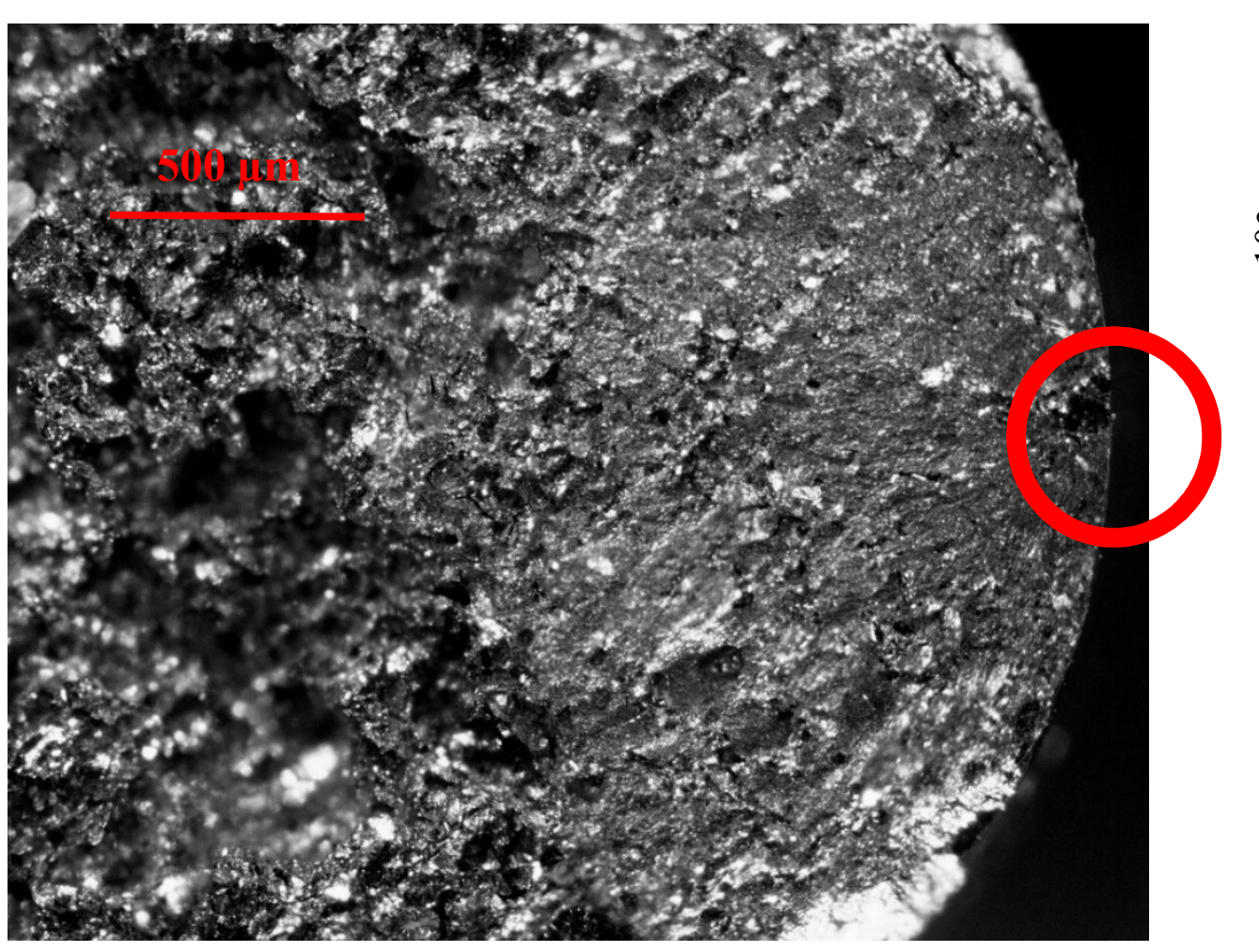


Sample Type: Additive Manufacturing Sample Treatment: H900 Direct Harden Sample Number: 9

Max Testing Stress: $950 \mathrm{MPa}$ Failure (yes/no): Yes

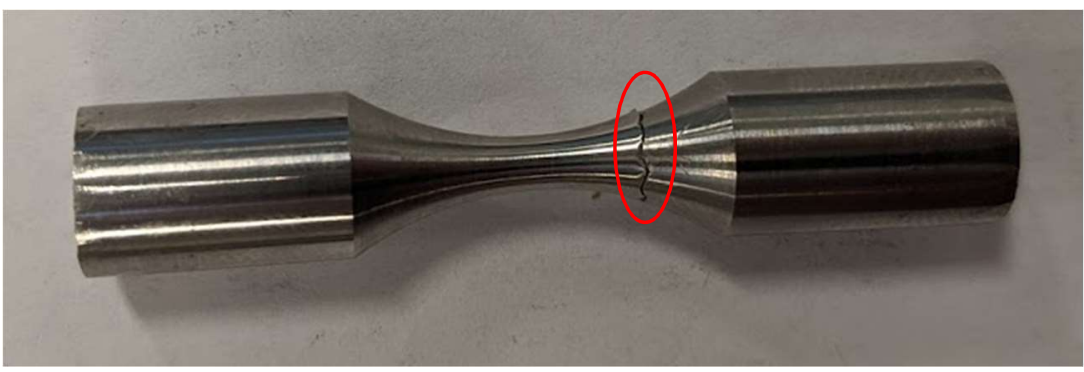

Cycles to Failure: 20160

Failure Cause: Surface Defect Area of Defect: DNF

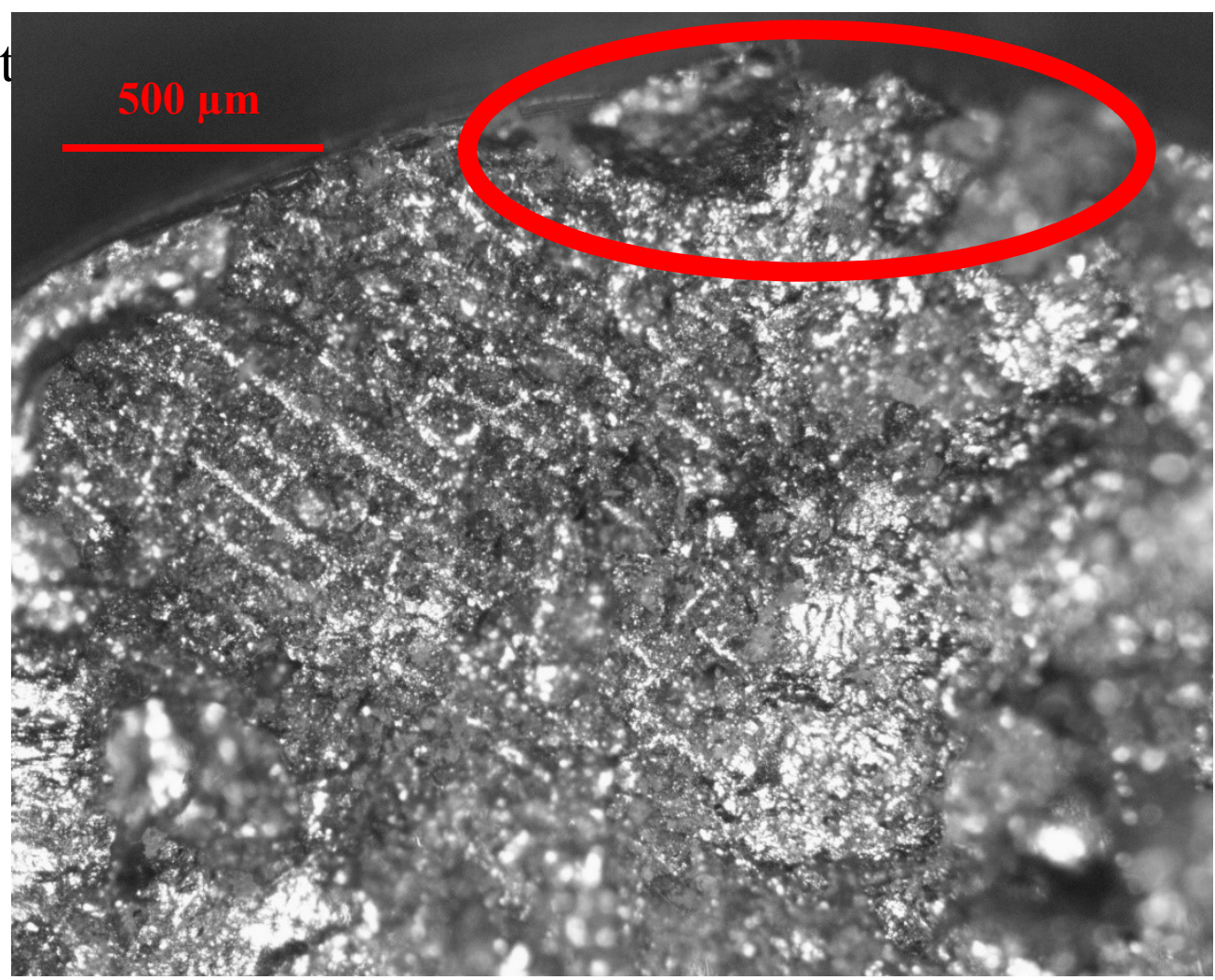


Sample Type: Additive Manufacturing Sample Treatment: H900 Direct Harden Sample Number: 10

Max Testing Stress: $950 \mathrm{MPa}$

Failure (yes/no): Yes

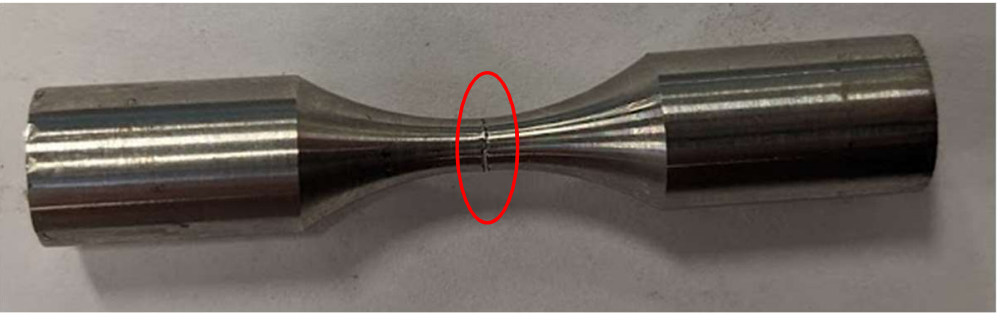

Cycles to Failure: 219007

Failure Cause: Surface Porosity Area of Defect: $0.001 \mathrm{~mm}^{2}$

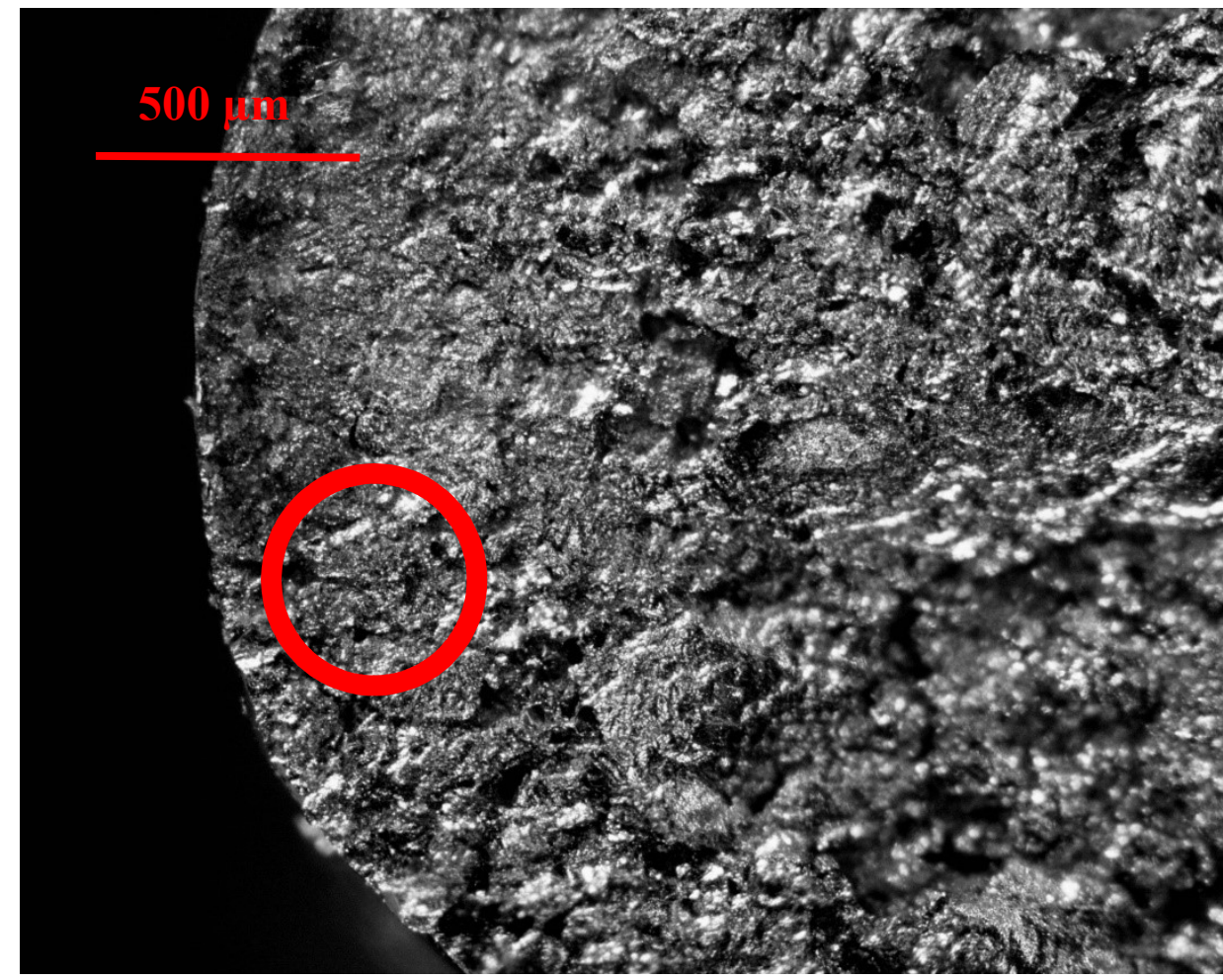


Sample Type: Additive Manufacturing Sample Treatment: H900 Direct Harden Sample Number: 11

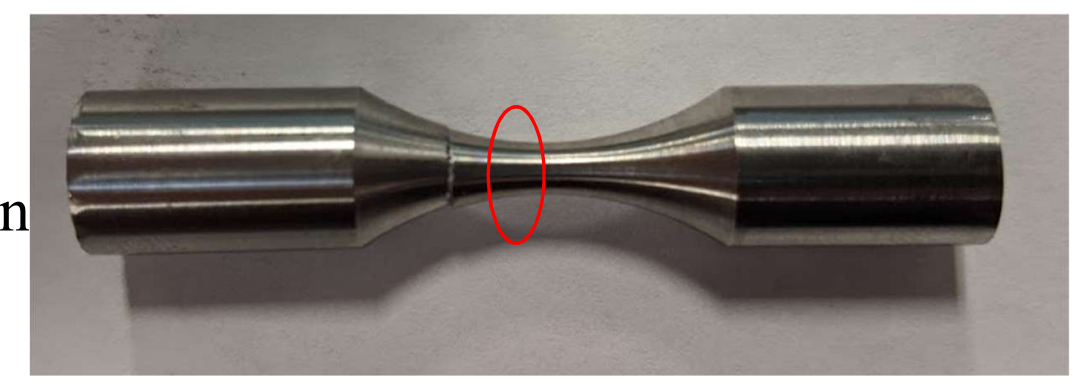

Max Testing Stress: $1050 \mathrm{MPa}$

Failure (yes/no): Yes

Cycles to Failure: 175296

Failure Cause: Surface Porosity Area of Defect: $0.003 \mathrm{~mm}^{2}$

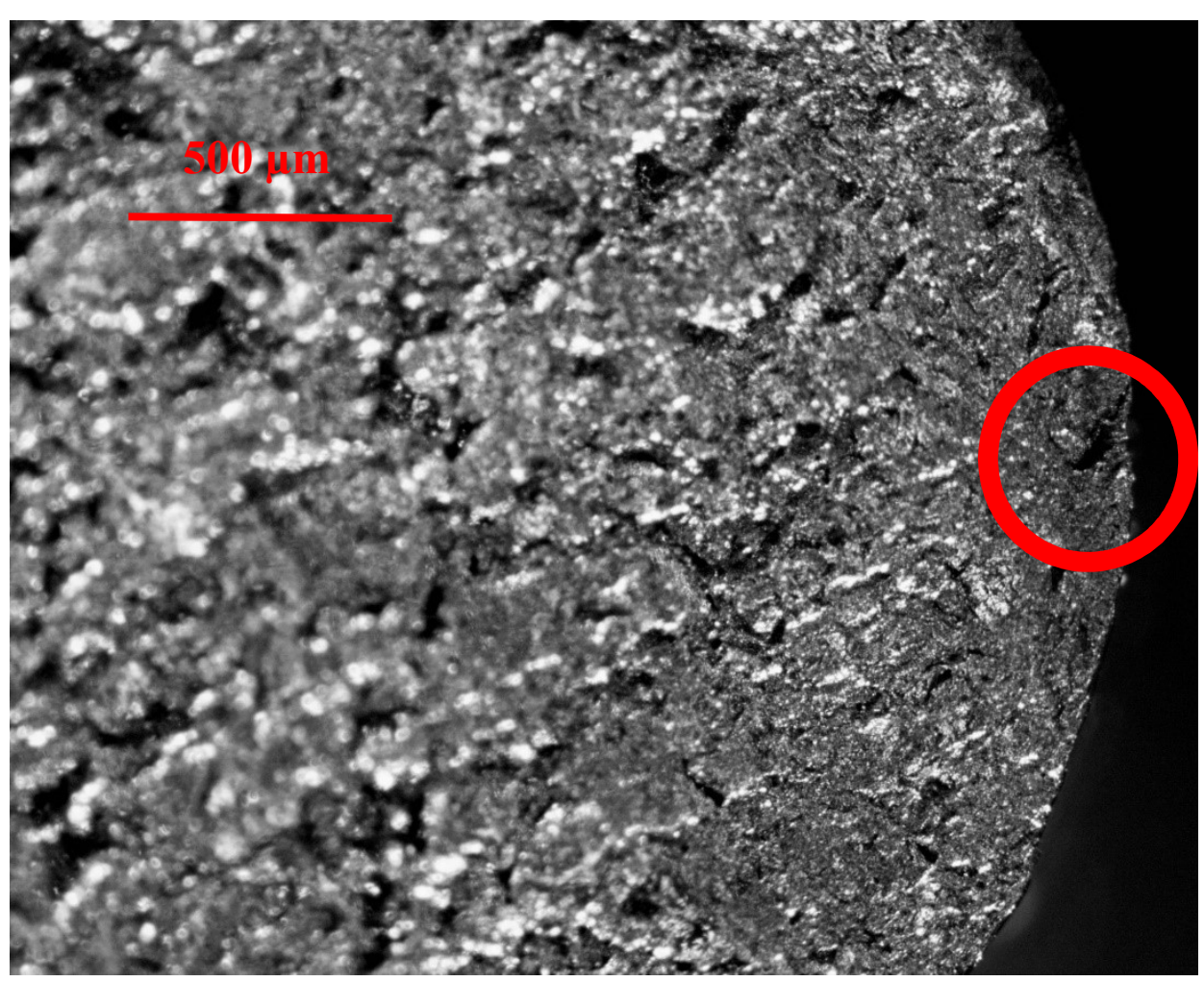


Sample Type: Additive Manufacturing Sample Treatment: H900 Direct Harden Sample Number: 12

Max Testing Stress: $1050 \mathrm{MPa}$

Failure (yes/no): Yes

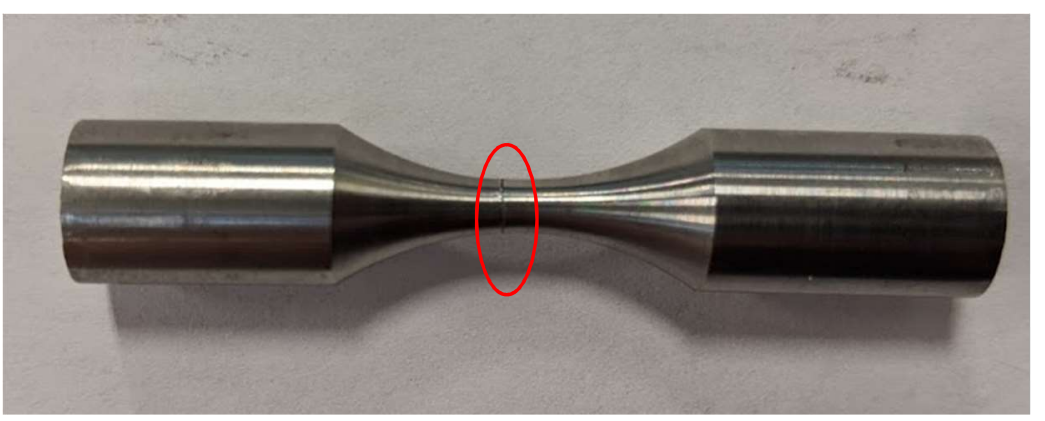

Cycles to Failure: 33671

Failure Cause: Surface Defec Area of Defect: $0.001 \mathrm{~mm}^{2}$

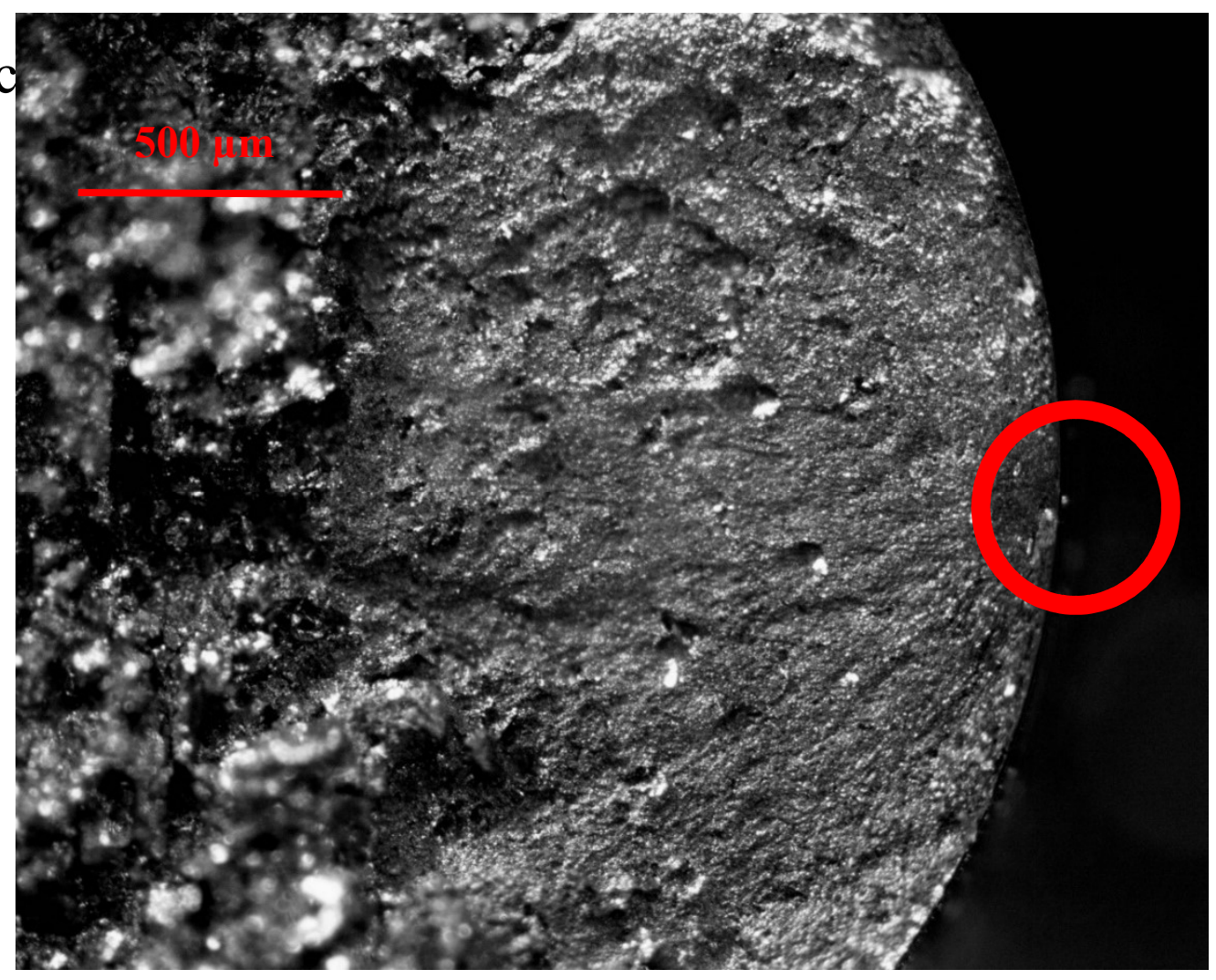


Sample Type: Additive Manufacturing Sample Treatment: H900 Direct Harden Sample Number: 13

Max Testing Stress: $1050 \mathrm{MPa}$

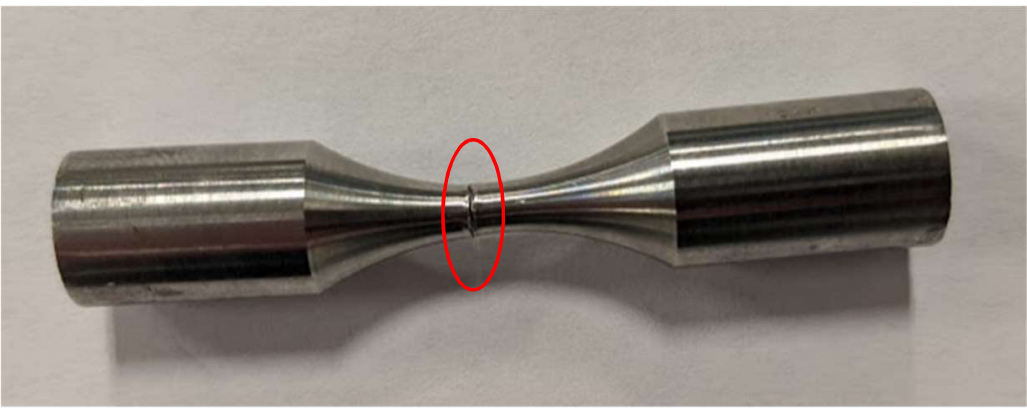

Failure (yes/no): Yes

Cycles to Failure: 323652

Failure Cause: Surface Defec Area of Defect: $0.002 \mathrm{~mm}^{2}$

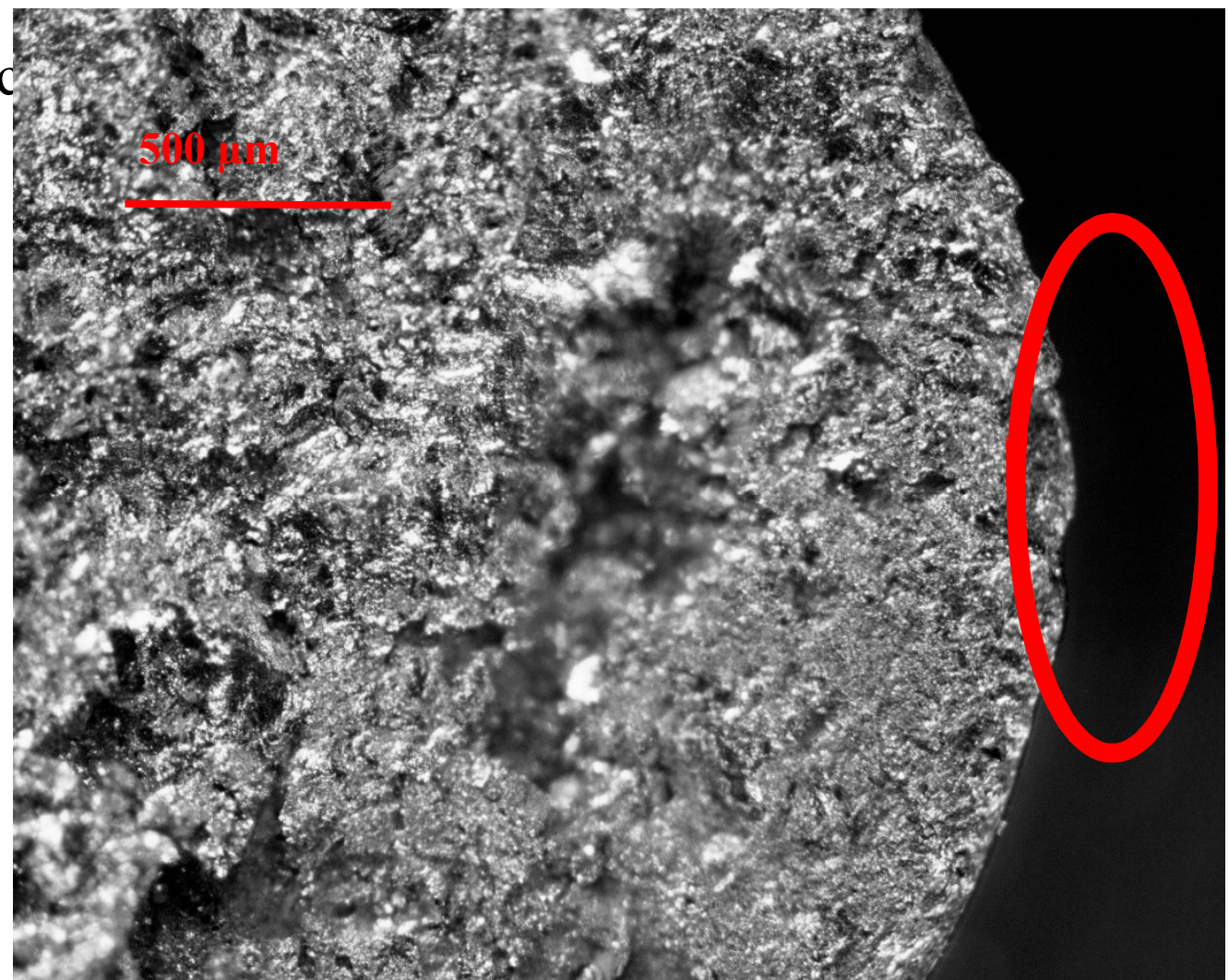


Sample Type: Additive Manufacturing

Sample Treatment: Solutionized + H900

Sample Number: 1

Max Testing Stress: $400 \mathrm{MPa}$

Failure (yes/no): No

Cycles to Failure: Run out

Failure Cause: N/A

Area of Defect: N/A 
Sample Type: Additive Manufacturing

Sample Treatment: Solutionized + H900

Sample Number: 2

Max Testing Stress: $600 \mathrm{MPa}$

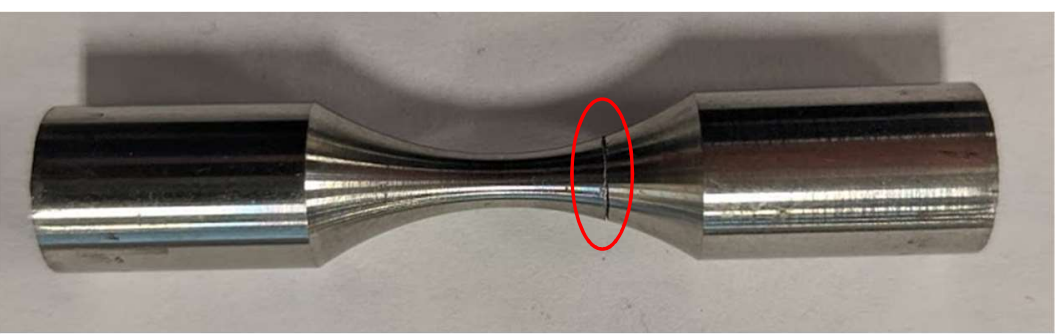

Failure (yes/no): Yes

Cycles to Failure: 981756

Failure Cause: Surface Defe

Area of Defect: $0.416 \mathrm{~mm}^{2}$

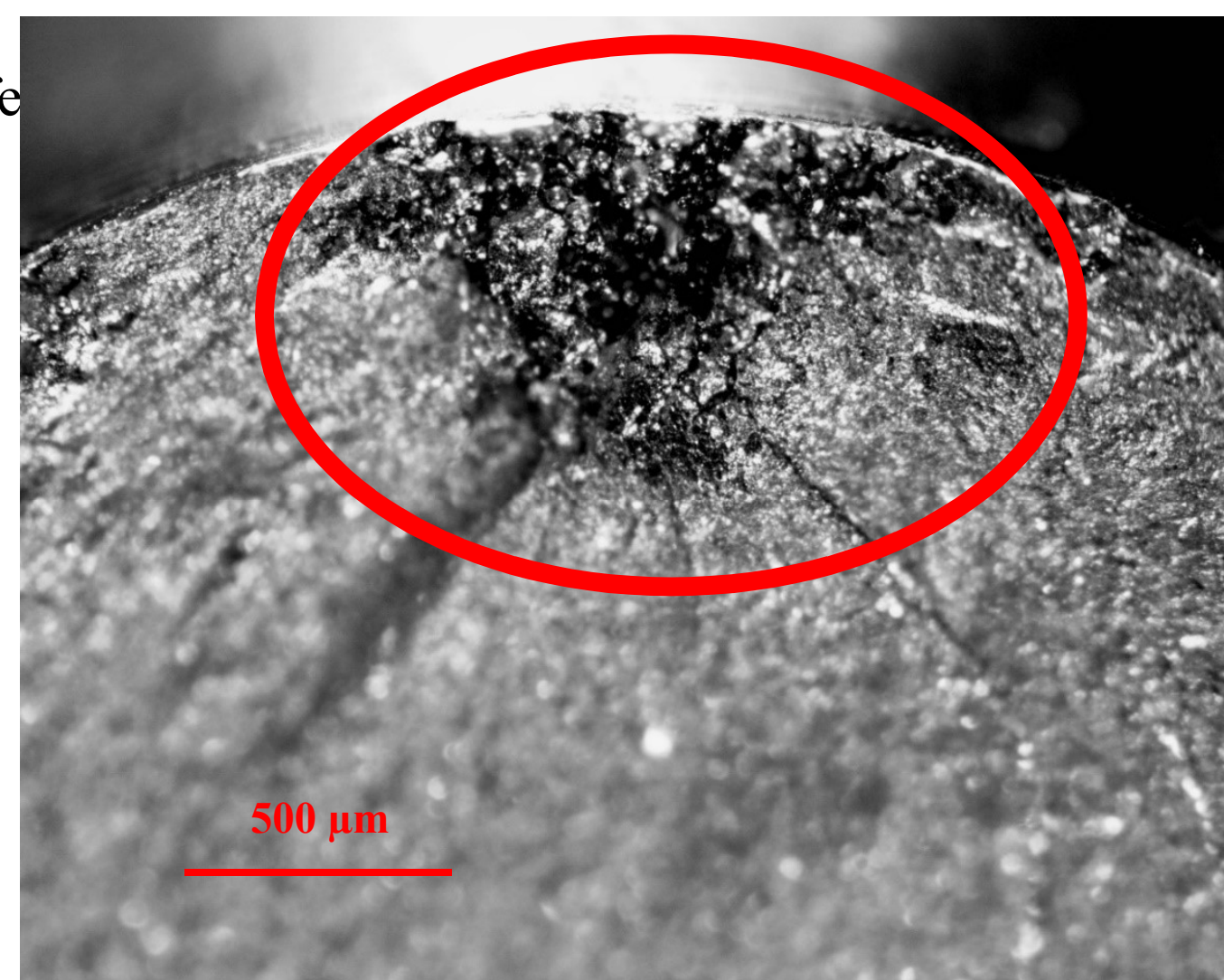


Sample Type: Additive Manufacturing

Sample Treatment: Solutionized + H900

Sample Number: 3

Max Testing Stress: $600 \mathrm{MPa}$

Failure (yes/no): no

Cycles to Failure: Run out

Failure Cause: N/A

Area of Defect: N/A 
Sample Type: Additive Manufacturing

Sample Treatment: Solutionized + H900

Sample Number: 4

Max Testing Stress: $750 \mathrm{MPa}$

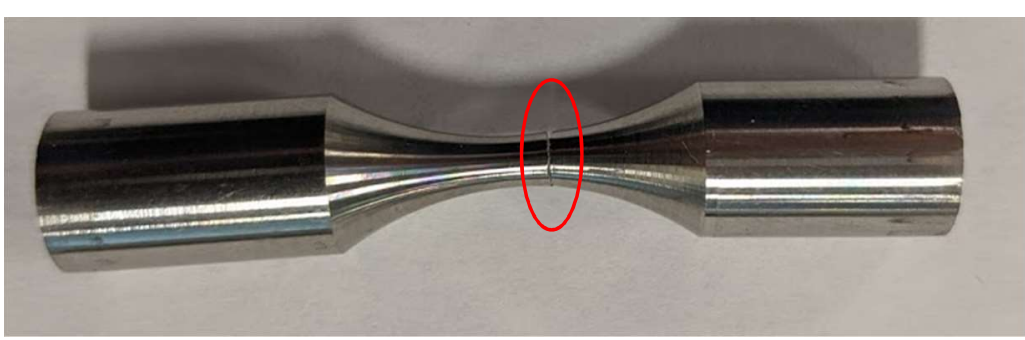

Failure (yes/no): Yes

Cycles to Failure: 1467905

Failure Cause:

Surface Porosity/Porosity

Area of Defect: $0.009 \mathrm{~mm}^{2}$

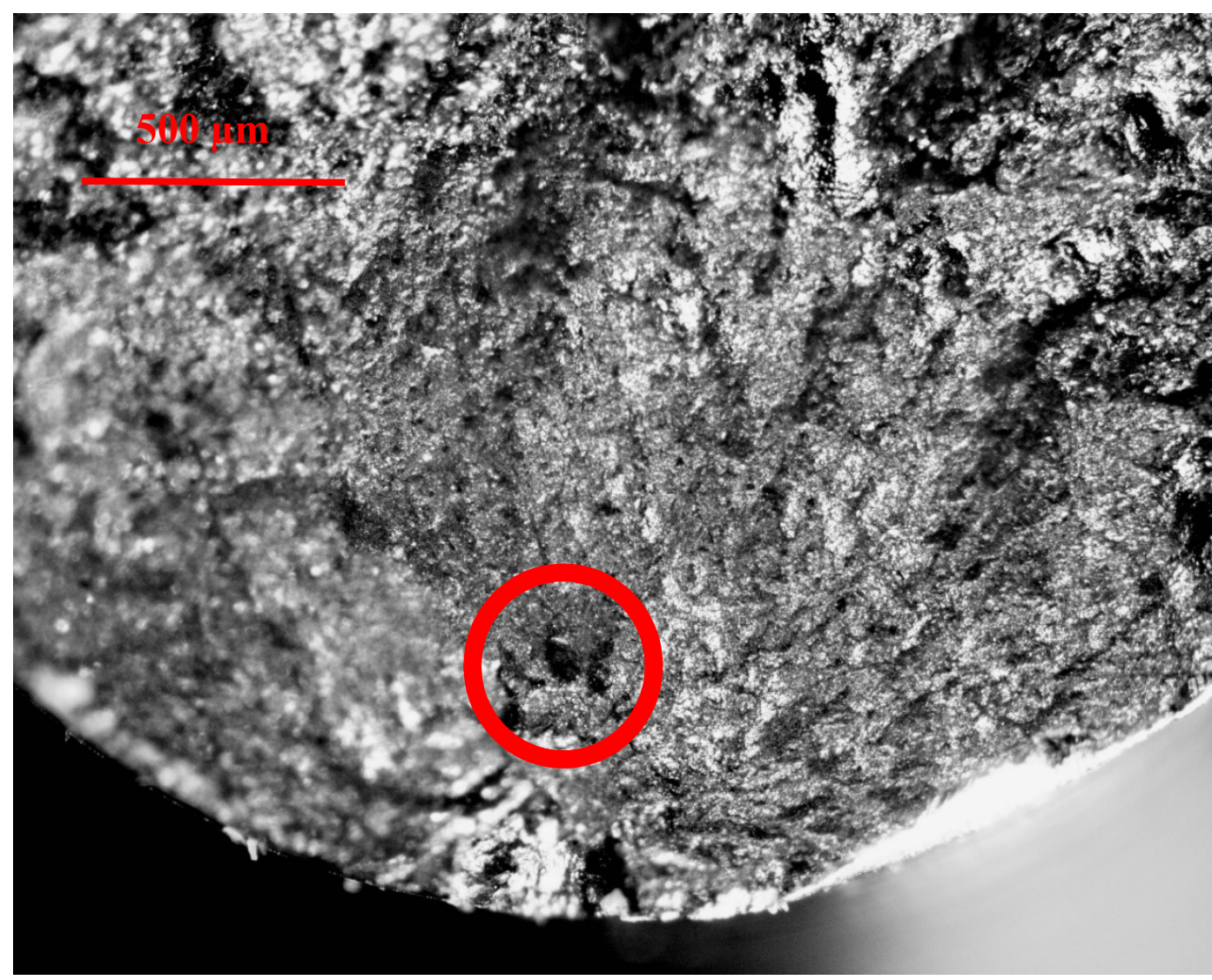


Sample Type: Additive Manufacturing

Sample Treatment: Solutionized + H900

Sample Number: 5

Max Testing Stress: $750 \mathrm{MPa}$

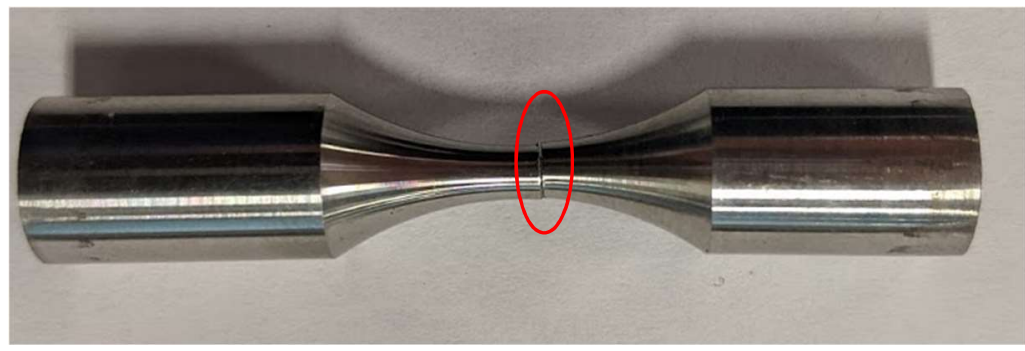

Failure (yes/no): Yes

Cycles to Failure: 2156087

Failure Cause: Surface Defect

Area of Defect: DNF

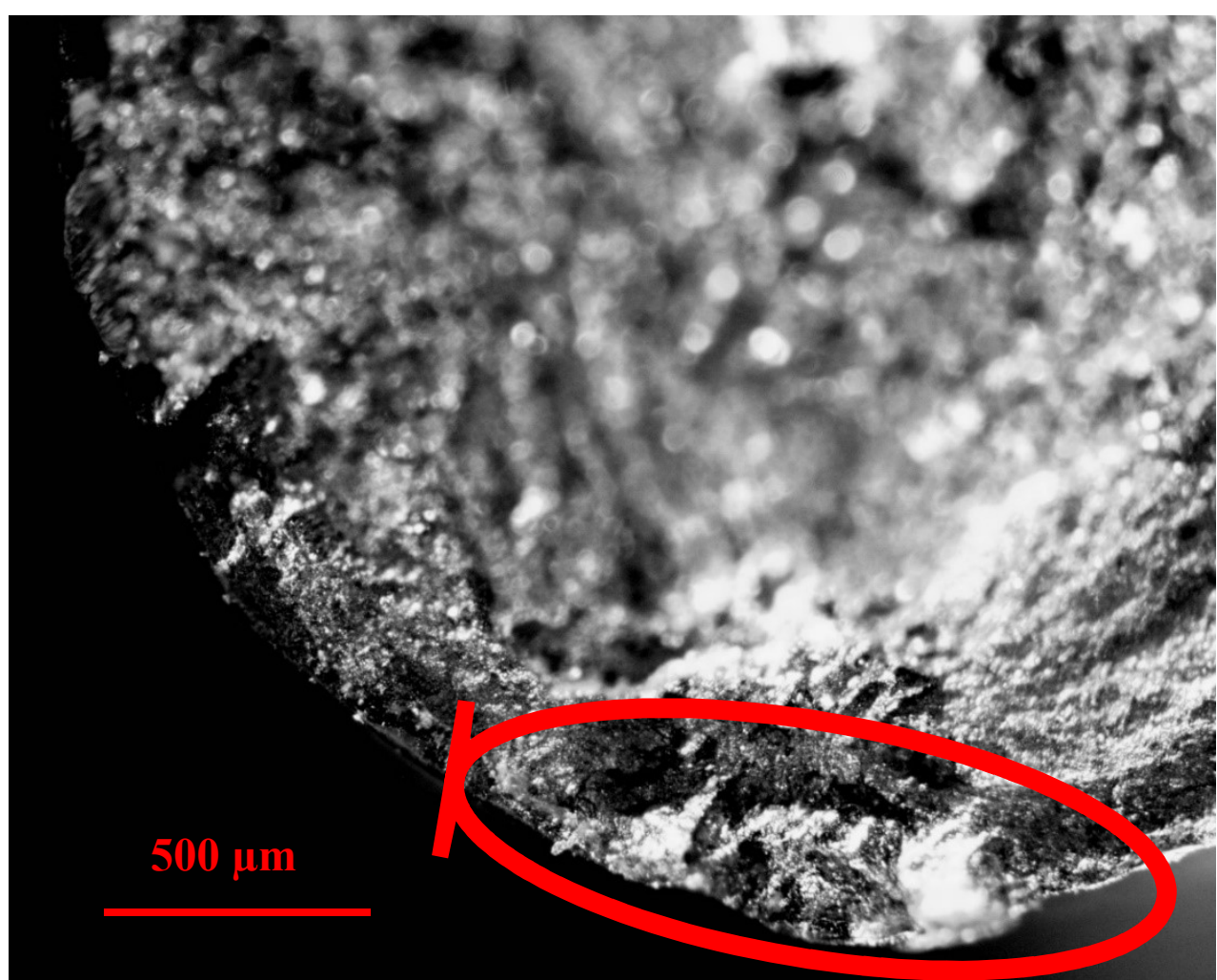


Sample Type: Additive Manufacturing

Sample Treatment: Solutionized + H900

Sample Number: 6

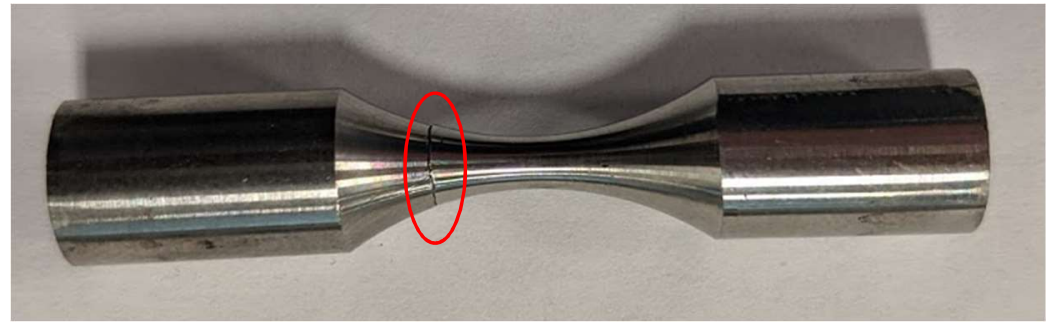

Max Testing Stress: $1200 \mathrm{MPa}$

Failure (yes/no): Yes

Cycles to Failure: 59677

Failure Cause:

Surface Defect / Porosity Area of Defect: N/A or

$0.131 \mathrm{~mm}^{2}$

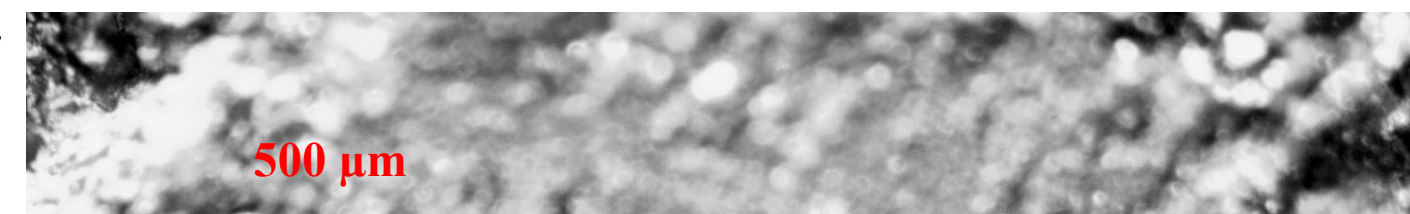
x. $500 \mu \mathrm{m}$

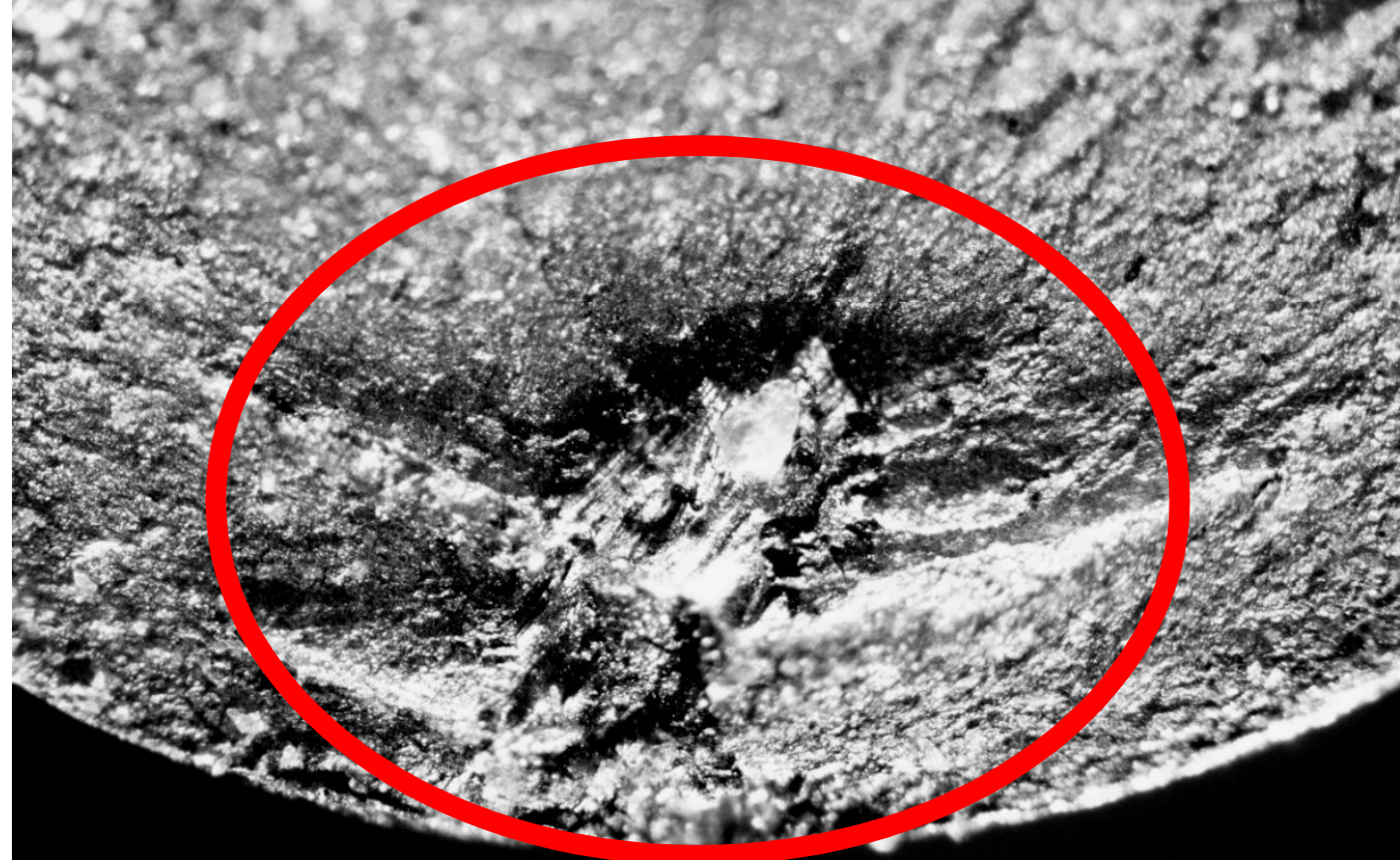


Sample Type: Additive Manufacturing

Sample Treatment: Solutionized + H900

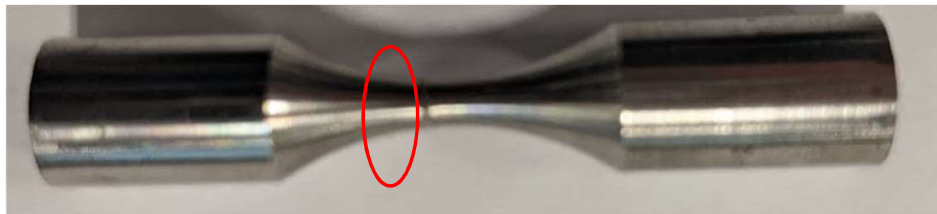

Sample Number: 7

Max Testing Stress: $850 \mathrm{MPa}$

Failure (yes/no): Yes

Cycles to Failure: 4910843

Failure Cause: Surface Defect

Area of Defect: DNF

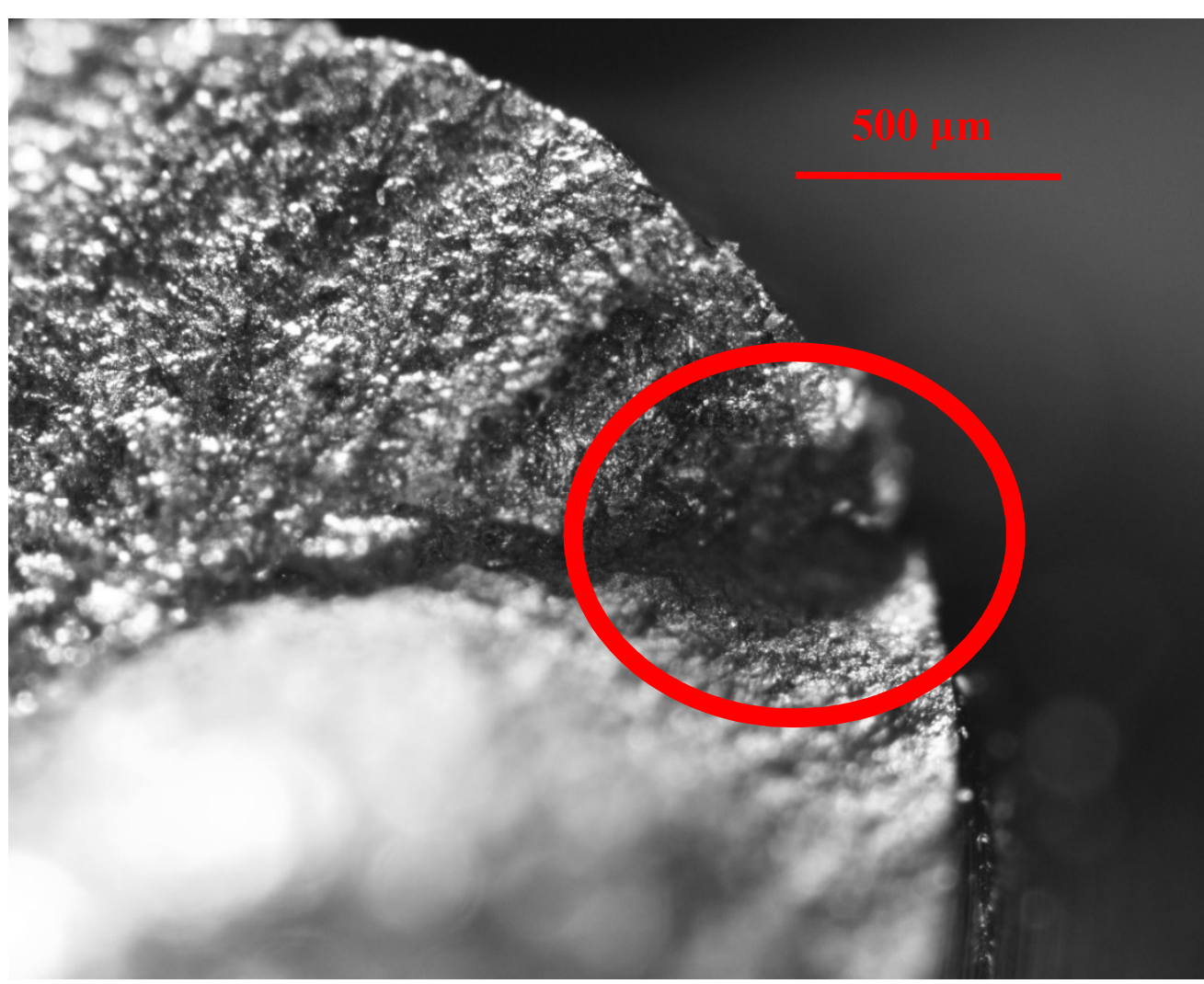


Sample Type: Additive Manufacturing

Sample Treatment: Solutionized + H900

Sample Number: 8

Max Testing Stress: $850 \mathrm{MPa}$

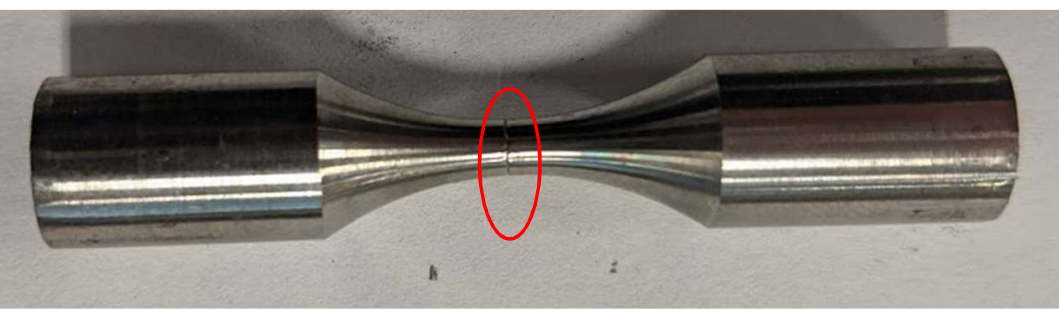

Failure (yes/no): Yes

Cycles to Failure: 1141056

Failure Cause: Surface Defect Area of Defect: DNF

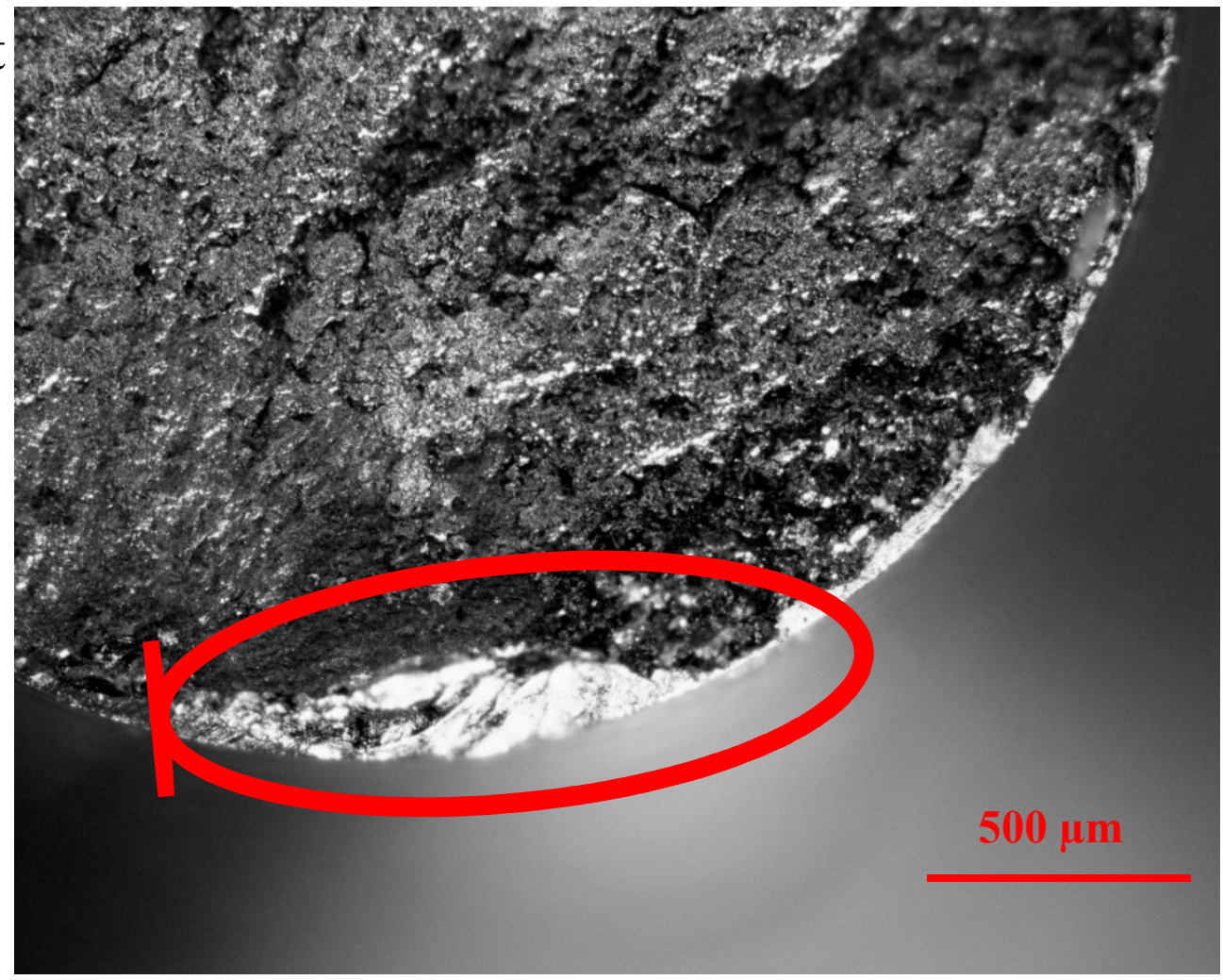


Sample Type: Additive Manufacturing Sample Treatment: Solutionized + H90 Sample Number: 9

Max Testing Stress: $950 \mathrm{MPa}$

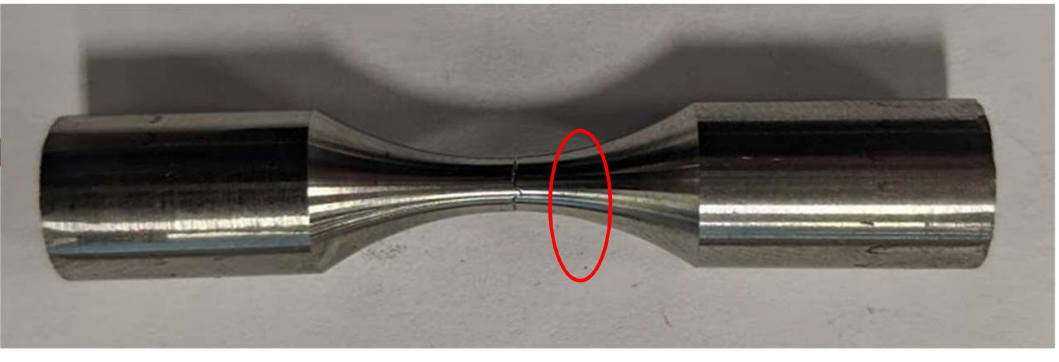

Failure (yes/no): Yes

Cycles to Failure: 1176882

Failure Cause: Surface Porosit Area of Defect: $0.007 \mathrm{~mm}^{2}$

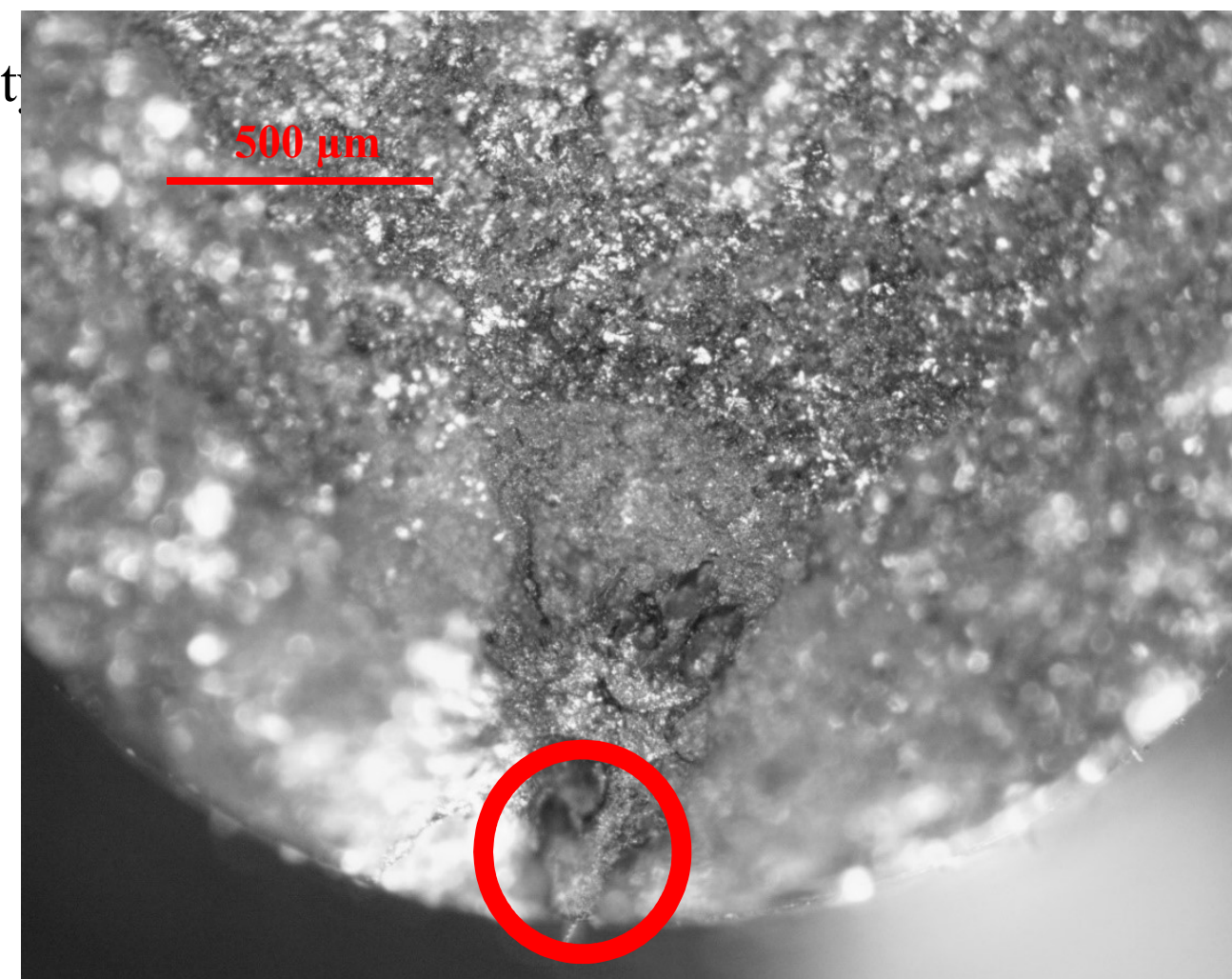


Sample Type: Additive Manufacturing Sample Treatment: Solutionized + H90 Sample Number: 10

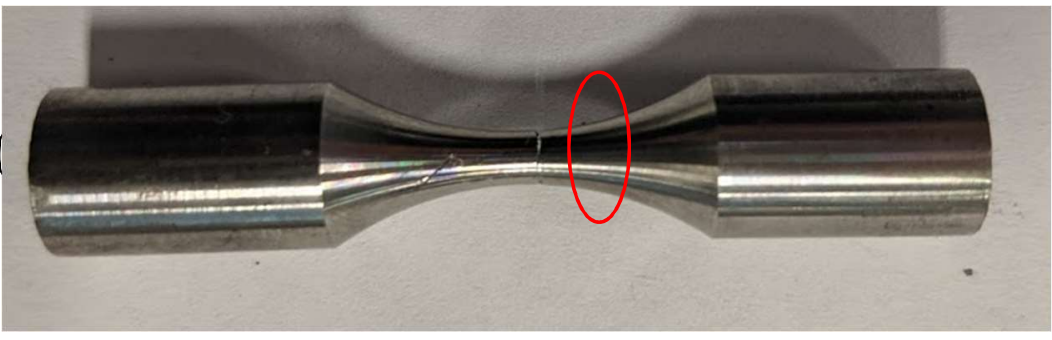

Max Testing Stress: $950 \mathrm{MPa}$

Failure (yes/no): Yes

Cycles to Failure: 31939

Failure Cause: Surface Defe Area of Defect: DNF

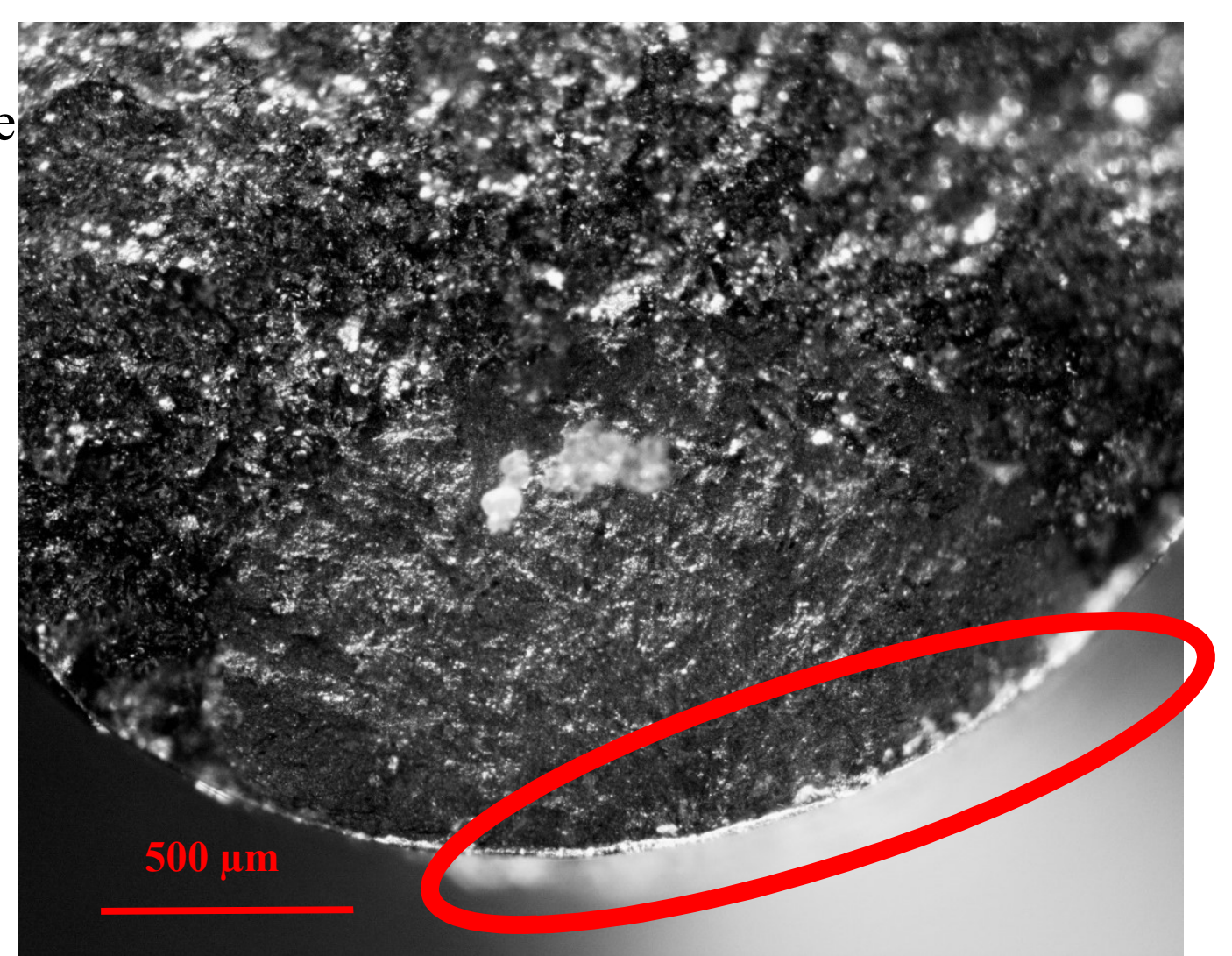


Sample Type: Additive Manufacturing Sample Treatment: Solutionized + H90 Sample Number: 11

Max Testing Stress: $950 \mathrm{MPa}$

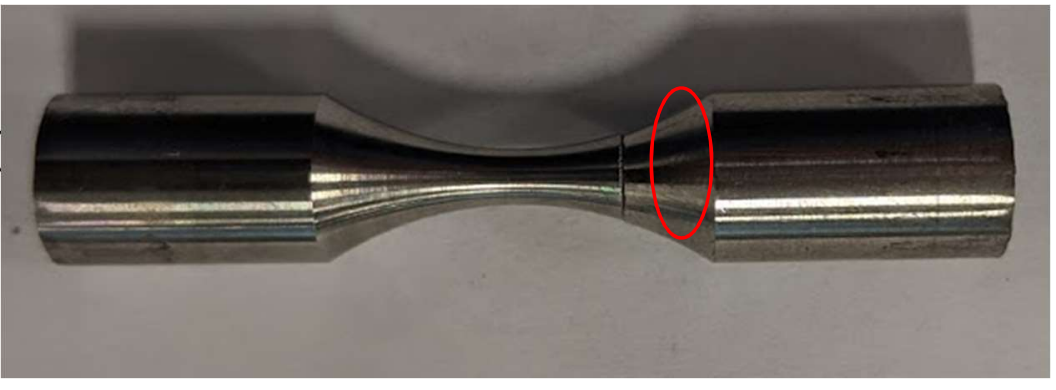

Failure (yes/no): Yes

Cycles to Failure: 832339

Failure Cause: Surface Defec Area of Defect: $0.002 \mathrm{~mm}^{2}$ 
Sample Type: Additive Manufacturing

Sample Treatment: Solutionized + H900

Sample Number: 12

Max Testing Stress: $1050 \mathrm{MPa}$

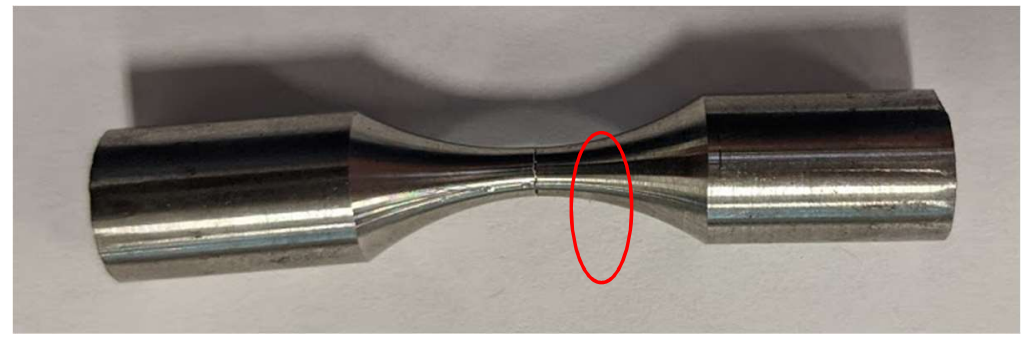

Failure (yes/no): Yes

Cycles to Failure: 155818

Failure Cause: Surface Defe

Area of Defect: $0.002 \mathrm{~mm}^{2}$

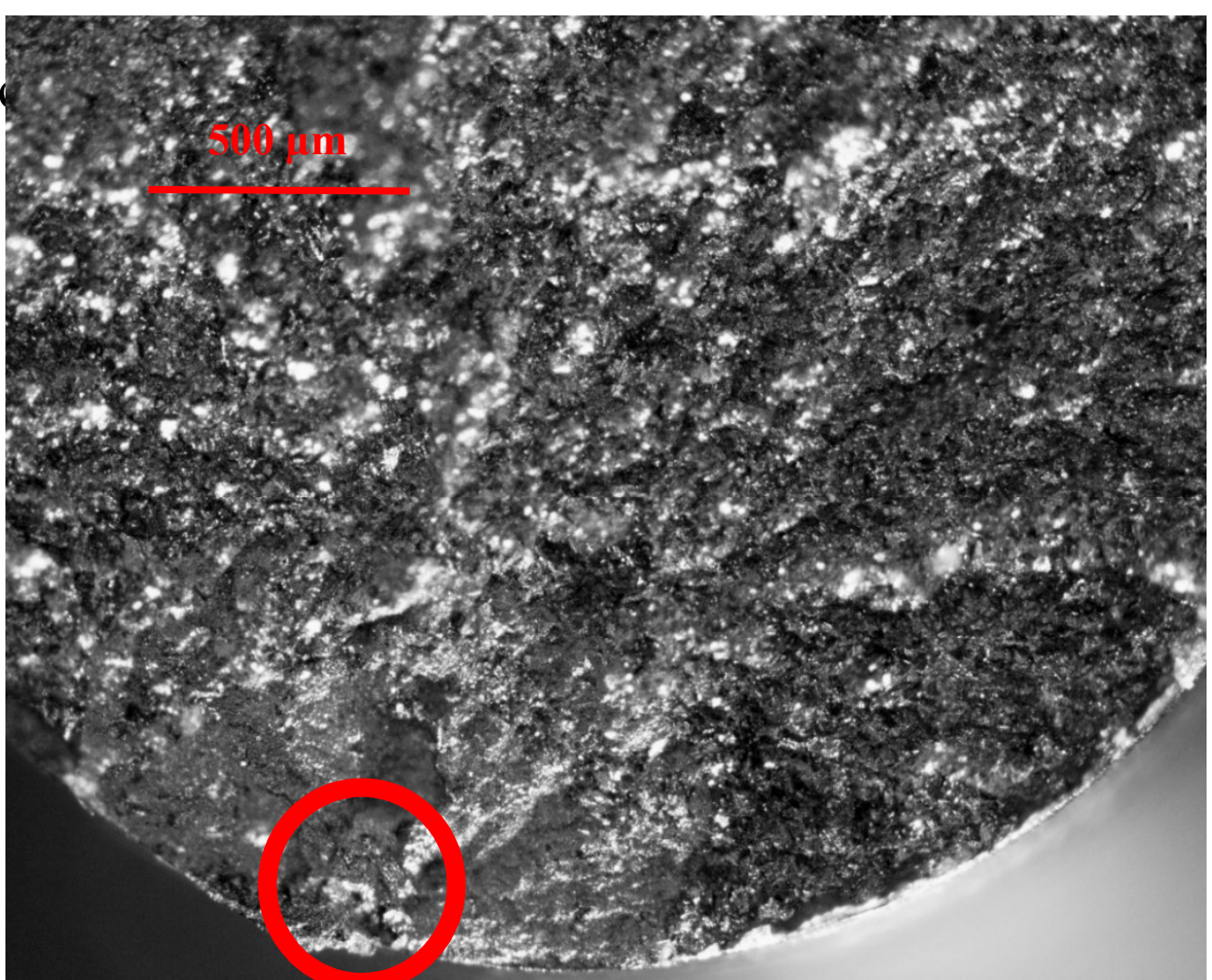


Sample Type: Additive Manufacturing

Sample Treatment: Solutionized + H900

Sample Number: 13

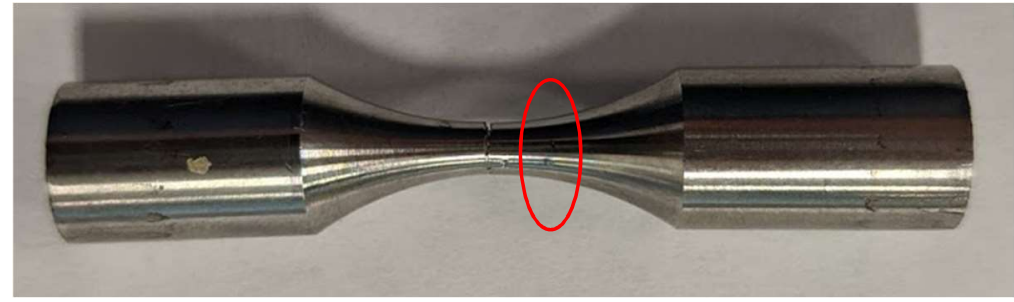

Max Testing Stress: $1050 \mathrm{MPa}$

Failure (yes/no): Yes

Cycles to Failure: 621937

Failure Cause:

Surface Defect / Porosity

Area of Defect: $0.011 \mathrm{~mm}^{2}$

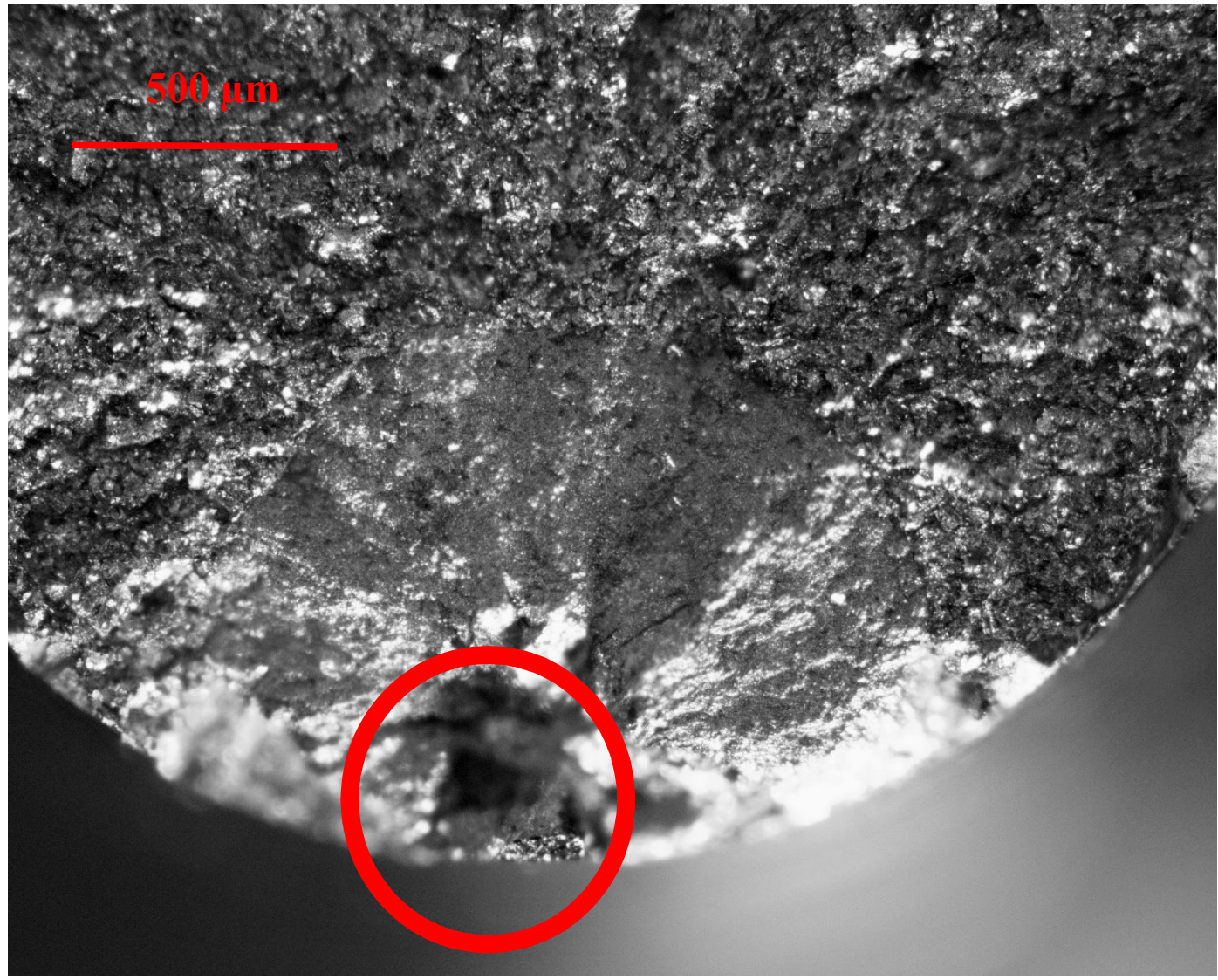


Sample Type: Additive Manufacturing

Sample Treatment: Solutionized + H900

Sample Number: 14

Max Testing Stress: $1050 \mathrm{MPa}$

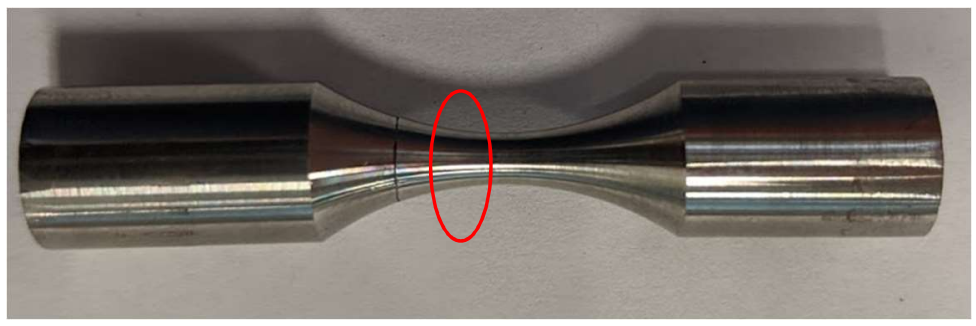

Failure (yes/no): Yes

Cycles to Failure: 544795

Failure Cause: Surface Defec

Area of Defect: $0.002 \mathrm{~mm}^{2}$

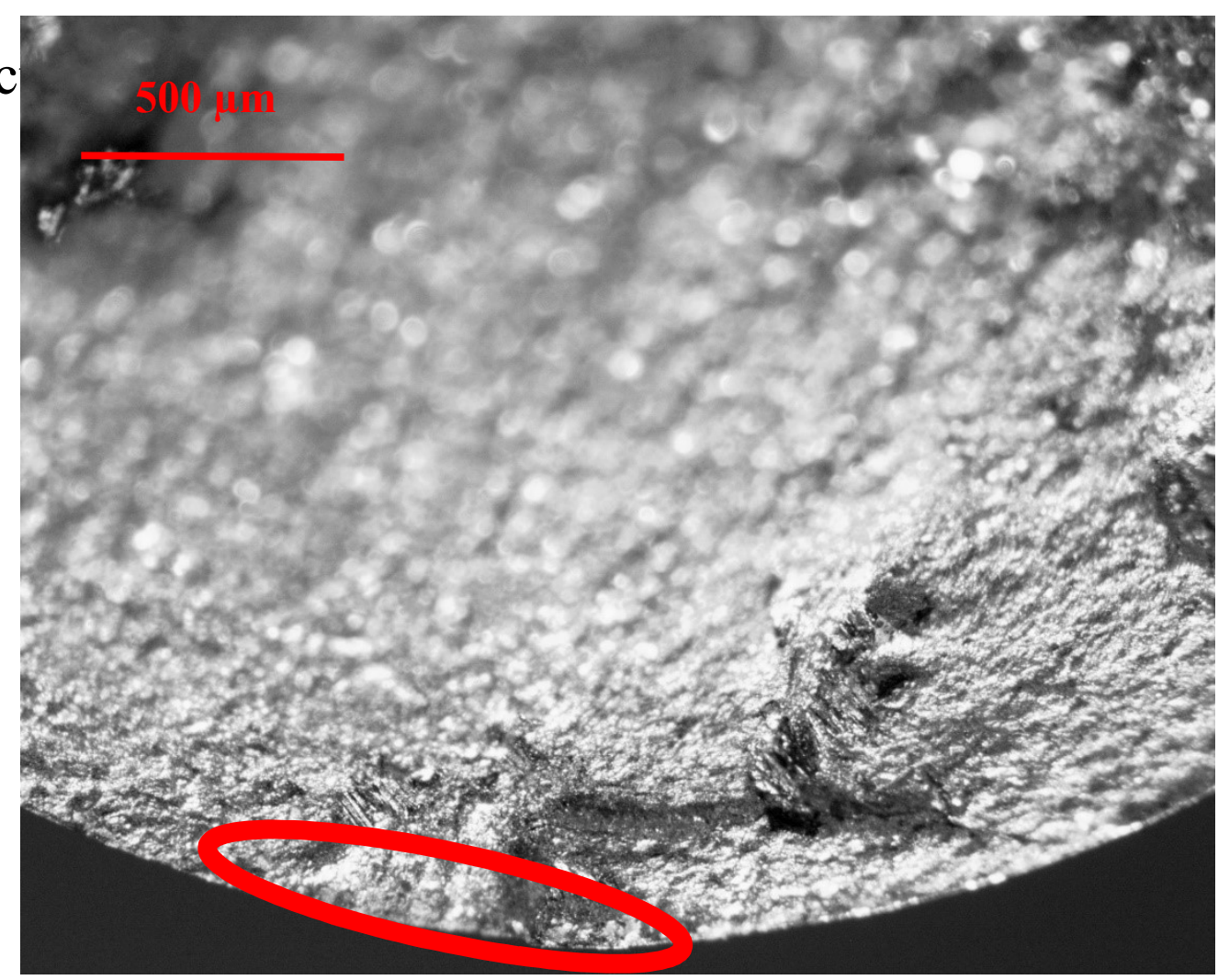


Sample Type: Wrought

Sample Treatment: Direct H900

Sample Number: 1

Max Testing Stress: 750

Failure (yes/no): No

Cycles to Failure: Run out

Failure Cause: N/A

Area of Defect: N/A 
Sample Type: Wrought

Sample Treatment: Direct H900

Sample Number: 2

Max Testing Stress: 900

Failure (yes/no): No

Cycles to Failure: Run out

Failure Cause: N/A

Area of Defect: N/A 
Sample Type: Wrought

Sample Treatment: Direct H900

Sample Number: 3

Max Testing Stress: 1200

Failure (yes/no): Yes

Cycles to Failure: 1641426

Failure Cause: Surface Defec Area of Defect: N/A
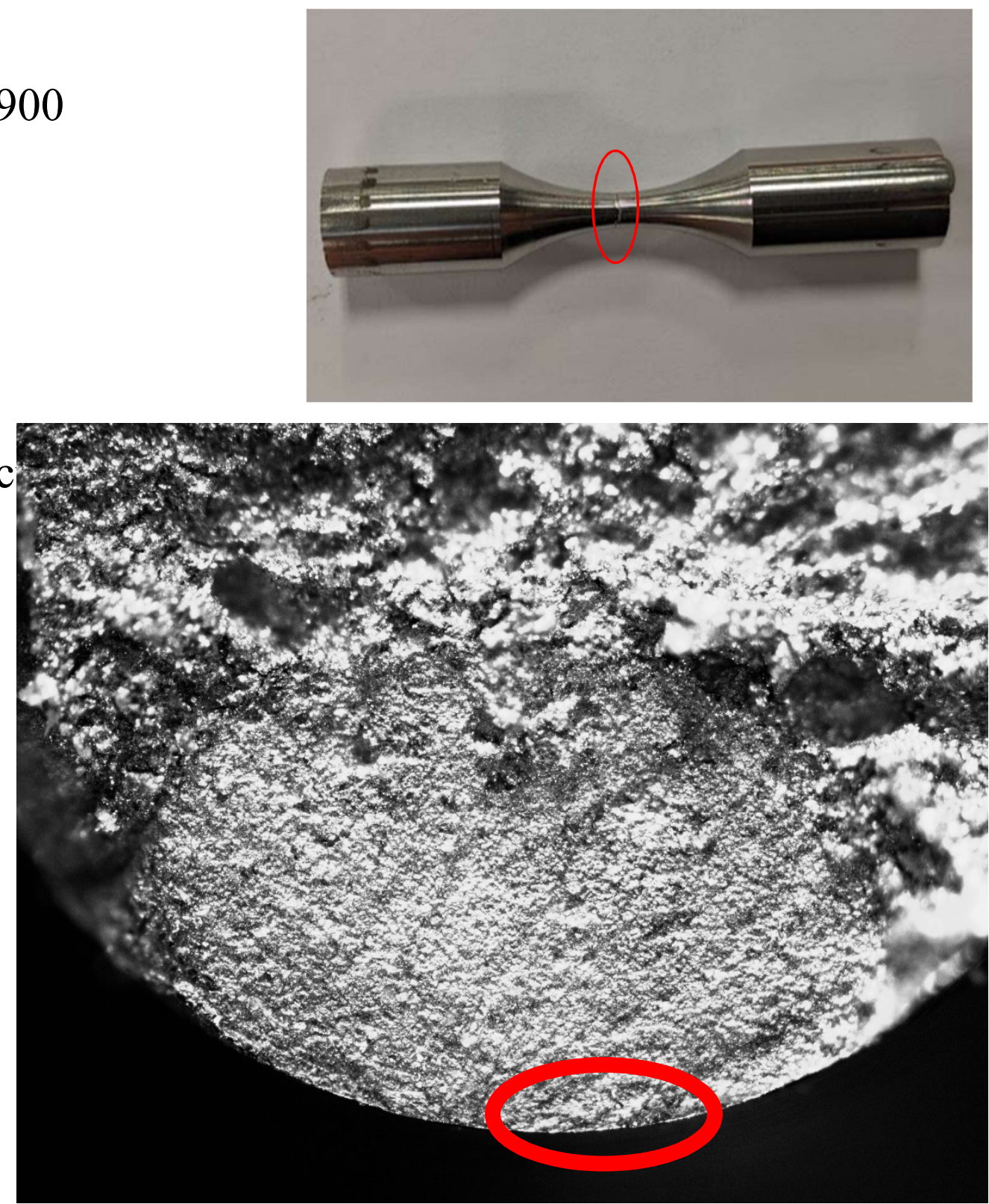
Sample Type: Wrought

Sample Treatment: Direct H900

Sample Number: 4

Max Testing Stress: 1050

Failure (yes/no): Yes

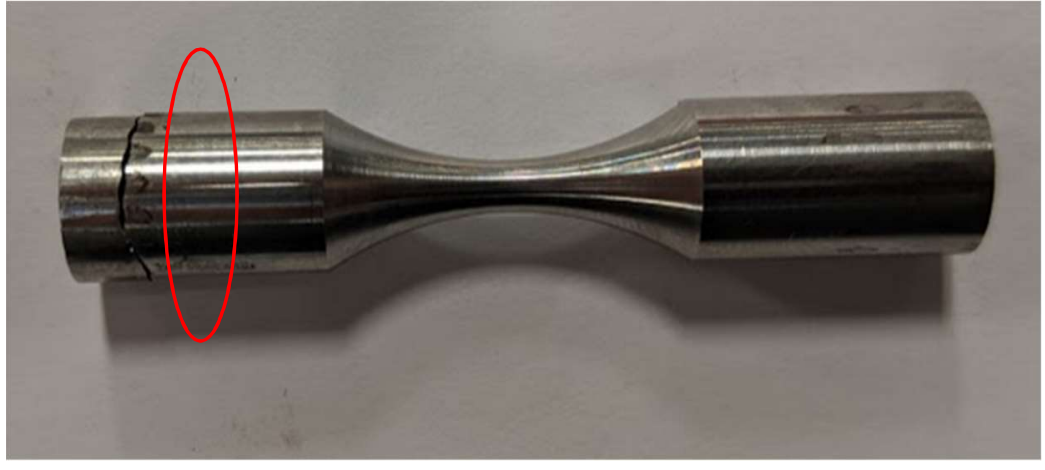

Cycles to Failure: 246274

Failure Cause: Internal Defec Area of Defect: N/A

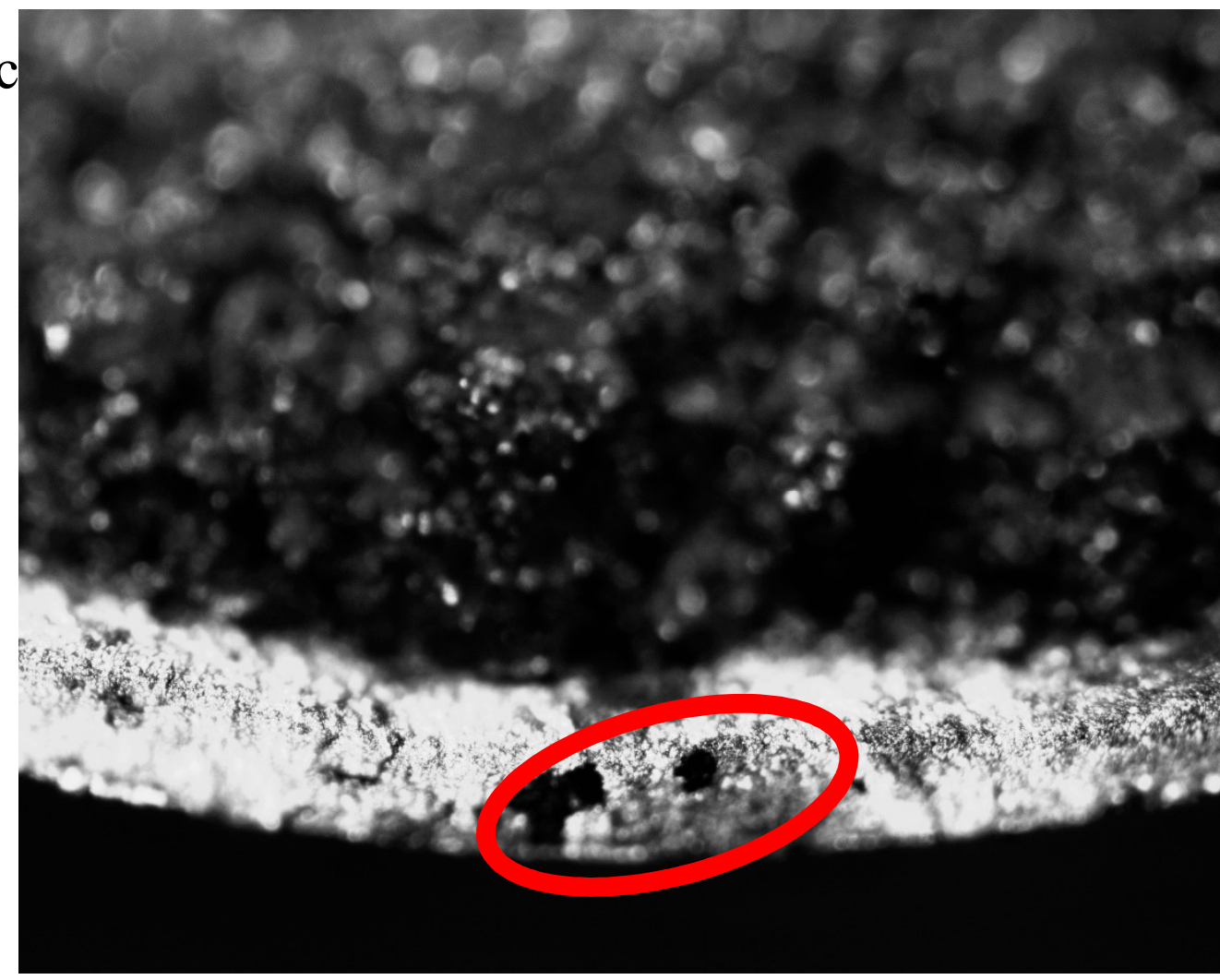


Sample Type: Wrought

Sample Treatment: Direct H900

Sample Number: 5

Max Testing Stress: 1050

Failure (yes/no): No

Cycles to Failure: Run out

Failure Cause: N/A

Area of Defect: N/A 
Sample Type: Wrought

Sample Treatment: Direct H900

Sample Number: 6

Max Testing Stress: 1050

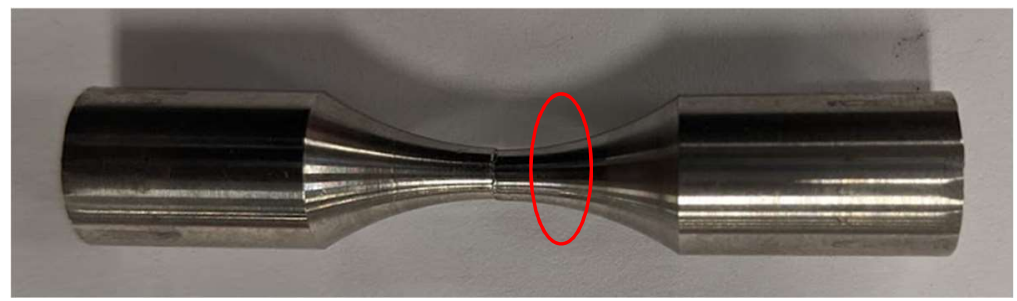

Failure (yes/no): Yes

Cycles to Failure: 5793430

Failure Cause: Surface Defec

Area of Defect: N/A

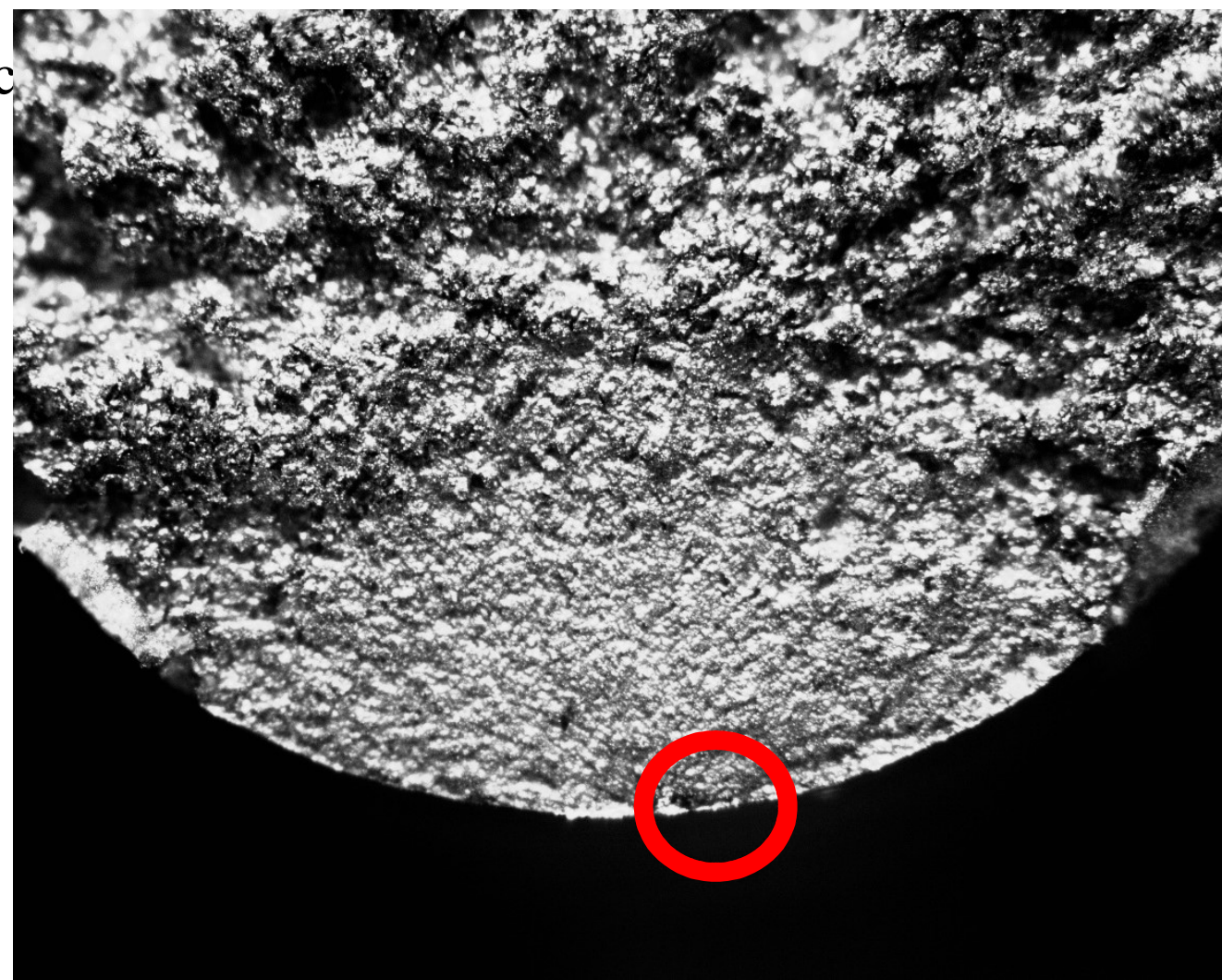


Sample Type: Wrought

Sample Treatment: Direct H900

Sample Number: 7

Max Testing Stress: 1150

Failure (yes/no): No

Cycles to Failure: Run out

Failure Cause: N/A

Area of Defect: N/A 
Sample Type: Wrought

Sample Treatment: Direct H900

Sample Number: 8

Max Testing Stress: 1150

Failure (yes/no): No

Cycles to Failure: Run out

Failure Cause: N/A

Area of Defect: N/A 
4. Sample Raw Data

Additive Manufacturing As-Built

\begin{tabular}{rrrrrrrrr}
\hline $\begin{array}{c}\text { Specimen } \\
\text { Number }\end{array}$ & $\begin{array}{c}\text { Testing } \\
\text { Stress (MPa) }\end{array}$ & $\begin{array}{c}\text { Measured } \\
\text { Diameter }\end{array}$ & $\begin{array}{c}\text { Cross- } \\
\text { Sectional Area }\end{array}$ & $\begin{array}{c}\text { Max Load } \\
(\mathbf{k N})\end{array}$ & $\begin{array}{c}\text { Min Load } \\
(\mathbf{k N})\end{array}$ & $\begin{array}{c}\text { Mean } \\
\text { Load (kN) }\end{array}$ & $\begin{array}{c}\text { Amplitude } \\
\text { Cycle at } \\
\text { Failure }\end{array}$ \\
\hline $\mathbf{1}$ & 750 & 3.175 & 7.92 & 5.938 & 0.594 & 3.266 & 2.672 & 166846 \\
$\mathbf{2}$ & 750 & 3.175 & 7.92 & 5.938 & 0.594 & 3.266 & 2.672 & 2220729 \\
$\mathbf{3}$ & 750 & 3.175 & 7.92 & 5.938 & 0.594 & 3.266 & 2.672 & 4117159 \\
$\mathbf{4}$ & 1200 & 3.175 & 7.92 & 9.501 & 0.950 & 5.225 & 4.275 & 41 \\
$\mathbf{5}$ & 850 & 3.175 & 7.92 & 6.730 & 0.673 & 3.701 & 3.028 & 1166233 \\
$\mathbf{6}$ & 850 & 3.175 & 7.92 & 6.730 & 0.673 & 3.701 & 3.028 & 94467 \\
$\mathbf{7}$ & 850 & 3.175 & 7.92 & 6.730 & 0.673 & 3.701 & 3.028 & 109567 \\
$\mathbf{8}$ & 950 & 3.175 & 7.92 & 7.521 & 0.752 & 4.137 & 3.385 & 81345 \\
$\mathbf{9}$ & 950 & 3.175 & 7.92 & 7.521 & 0.752 & 4.137 & 3.385 & 43871 \\
$\mathbf{1 0}$ & 1050 & 3.175 & 7.92 & 8.313 & 0.831 & 4.572 & 3.741 & 30195 \\
$\mathbf{1 1}$ & 1050 & 3.175 & 7.92 & 8.313 & 0.831 & 4.572 & 3.741 & 23985 \\
$\mathbf{1 2}$ & 600 & 3.175 & 7.92 & 4.750 & 0.475 & 2.613 & 2.138 & Run out \\
\hline
\end{tabular}


Additive Manufacturing Direct H900 Harden

\begin{tabular}{rrrrrrrrr}
\hline $\begin{array}{c}\text { Specimen } \\
\text { Number }\end{array}$ & $\begin{array}{c}\text { Testing } \\
\text { Stress (MPa) }\end{array}$ & $\begin{array}{c}\text { Measured } \\
\text { Diameter }\end{array}$ & $\begin{array}{c}\text { Cross- } \\
\text { Sectional } \\
\text { Area }\end{array}$ & $\begin{array}{c}\text { Max Load } \\
(\mathbf{k N})\end{array}$ & $\begin{array}{c}\text { Min Load } \\
(\mathbf{k N})\end{array}$ & $\begin{array}{c}\text { Mean Load } \\
\mathbf{( k N )}\end{array}$ & $\begin{array}{c}\text { Amplitude } \\
\text { Cycle at } \\
\text { Failure }\end{array}$ \\
\hline $\mathbf{1}$ & 500 & 3.175 & 7.92 & 3.959 & 0.396 & 2.177 & 1.781 & Run out \\
$\mathbf{2}$ & 750 & 3.175 & 7.92 & 5.938 & 0.594 & 3.266 & 2.672 & 7228279 \\
$\mathbf{3}$ & 750 & 3.175 & 7.92 & 5.938 & 0.594 & 3.266 & 2.672 & 2707879 \\
$\mathbf{4}$ & 1200 & 3.175 & 7.92 & 9.501 & 0.950 & 5.225 & 4.275 & 32928 \\
$\mathbf{5}$ & 850 & 3.175 & 7.92 & 6.730 & 0.673 & 3.701 & 3.028 & 56900 \\
$\mathbf{6}$ & 850 & 3.175 & 7.92 & 6.730 & 0.673 & 3.701 & 3.028 & 86494 \\
$\mathbf{7}$ & 850 & 3.175 & 7.92 & 6.730 & 0.673 & 3.701 & 3.028 & 3379999 \\
$\mathbf{8}$ & 950 & 3.175 & 7.92 & 7.521 & 0.752 & 4.137 & 3.385 & 584651 \\
$\mathbf{9}$ & 950 & 3.175 & 7.92 & 7.521 & 0.752 & 4.137 & 3.385 & 20160 \\
$\mathbf{1 0}$ & 950 & 3.175 & 7.92 & 7.521 & 0.752 & 4.137 & 3.385 & 219007 \\
$\mathbf{1 1}$ & 1050 & 3.175 & 7.92 & 8.313 & 0.831 & 4.572 & 3.741 & 175296 \\
$\mathbf{1 2}$ & 1050 & 3.175 & 7.92 & 8.313 & 0.831 & 4.572 & 3.741 & 33671 \\
$\mathbf{1 3}$ & 1050 & 3.175 & 7.92 & 8.313 & 0.831 & 4.572 & 3.741 & 323652 \\
\hline
\end{tabular}


Additive Manufacturing Solutionize and H900 Harden

\begin{tabular}{|c|c|c|c|c|c|c|c|c|}
\hline $\begin{array}{c}\text { Specimen } \\
\text { Number }\end{array}$ & $\begin{array}{c}\text { Testing } \\
\text { Stress (MPa) }\end{array}$ & $\begin{array}{l}\text { Measured } \\
\text { Diameter }\end{array}$ & $\begin{array}{c}\text { Cross- } \\
\text { Sectional Area }\end{array}$ & $\begin{array}{l}\text { Max Load } \\
(\mathbf{k N})\end{array}$ & $\begin{array}{l}\text { Min Load } \\
\quad(k N)\end{array}$ & $\begin{array}{l}\text { Mean Load } \\
(k \mathbf{N})\end{array}$ & Amplitude & $\begin{array}{l}\text { Cycle at } \\
\text { Failure }\end{array}$ \\
\hline 1 & 400 & 3.175 & 7.92 & 3.167 & 0.317 & 1.742 & 1.425 & Run out \\
\hline 2 & 600 & 3.175 & 7.92 & 4.750 & 0.475 & 2.613 & 2.138 & 981756 \\
\hline 3 & 600 & 3.175 & 7.92 & 4.750 & 0.475 & 2.613 & 2.138 & Run out \\
\hline 4 & 750 & 3.175 & 7.92 & 5.938 & 0.594 & 3.266 & 2.672 & 1467905 \\
\hline 5 & 750 & 3.175 & 7.92 & 5.938 & 0.594 & 3.266 & 2.672 & 2156087 \\
\hline 6 & 1200 & 3.175 & 7.92 & 9.501 & 0.950 & 5.225 & 4.275 & 59677 \\
\hline 7 & 850 & 3.175 & 7.92 & 6.730 & 0.673 & 3.701 & 3.028 & 4910843 \\
\hline 8 & 850 & 3.175 & 7.92 & 6.730 & 0.673 & 3.701 & 3.028 & 1141056 \\
\hline 9 & 950 & 3.175 & 7.92 & 7.521 & 0.752 & 4.137 & 3.385 & 1176882 \\
\hline 10 & 950 & 3.175 & 7.92 & 7.521 & 0.752 & 4.137 & 3.385 & 31939 \\
\hline 11 & 950 & 3.175 & 7.92 & 7.521 & 0.752 & 4.137 & 3.385 & 832339 \\
\hline 12 & 1050 & 3.175 & 7.92 & 8.313 & 0.831 & 4.572 & 3.741 & 155818 \\
\hline 13 & 1050 & 3.175 & 7.92 & 8.313 & 0.831 & 4.572 & 3.741 & 621937 \\
\hline 14 & 1050 & 3.175 & 7.92 & 8.313 & 0.831 & 4.572 & 3.741 & 544795 \\
\hline
\end{tabular}


Wrought Direct H900 Harden

\begin{tabular}{ccccccccc}
\hline $\begin{array}{c}\text { Specimen } \\
\text { Number }\end{array}$ & $\begin{array}{c}\text { Testing } \\
\text { Stress (MPa) }\end{array}$ & $\begin{array}{c}\text { Measured } \\
\text { Diameter }\end{array}$ & $\begin{array}{c}\text { Cross- } \\
\text { Sectional Area }\end{array}$ & $\begin{array}{c}\text { Max Load } \\
(\mathbf{k N})\end{array}$ & $\begin{array}{c}\text { Min Load } \\
\mathbf{( k N )}\end{array}$ & $\begin{array}{c}\text { Mean Load } \\
\mathbf{( k N )}\end{array}$ & $\begin{array}{c}\text { Amplitude } \\
\text { Cycle at } \\
\text { Failure }\end{array}$ \\
\hline $\mathbf{1}$ & 750 & 3.175 & 7.92 & 5.938 & 0.594 & 3.266 & 2.672 & Run out \\
$\mathbf{2}$ & 900 & 3.175 & 7.92 & 7.126 & 0.713 & 3.919 & 3.207 & Run out \\
$\mathbf{3}$ & 1200 & 3.175 & 7.92 & 9.501 & 0.950 & 5.225 & 4.275 & 1641426 \\
$\mathbf{4}$ & 1050 & 3.175 & 7.92 & 8.313 & 0.831 & 4.572 & 3.741 & 246274 \\
$\mathbf{5}$ & 1050 & 3.175 & 7.92 & 8.313 & 0.831 & 4.572 & 3.741 & Run out \\
$\mathbf{6}$ & 1050 & 3.175 & 7.92 & 8.313 & 0.831 & 4.572 & 3.741 & 5793430 \\
$\mathbf{7}$ & 1150 & 3.175 & 7.92 & 9.105 & 0.910 & 5.008 & 4.097 & Run out \\
$\mathbf{8}$ & 1150 & 3.175 & 7.92 & 9.105 & 0.910 & 5.008 & 4.097 & Run out \\
\hline
\end{tabular}




\section{CURRICULUM VITAE}

\section{Sean Dobson}

Address: 3813 Brody Lane, Louisville, KY 40299

Phone: Cell (502) 475-5106

Email: seanddobson@gmail.com | sean.dobson@1ouisville.edu

\section{EDUCATION}

Master of Science in Mechanical Engineering (GPA 3.9/4.0)

Bachelor of Science in Mechanical Engineering (GPA 3.2/4.0)

Expected May 2020

J.B. Speed School of Engineering

University of Louisville, Kentucky

\section{SKILLS}

Mechanical Testing: Tensile, fatigue, and hardness testing and analysis.

Material Science: Metallurgical sample preparation, analysis, characterization, and SEM/EDAX.

Course Work: AM Materials, Mechanics of Materials, Mechatronics, Machine Design, Engineering Economics, Manufacturing, Thermo- and Fluid Dynamics, Heat Transfer, MATLAB

Computer Aided Design: Fusion (Topology Opt./Generative Design), Solidworks and CATIA V5

\section{WORK EXPERIENCE}

Graduate Research Assistant (Apr. 2019 - Present)

Additive Manufacturing Researcher

- Thesis concerning the topic of AM 17-4 PH stainless steel and its effect on fatigue behavior. Involves extensive testing and characterization of material properties and technical writing.

- Responsible for training of undergraduate researchers, machine maintenance and operation, communication with industry partners, and effective presentation of results.

Undergraduate Research Assistant (Jan. 2018 - Apr. 2019)

Additive Manufacturing Researcher, Co-op

- Student lead for projects with Universal Technology Corporation, the U.S. Navy, and NASA with tasks to complete builds, prepare and analyze samples, as well as report and present results to industry partners and professors in a clear and concise manner. Utilized additive and traditional manufacturing as well as extensive testing devices and apparatus.

- Presented at Solid Freeform Fabrication Symposium in 2018 and 2019, publishing one paper as lead author, and attended Additive Manufacturing User Group Conference in 2019.

Gulfstream Aerospace Corporation (Aug. 2017 - Dec. 2017)

Second Co-op Rotation

- A member of the Gulfstream 3D Printing Laboratory Team, receiving invaluable hands-on experience supporting lab tests with industrial SLA, FFF, Polyjet and SLM AM technologies.

- Instructor for the Introduction to 3D Printing Course for fellow Gulfstream employees.

First Co-op Rotation (Jan. 2017 - Apr. 2017)

- Member of the Electro-Mechanical Systems Department supporting the effort to design, test and certify unannounced programs alongside three separate divisions of the department: flight controls, hydraulics, and equipment and furnishing.

ModMan Technology, LLC (Aug. 2018 - Apr. 2019)

Co-Founder, Project Manager

- Project manager for the design of a modular desktop manufacturing machine with the ability to 3D print, mill, laser cut, and injection mold through the use of interchangeable heads. 
- Approved by the University of Louisville Mechanical Engineering Department Heads to prototype product as senior design project.

\section{LEADERSHIP EXPERIENCE}

Triangle Fraternity of Engineers, Architects, and Scientists: President* Leadership Advantage: Facilitator

Boy Scouts of America, Troop 346: Eagle Scout

Speed School Student Council: Executive Director of Public Relations

Triangle Fraternity: Standards Board Member

Triangle Fraternity: Fundraising/Recruitment Chair

Office of Speed School Admissions: Speed School Student Ambassador

Leadership Advantage: Head Operator

Adopt-a-Highway Clean Up: Volunteer Lead
Apr. 2018 - Apr. 2019

Apr. 2017 - Apr. 2018

Oct. 2008 - Nov. 2011

Mar. 2016 - Mar.2017

Feb. 2018 - Apr.2018

Apr. 2016 - Apr. 2017

May 2016 - Apr. 2019

Apr. 2016 - Aug.2016

Jan. 2018 - May 2019 